\title{
BÁRBARA PICK
}

\section{INFLUÊNCIA DA ATENUAÇÃO DA LUZ PROVOCADA POR MATERIAIS RESTAURADORES INDIRETOS ESTÉTICOS SOBRE A POLIMERIZAÇÃO DE UM CIMENTO RESINOSO}




\section{Bárbara Pick}

\section{Influência da atenuação da luz provocada por materiais restauradores indiretos estéticos sobre a polimerização de um cimento resinoso}

Dissertação apresentada à Faculdade de Odontologia da Universidade de São Paulo, para obter o título de Mestre, pelo Programa de Pós-Graduação em Odontologia.

Área de Concentração: Materiais Dentários

Orientador: Prof. Dr. Paulo Eduardo Capel Cardoso

São Paulo 


\section{FOLHA DE APROVAÇÃO}

Pick B. Influência da atenuação da luz provocada por materiais restauradores indiretos estéticos sobre a polimerização de um cimento resinoso [Dissertação de Mestrado]. São Paulo: Faculdade de Odontologia da USP; 2007.

São Paulo, 03 de julho de 2007.

\section{Banca Examinadora}

1) $\operatorname{Prof}(a) \cdot \operatorname{Dr}(a)$.

Titulação:

Julgamento:

Assinatura:

2) $\operatorname{Prof}(a) . \operatorname{Dr}(a)$.

Titulação:

Julgamento: Assinatura:

3) $\operatorname{Prof}(a) . \operatorname{Dr}(a)$.

Titulação:

Julgamento: Assinatura: 


\section{DEDICATÓRIA}

O importante na vida é amar e ser amado, porque se por algum motivo suas ambições ou suas lutas não se realizarem ou não forem vencidas, esta pessoa que você amou irá lutar por seus ideais...

Em 1928, Armindo Bernardo Pick, nasceu em Santa Cruz do Sul, no estado do Rio Grande do Sul. Aos vinte anos se mudou para Joaçaba, em Santa Catarina, para aprender com um dentista o seu ofício. Em 1950, montou um consultório odontológico em Coronel Vivida, no estado do Paraná, onde realizava extrações dentárias, próteses totais e incrustações metálicas. Até hoje as pessoas da época relatam o capricho e amor à sua profissão. Em 1968, chegaram à cidade os primeiros odontólogos formados e, dessa forma, perdeu seu espaço de trabalho. Faleceu em 1983. Deixou uma família que the ama muito e com ela valores como perseverança, honestidade e ética.

Vô, acreditei nos seus ideais... Esta dissertação é inteiramente dedicada a você!

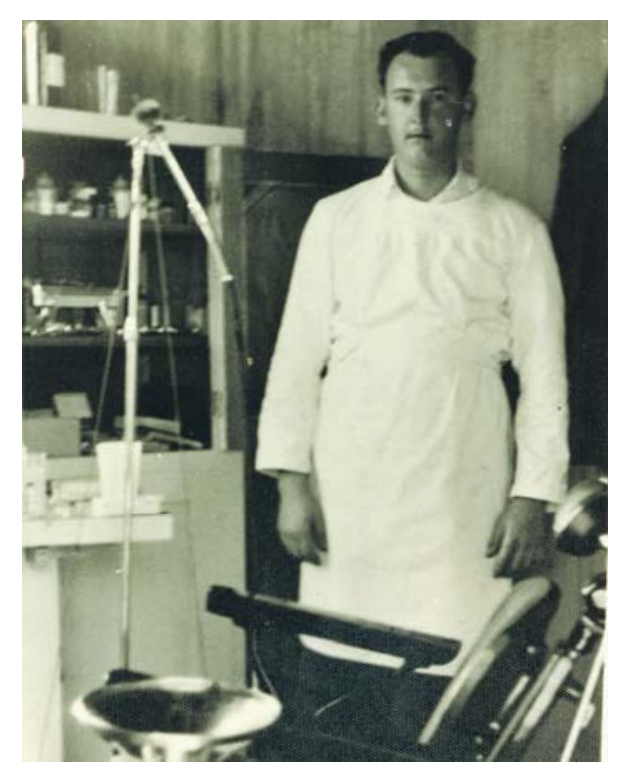




\section{AGRADECIMENTOS}

À Deus, sempre senti Sua presença nas minhas conquistas e quando precisei...

À minha amada mãe, Maria Luiza Pick, sempre presente nos momentos mais felizes e dificeis da minha vida... N Nunca mediu esforços para me tornar uma pessoa melhor. $\mathcal{E}$, ao meu pai, Lauri Antonio Pick, pois sua segurança, firmeza e amor me permitiram realizar tudo o que conquistei. Obrigada por acreditarem sempre em mim!

Ao meu noivo, Enan Alexandre Ornaghi, que há seis anos compartilhamos os sonhos, os ideais de vida e este sentimento tranqüilo, seguro, de saudades, de afinidade e de paixão. Viver com você é um eterno aprendizado... Eu te amo porque simplesmente te amo!

Ao meu querido "mano sam" Rafael Pick, que está sempre me mostrando um ângulo diferente de encarar a vida: um jeito aventureiro e descontraído... Você foi meu primeiro e eterno melhor amigo, obrigada!

Ao meu orientador, Dr. Paulo Eduardo Capel Cardoso, pela introdução à pesquisa e por me motivar nos momentos difíceis. Para mim, este mestrado foi uma experiência de vida, acredito que em tudo que aprendi você estava presente...

À minha vó Frida, que apesar de estar longe sempre participa das minhas vitórias e angústias, a sua alegria de viver é uma lição para mim!

À vó e vô Frizon, qualidades como perseverança, paciência, responsabilidade e tolerância fazem parte de vocês... Obrigada pelo carinho!

À $\mathcal{N}$ essa, minha irmãzinha do coração, a sua doçura e companheirismo tornaram muito mais fácil esta etapa da minha vida. N Nunca faltaram palavras de incentivo e aprovação a mim... 
Aos meus amigos queridos, Paula e Píndaro, Cibelle e Hildegard, Karen e Joelson, Evandro e Flávia e ao meu afilhadinho Evandro, pelos momentos de descontração e alegria, tão importantes quanto os momentos de estudo...

Às minhas tias Stela, Dalva, Adriana e Mônica que há muito tempo torcem por mim!

À minha amiga paulistana Carina Castellan, a nossa amizade foi um presente que conquistamos nesta etapa da nossa vida. Obrigada por me mostrar os caminhos mais diretos e "focados". Sua opinião sempre foi muito importante para mim...

Ao meu maninho gaúcho Vinícius Rosa, os momentos de risada e "desespero" juntos sempre ficarão na minha memória. Aprendi muito com você. Obrigada por tudo!

À minha amiga Fernanda Calheiros, que me ajudou muito na compreensão de cadeias poliméricas entrelaçadas, cruzadas, reticuladas... Você é uma pessoa espetacular e, pode ter certeza, que sempre que eu estiver preocupada ou nervosa vou fechar os meus olhos, imaginar que estou em um lindo campo esverdeado, abrindo os braços e cantando...

Ao professor Dr. Roberto Ruggiero Braga, obrigada por compartilhar comigo o seu conhecimento de forma tão clara. Sua dedicação contribuiu para o meu crescimento intelectual.

Ao professor Dr. Igor Medeiros Studart, sempre presente nas horas difíceis... Obrigada pelos momentos de estudo!

Ao professor Dr. Antonio Muench, a sua genialidade nem se compara à dos "gênios da Estatística”, obrigada por me ensinar a estatística que tanto gosto de calcular.

À professora Dra. Rosa Helena Miranda Grande pelo carinho e pelas sábias palavras... 
Ao Dr. Marlus Drulla, à Dra. Carolina Jordão e à Crsitiana Cáceres e a toda equipe da Clínica Espaço Sorriso, pelo apoio na minha ausência, sem a confiança que tenho em vocês nada disso seria possível.

À minha amiga e eterna professora Moira Pedroso Leão, pelas Congas conversas e discussões... Muito obrigada!

Ao meu professor-modelo Dr. Márcio Fraxino Bindo, uns dos responsáveis por eu estar defendendo esta dissertação, pois foi o meu primeiro incentivador. Admiro seu caráter e sua inteligência... Obrigada pelo apoio!

Aos meus colegas e amigos da Pós-graduação: Adriana de Fátima Vasconcelos Pereira, Andrea Mello de Andrade, Carmen Silvia Costa Pfeifer, Caroline Lumi Miyazaki ,Cristina Yuri Okada, Fábio Zovico, Fernanda Sadek, Flavia Gonçalves, Flávia Pires, Isis Andréa Poiate, Janaína Oliveira Lima, José Roberto Bauer, Kelle Cristina Garcia, Leticia Cristina Cidreira Boaro, Marcelo Mendes Pinto, Márcia Borba, Maria Tereza Moura de Oliveira, Maurício Neves Gomes, Nívea Regina de Godoy Fróes Salgado, Soraia de Fátima Carvalho Souza e Tathy Aparecida Xavier por compartilhar momentos de alegria.

Ao professor Dr. Yoshio Kawano, pela paciência em realizar as intermináveis leituras de grau de conversão das amostras. A sua companfia foi sempre agradabilíssima!

Ao professor Dr. Mikiya Muramatso e ao mestrando Emerson Silva pela disponibilidade em realizar os ensaios de transmitância relativa no Laboratório de Ótica da USP. Espero um dia poder retribuir toda a atenção que vocês me proporcionaram.

Ao professor Dr. Rafael Yagüe Ballester pelas traduções em espanhol.

À Carla Castiglia Gonzaga por me ajudar na elaboração do projeto de pesquisa desta dissertação e na confecção dos discos de Empress 2. 
Ao mestre Washington Steagall por me orientar nos ensaios de espectrometria.

Aos professores do Departamento: Carlos Eduardo Francci, Fernando Neves, José Fortunato Ferreira Santos, Josete Cruz Meira, Leonardo Elloy Rodrigues, Paulo Francisco Césare Walter Gomes Miranda pelos ensinamentos.

A Rosa Cristina Nogueira, Mirtes Regina Martins Saduto, Antônio Carlos Lascala e Silvio Peixoto Soares pela ajuda e convívio.

Ao Serviço de Documentação Odontológica pela revisão e formatação do texto.

À Faculdade de Odontologia da Universidade de São Paulo, por realizar meu sonho. 


\section{EPÍGRAFE}

O Que Ficow?...

De tudo, ficaram três coisas:

A certeza de que estamos sempre começando....

A certeza de que precisamos continuar..

A certeza de que seremos interrompidos antes de terminar...

Portanto, devemos:

Fazer da interrupção um caminho novo...

Da queda, um passo de dança...

Do medo, uma escada...

Do sonho, uma ponte...

Da procura, um encontro...

Fernando Pessoa 
Pick B. Influência da atenuação da luz provocada por materiais restauradores indiretos estéticos sobre a polimerização de um cimento resinoso [Dissertação de Mestrado]. São Paulo: Faculdade de Odontologia da USP; 2007.

\section{RESUMO}

Objetivo: O objetivo desta pesquisa foi verificar o efeito da interposição de diferentes materiais restauradores indiretos na resistência à flexão em três pontos $(\mathrm{RF})$, microdureza Knoop (MK) e grau de conversão FT-Raman (GC) de um cimento resinoso. Material e métodos: Os materiais restauradores indiretos selecionados para a confecção dos discos (2 mm de espessura e $11 \mathrm{~mm}$ de diâmetro) foram: a vitrocerâmica IPS Eris/Ivoclar-Vivadent (E); a cerâmica de infra-estrutura IPS Empress 2/Ivoclar-Vivadent recoberta pela vitrocerâmica IPS Eris/Ivoclar-Vivadent (EE); a resina composta microhíbrida Sinfony/3M ESPE (S); a resina composta microparticulada SR Adoro/Ivoclar-Vivadent (A). Inicialmente, foi determinada a transmitância relativa (TR) destes materiais restauradores através da análise de imagens digitais obtidas por uma câmera CCD e de um espectrômetro de luz visível. Em seguida, os corpos-de-prova (cps, $10 \times 2 \times 1 \mathrm{~mm}$ ) do cimento resinoso Nexus 2/SDS Kerr, com (dual) e sem catalisador (fotoativado), foram polimerizados sob os discos de materiais

restauradores indiretos utilizando o aparelho de fotoativação de luz halógena Optilux ${ }^{\mathrm{TM}}$ 501/SDS Kerr (QTH) ou o diodo emissor de luz L.E.Demetron 1/SDS Kerr (LED). Os cps também foram fotoativados sem a interposição dos discos, deixando um espaço de zero (E0) e dois (E2) mm entre a ponta do fotoativador e a superfície do cimento. Para avaliação da MK e GC, cada cp foi dividido em quatro zonas: face irradiada - centro (IC); irradiada - borda (IB); não-irradiada - centro (NC); não-irradiada - borda (NB). Além disso, foi avaliada a emissão espectral dos dois aparelhos de fotoativação com valores de irradiância relativa (\%) e absoluta $\left(\mathrm{mW} / \mathrm{cm}^{2}\right)$. Resultados: A espectrometria foi o método mais sensível para detectar diferenças 
de TR entre os materiais restauradores e detectou que a resina $\mathrm{S}\left(3,5 \%{ }^{\mathrm{a}}\right)$ transmitiu mais luz e a cerâmica $\mathrm{E}$ transmitiu menos $\operatorname{luz}\left(1,6 \%^{\mathrm{c}}\right)$. A análise de variância mostrou que o cimento dual apresentou médias superiores $(P<0,001)$ de RF $(201,3 \mathrm{MPa})$, MK $(42,3 \mathrm{KHN})$ e GC (74,8\%) em relação ao fotoativado. E, que o QTH $\left(191,5 \mathrm{MPa}^{\mathrm{a}}\right)$ promoveu média de RF superior $(P<0,001)$ em relação ao LED $\left(164,4 \mathrm{MPa}^{\mathrm{b}}\right)$. Em contrapartida, o LED aumentou os valores de MK do cimento em algumas interações e em outras não houve diferença estatística entre os aparelhos. O método FT-Raman apresentou uma menor sensibilidade do que o ensaio de MK para detectar diferenças entre os grupos experimentais. A interposição dos discos de cerâmica reduziu significativamente a RF e MK do cimento fotoativado em relação aos grupos E0 e E2, no entanto, quando foi adicionado o catalisador ao cimento estas reduções não ocorreram. A zona IC $\left(39,6 \mathrm{KHN}^{\mathrm{a}}\right)$ dos cps apresentou maiores médias de $\mathrm{MK}$ e a zona NB $\left(34,6 \mathrm{KHN}^{\mathrm{c}}\right)$ as menores, evidenciando a distribuição não-uniforme da luz sobre o cp. Foi verificado ainda uma correlação positiva entre as médias de GC e MK. Conclusão: A partir dos resultados desta pesquisa concluiu-se que houve uma tendência na qual os materiais restauradores que transmitiram mais luz ao cimento resinoso, principalmente o de pasta única (fotoativado), lhe proporcionou melhores condições para uma reação de polimerização mais eficiente e,consequentemente, propriedades físicas máximas.

Palavras-chave: cimentos de resina; propriedades físicas; luz; transmissão; materiais dentários. 
Pick B. Influence of the light attenuation caused by aesthetic indirect restoration materials on the polymerization of a resin cement [Dissertação de Mestrado]. São Paulo: Faculdade de Odontologia da USP; 2007.

\section{ABSTRACT}

Objective: The aim of this study was to verify the effect of interposing different indirect restorative materials on the three-point flexural strength (FS), Knoop microhardness (KHN) and FT-Raman degree of conversion (DC) of a resin cement. Methods: Disks (2-mm thick and $11-\mathrm{mm}$ in diameter) were built using the indirect restorative materials IPS Eris (IvoclarVivadent glass-ceramic, E), IPS Empress 2 (Ivoclar-Vivadent framework ceramic) veneered by IPS Eris (EE), Sinfony (3M ESPE, micro-hybrid composite resin, S) and SR Adoro (Ivoclar-Vivadent microfilled composite resin, A). Initially, their relative transmittance (RT) was determined analyzing digital images obtained by a CCD camera and with visible light spectrometry. Then, bar-shaped specimens (sps, $10 \times 2 \times 1 \mathrm{~mm}$ ) of the Nexus 2 resin cement (SDS Kerr) were prepared either with (dual) or without catalyst (light-cured), and photoactivated throught the different restorative materials disks using a halogen light curing unit (QTH, Optilux ${ }^{\mathrm{TM}}$ 501, SDS Kerr) or a light emitting diode (LED, L.E.Demetron 1, SDS Kerr). The sps were also light-cured without interposing the disks, keeping the curing unit light guide either in contact (S0) or $2 \mathrm{~mm}$ (S2) from the cement surface. For KHN and DC evaluation, each sp was divided in four regions: irradiated-center (IC), irradiated-edge (IE), non-irradiated-center (NC) and non-irradiated-edge (NE). Light curing unit spectral emissions were obtained with the relative $(\%)$ and absolute $\left(\mathrm{mW} / \mathrm{cm}^{2}\right)$ irradiance values. Results: The spetrometry was more capable to detect the RT differences between the restoration materials than the CCD camera and indicated that the $\mathrm{S}$ resin $\left(3,5 \%{ }^{\mathrm{a}}\right)$ transmitted more light and the $\mathrm{E}$ ceramic $\left(1,6 \%^{\mathrm{c}}\right)$ transmitted less light. ANOVA revealed higher FS, KHN and DC values for 
the cement in dual-cure mode compared to light-cure $(\mathrm{p}<0.001)$. The QTH $\left(192 \mathrm{MPa}^{\mathrm{a}}\right)$ promoted higher FS than LED (164 $\left.\mathrm{MPa}^{\mathrm{b}}\right)$. On the other hand, the LED increased the KHN values in some interactions with the EE group and in other interactions there were not statistic differences between the curing units. The FT-Raman method was less sensitive than KHN to detect differences between the experimental groups. The ceramic materials reduced the lightcured cement's FS and KHN compared to the S0 and S2 groups; however, when the catalyst was added to the cement these reductions did not occurred. The IC regions showed the highest KHN values and the NE, the lowest, indicating the non-uniform distribution of the light. A positive correlation was found between DC and KHN. Conclusion: It was possible to conclude that there was a tendency for the restorative materials which allowed more light transmission to provided better conditions for an efficient polymerization reaction and, consequently, desirable physical properties of the resin cement, more noticeable when used in light-cure mode.

Keywords: resin cements; physical properties; light; transmission; dental materials. 
Pick B. Influencia de la atenuación de la luz provocada por materiales restauradores indirectos estéticos sobre la polimerización de um cemento resinoso [Dissertação de Mestrado]. São Paulo: Faculdade de Odontologia da USP; 2007.

\section{RESUMEN}

Objetivo: El objetivo de esta investigación fue verificar si la interposición de diferentes materiales restauradores indirectos durante la fotoactivación de un cemento resinoso interfiere en su resistencia a la flexión en tre puntos (RF), microdureza Knoop (MK) y grado de conversión FT-Raman (GC). Material y métodos: Los materiales restauradores indirectos seleccionados para confeccionar los discos (de $2 \mathrm{~mm}$ de espesura y $11 \mathrm{~mm}$ de diámetro) fueron la vitrocerámica IPS Eris/Ivoclar-Vivadent (E); la cerámica de infraestructura IPS Empress 2/Ivoclar -Vivadent recubierta por la vitrocerámica IPS Eris/Ivoclar-Vivadent (EE); el composite microhíbrido Sinfony/3M ESPE (S); el composite microparticulado SR Adoro/Ivoclar-Vivadent (A). Inicialmente se analizó la transmitancia relativa (TR) de estos materiales restauradores con el auxilio de una cámara CCD y de un espectrofotómetro. A seguir, los cuerpos de prueba (cps, $10 \times 2 \times 1 \mathrm{~mm}$ ) del cemento resinoso Nexus 2/SDS Kerr, con (dual) y $\sin$ (fotoactivado) catalizador, fueron polimerizados bajo los discos de los

materiales restauradores indirectos, usando el fotoactivador de luz halógena Optilux ${ }^{\mathrm{TM}}$ 501/SDS Kerr (QTH) o un diodo emisor de luz L.E.Demetron 1/SDS Kerr (LED). Los cps también fueron fotoactivados sin la interposición de los discos, dejando una distancia de cero (E0) y dos (E2) mm entre la extremidad del fotoactivador y la superficie del cemento. Cada cp fue dividido en cuatro regiones para mensuración de la MK y GC: lado irradiado - centro (NC); irradiado - borde (IB); no irradiado - centro (NC); no irradiado - borde (NB). También fue evaluado o espectro de emisión de los dos fotoactivadores, mensurando los valores de irradiancia relativa $(\%)$ y absoluta $\left(\mathrm{mW} / \mathrm{cm}^{2}\right)$. Resultados: La espectrometría fue el método 
más sensible para detectar diferencias de TR entre los materiales restauradores y detectó que el composite $\mathrm{S}\left(3,5 \%{ }^{\mathrm{a}}\right)$ transmitió más luz y la cerámica $\mathrm{E}$ menos $\left(1,6^{\mathrm{c}}\right)$. El análisis de variancia evidenció que el cemento dual obtuvo medias superiores $(\mathrm{P}<0,001)$ de $\mathrm{RF}$ (201,3MPa), MK (42,3KHN) y GC (74,8\%) cuando comparado con el fotoactivado. El aparato QTH produjo media de RF $\left(191,5 \mathrm{MPa}^{\mathrm{a}}\right)$ superior $(\mathrm{P}<0,001)$ cuando comparada al LED $\left(164,4 \mathrm{MPa}^{\mathrm{b}}\right)$. Por el contrario, el LED aumentó los valores de MK del cemento en algunas interacciones, mientras en otras no fue detectada diferencia estadística entre aparatos. El método FT-Raman fue menos sensible para detectar diferencias entre los grupos experimentales. La interposición de discos de cerámica redujo sinnificativamente la RF y la MK del cemento fotoactivado, cuando comparados con los grupos E0 y E2; sin embargo, cuando se adicionó el catalizador al cemento, no se verificaron estas reducciones. La región IC de los cps presentó media más alta $\left(39,6 \mathrm{KHN}^{\mathrm{a}}\right)$ de $\mathrm{MK}$ y la región $\mathrm{NB}$, la menor $\left(34,6 \mathrm{KHN}^{\mathrm{c}}\right)$, lo que deja claro que la luz no se distribuyó uniformemente en los cp. Se verificó correlación positiva entre las medias de GC y MK. Conclusión: Se concluye que los materiales restauradores que tienden a transmitir más luz al cemento resinoso, principalmente el de pasta única (fotoactivado), proporcionan mejores condiciones de polimerización y, en consecuencia, las propiedades físicas máximas.

Palabras clave: cementos de resina; propiedades físicas; luz; transmisión; materiales dentales. 


\section{SUMÁRIO}

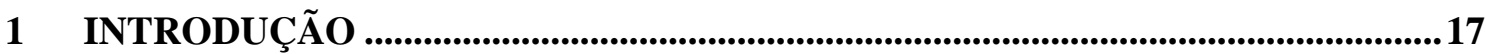

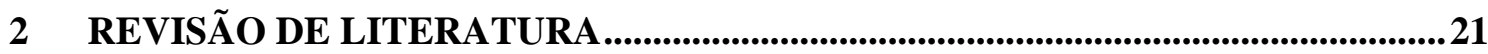

2.1 Caracterização dos cimentos resinosos..............................................................22

2.2 Fontes de luz e sua transmissão através de materiais restauradores.................29

2.3 Fatores que interferem na polimerização dos cimentos resinosos .....................41

2.4 Ensaios laboratoriais para avaliar o grau de conversão de compósitos ............47

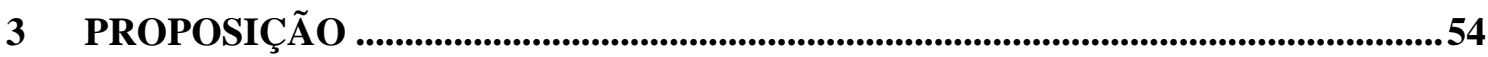

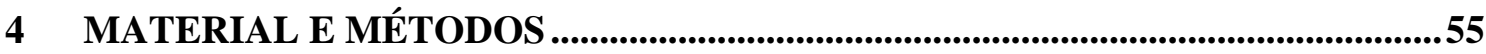

4.1 Obtenção da emissão espectral dos aparelhos de fotoativação.............................56

4.2 Confecção dos discos de materiais restauradores indiretos estéticos ................59

4.3 Avaliação da TR dos materiais restauradores indiretos: ....................................69

4.4 Confecção dos cps de cimento resinoso: ..............................................................72

4.5 Avaliação das propriedades físicas dos cimentos resinosos:................................ 76

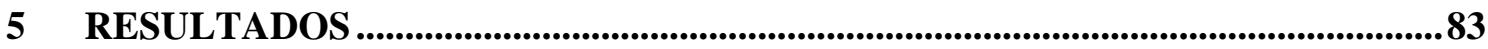

5.1 Emissão espectral dos aparelhos de fotoativação ................................................83

5.2 TR dos materiais restauradores indiretos estéticos...........................................86

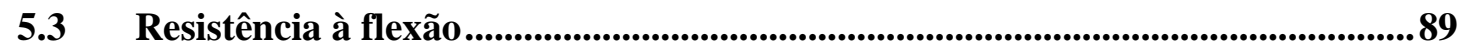

5.4 Microdureza Knoop .................................................................................................92

5.5 GC pelo método FT-Raman ..............................................................................................99

5.6 Correlações e análises de regressão .......................................................................... 102

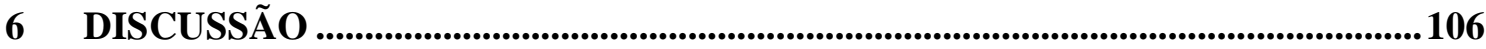

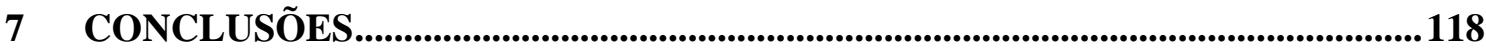

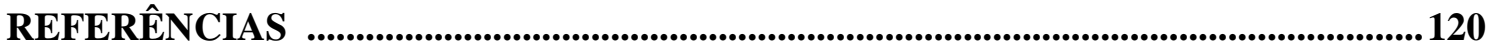




\section{INTRODUÇÃO}

As restaurações indiretas livres de metal são uma realidade atualmente, pois mimetizam a translucidez e a cor natural do dente. Com relação às cerâmicas odontológicas, a sua resistência mecânica foi otimizada pelo aumento do conteúdo cristalino em suas composições ${ }^{(1,2)}$. Tal resistência intrínseca aliada aos sistemas adesivos e cimentos resinosos, proporcionam resistência à fratura e longevidade clínica ${ }^{(1,3-5)}$.

Duas teorias foram propostas para explicar tal comportamento mecânico. Uma sugere que os cimentos resinosos preenchem os defeitos presentes na superfície das cerâmicas, impedindo que as trincas se propaguem e, assim, aumentando a resistência à fratura do material. E a outra teoria propõe que a contração de polimerização do cimento resinoso promove uma tensão fazendo com que as moléculas de cerâmica se aproximem e, com isso, a sua resistência se eleva ${ }^{(6)}$.

Paralelamente ao desenvolvimento das cerâmicas, as resinas compostas de uso indireto foram sendo aperfeiçoadas e introduzidas na Odontologia. Embora estes materiais apresentem propriedades mecânicas satisfatórias, facilidade na execução de reparos e ajustes oclusais e técnica de confecção menos sensível quando comparados às cerâmicas, ainda se faz necessária a cimentação adesiva para alcançar uma resistência à fratura satisfatória ${ }^{(4)}$.

Os cimentos resinosos irão funcionar como amortecedores de impacto e assim, distribuirão as tensões durante a função pelo conjunto dente-cimento-restauração ${ }^{(5)}$. E, para que tal efeito ocorra o cimento resinoso deverá apresentar propriedades como: resistência mecânica ${ }^{(7,8)}$, módulo de elasticidade intermediário entre o material restaurador e ao do dente 
${ }^{(8)}$, limite de proporcionalidade elevado ${ }^{(8)}$, resiliência ${ }^{(8)}$, baixa solubilidade ${ }^{(7)}$, adesão à estrutura dentária ${ }^{(7)}$ e biocompatibilidade ${ }^{(7)}$.

Os cimentos resinosos são resinas compostas de baixa viscosidade, isto é, constituemse numa matriz polimérica que aglutina partículas inorgânicas com tamanho e distribuição variada ${ }^{(9)}$. Estes cimentos podem ser classificados quanto ao seu sistema de ativação em quimicamente ativado, fotoativado ou de ativação dupla (dual). Os cimentos quimicamente ativados, como não dependem da luz para desencadear a reação de polimerização, são indicados para restaurações que impedem parcial ou totalmente a passagem de luz. Porém, possui como desvantagem a incorporação de bolhas durante a mistura das pastas, que prejudica as suas propriedades mecânicas, instabilidade de cor e, principalmente, a impossibilidade de controlar o tempo de trabalho ${ }^{(10)}$. Diante disso, os cimentos fotoativados e duais são os mais utilizados.

Independentemente do tipo de ativação, é fundamental que o cimento alcance o maior grau de conversão possível para atingir propriedades físicas desejáveis ${ }^{(11)}$. No caso da maioria dos cimentos fotoativados ou duais, que possuem a canforoquinona como fotoiniciador, é necessário um aparelho de fotoativação que emita luz com comprimento de onda entre 470 e $480 \mathrm{~nm}^{(12-14)}$ e com uma potência que forneça uma quantidade suficiente de fótons, para que o seu grau de conversão seja satisfatório. Caso contrário, resultará em falhas clínicas, como: deslocamento ou fratura da peça protética ${ }^{(15-18)}$, microinfiltração, cáries recorrentes ${ }^{(18-21)}$ e sensibilidade pós-operatória ${ }^{(16,18-21)}$.

Vários são os fatores que podem afetar no grau de conversão dos cimentos resinosos: espessura $^{(10,14,15,17,18,22-25)}$, opacidade ${ }^{(24)}$ e composição do material restaurador ${ }^{(18,19,22,26)}$, croma e valor da peça protética $(15,18,19)$, irradiância e qualidade da luz do aparelho de fotoativação $^{(15,18,23,27-29)}$, tempo de exposição do cimento à luz ${ }^{(14,19,23,24,27)}$, espessura e 
composição do agente cimentante ${ }^{(10,24,30)}$, tempo decorrido após a fotoativação ${ }^{(23)}$ e distância entre a fonte luminosa e o cimento ${ }^{(24)}$.

Quanto à transmissão da luz pelo material restaurador, as porcelanas, as cerâmicas e as resinas compostas utilizadas na confecção de restaurações indiretas são materiais que possuem duas ou mais fases e, desta maneira, quando um feixe de luz incide, numerosas reflexões e refrações de luz ocorrem nos limites destas fases, desencadeando um espalhamento de luz. O grau de espalhamento de cada material depende do comprimento de onda da luz incidente ${ }^{(31,32)}$, do tamanho das partículas ${ }^{(33)}$, da composição de cada fase ${ }^{(33)}$ e, consequentemente, dos seus índices de refração ${ }^{(34)}$, além da porosidade presente no material (34). Desta maneira, quanto maior o espalhamento da luz, menor a transmissão da luz ${ }^{(33)}$. Portanto, presume-se que cada composição de material restaurador indireto promoverá um comportamento distinto à atenuação da luz e, por conseqüência, o cimento resinoso fotoativado sob estes materiais responderá de forma diferente.

Em amostras de resinas compostas de uso direto, já está comprovado que o grau de conversão, representado pela dureza do material, é heterogêneo quando as amostras são fotoativadas numa única direção. Isto é, no centro da amostra sempre haverá um grau de polimerização superior em relação às bordas ${ }^{(35)}$. Porém, não se sabe se o espalhamento da luz que ocorre nos materiais restauradores indiretos é capaz de minimizar esta heterogeneidade em uma amostra de cimento resinoso fotoativado sob estes materiais.

Além disso, se uma dose ideal de energia é fornecida a uma resina quando se aplica uma irradiância de $600 \mathrm{~mW} / \mathrm{cm}^{2}$ por $30 \mathrm{~s}{ }^{(36)}$, para um cimento que está sujeito à atenuação da luz causada pela presença de uma restauração, esta irradiância ou este tempo poderá ser insuficiente para a sua polimerização. Desta maneira, quantificar esta atenuação é de extrema importância para que se consiga compensar esta atenuação através do aumento do tempo ou da irradiância e o cimento atinja as propriedades mecânicas desejáveis. 
Outra forma de compensar esta atenuação seria utilizando uma fonte de luz com uma faixa de comprimento de onda específico para ativação do fotoiniciador. Assim, toda a energia liberada pelo aparelho seria absorvida e, teoricamente, o grau de conversão do cimento seria maior. Desta maneira, comparar a eficiência de um aparelho de lâmpada halógena de quartzo-tungstênio (QTH), que irradia luz com comprimento de onda da faixa do violeta-azul (380 a $530 \mathrm{~nm}$ ), com um diodo emissor de luz (LED), que irradia uma faixa de comprimento de onda mais estreita $(440$ a $480 \mathrm{~nm})$ torna-se significante ${ }^{(15,17)}$.

Assim como são inúmeras as variáveis relacionadas à polimerização dos cimentos resinosos sob materiais restauradores, há diferentes métodos para avaliar o grau de conversão dos mesmos. Porém, cada método possui vantagens e desvantagens. Ao utilizar diversos ensaios laboratoriais para avaliar um determinado material sob as mesmas variáveis, se reunirão mais informações sobre as suas propriedades físicas e, a partir dos resultados obtidos, seleciona-se o tipo de ensaio mais indicado para um objetivo específico.

A presente pesquisa, além de comparar ineditamente o efeito da transmissão da luz de diferentes composições de materiais restauradores na polimerização de um cimento resinoso, utilizou diversos ensaios laboratoriais a fim de se obter um maior número de respostas para os resultados encontrados. 


\section{REVISÃO DE LITERATURA}

A cimentação adesiva é o calcanhar de Aquiles de uma restauração indireta estética. A perfeita combinação entre um sistema adesivo e um alto grau de conversão dos monômeros

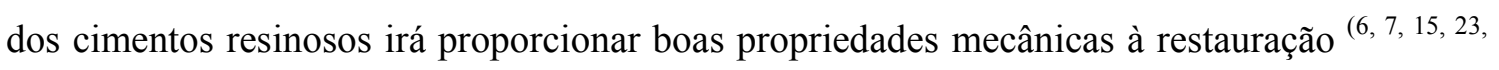
${ }^{24,37)}$, baixa solubilidade do cimento ${ }^{(11)}$, estabilidade da peça protética ${ }^{(15,38)}$ e, ainda, evitará a microinfiltração ${ }^{(19,21)}$ e a sensibilidade pós-operatória ${ }^{(7,21)}$. Além disso, manterá a estética, pois não haverá excesso de ligações duplas residuais que causa a alteração de cor do cimento resinoso e prejudica a aparência de restaurações mais translúcidas ${ }^{(7,24)}$

Dentre os fatores que interferem na qualidade da polimerização do cimento resinoso, destacam-se o tipo de sistema de ativação, a espessura da restauração e o tempo de exposição à luz, e estes já estão identificados na literatura $(14,22,27,39,40)$.

Com a introdução de novos materiais restauradores de uso indireto, agentes de cimentação resinosos e aparelhos de fotoativação, é necessária a realização de uma pesquisa que englobe estes materiais e equipamentos atuais e que avalie o resultado final da interação dos mesmos.

Além disso, é interessante aplicar diversos ensaios laboratoriais com as mesmas variáveis em uma única pesquisa, pois será possível discutir e explicar os resultados a partir das próprias evidências obtidas na pesquisa. Desta maneira, também se identificará qual o ensaio mais sensível ou específico para avaliar um determinado fenômeno ou propriedade.

Esta revisão de literatura será dividida em quatro partes para compreender sistematicamente como estes diferentes fatores interagem entre si: (1) caracterização dos cimentos resinosos; (2) fontes de luz e sua transmissão através de materiais restauradores; (3) 
fatores que interferem a polimerização dos cimentos resinosos; (4) ensaios laboratoriais para avaliação do grau de conversão dos polímeros.

\subsection{Caracterização dos cimentos resinosos}

Um compósito contém pelo menos duas fases distintas, sendo uma matriz orgânica e uma fase inorgânica. A porção orgânica é formada basicamente por monômeros que desencadeiam a reação de polimerização. Já a parte inorgânica do material é composta basicamente por partículas de quartzo ou de vidro que tem como função promover resistência mecânica ao material ${ }^{(13,41)}$. Os cimentos resinosos são essencialmente resinas compostas de baixa viscosidade $^{(9)}$.

O monômero mais usado nos cimentos resinosos é o Bis-GMA (dimetacrilato glicidílico do bis-fenol A), que é um metacrilato bifuncional derivado da reação do bisfenol-A com o metacrilato de glicidila (Figura 2.1.A). Este monômero possui dois grupos fenólicos (anéis aromáticos), que proporcionam um alto grau de rigidez à molécula, e grupos hidroxila que fazem pontes de hidrogênio inter-moleculares ${ }^{(13)}$. Como o Bis-GMA é um monômero extremamente viscoso, incorporam-se nos cimentos resinosos um dimetacrilato de baixa viscosidade, como o TEGDMA (dimetacrilato de trietilenoglicol) ${ }^{(9)}$. Apesar de o TEGDMA (Figura 2.1.B) ser o composto mais comum para controlar a viscosidade, outros monômeros podem ser incorporados ao compósito, como o metacrilato de metila (MMA) e o dimetacrilato de etileno glicol (EDMA) ${ }^{(42)}$. 
Outro monômero comumente utilizado nos cimentos resinosos para substituir o BisGMA ou complementar a composição da matriz polimérica é o dimetacrilato de uretano (UDMA). Este monômero pode possuir uma estrutura alifática ou aromática. Geralmente, é utilizado o monômero alifático (Figura 2.1.C), pois este tipo possui uma viscosidade relativamente baixa e não requer a utilização de um monômero diluente ${ }^{(13)}$. A presença de ligações de uretano facilita a transferência de cadeia de um radical livre para outro monômero ou cadeia polimérica inativa, proporcionando um aumento na densidade de ligações cruzadas do polímero ${ }^{(16)}$. Já o dimetacrilato de uretano que contém grupos aromáticos possui uma estrutura mais complexa e é mais viscoso, assim eventualmente, requer a presença de um monômero diluente ${ }^{(13)}$.

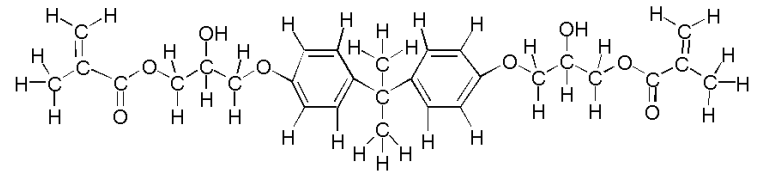

Figura 2.1.A - Molécula de Bis-GMA

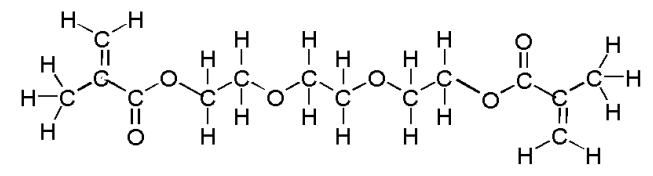

Figura 2.1.B - Molécula de TEGDMA

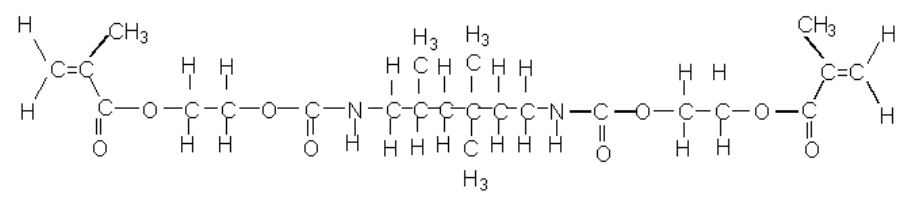

Figura 2.1.C - Molécula de UDMA

Para garantir as propriedades do compósito por um longo período de armazenagem e tempo de trabalho adequado, é essencial que se evite a sua polimerização prematura dentro da embalagem. Para isto, é adicionado cerca de $0,1 \%$ de um inibidor de reação, como a hidroquinona ou o hidroxitolueno butilado (HTB). A matriz polimérica também possui ativadores e iniciadores de reação ${ }^{(9,41,42)}$ que serão abordados no decorrer desse capítulo. 
Com relação à carga inorgânica dos compósitos, o tipo, a concentração, o tamanho e a sua distribuição na matriz polimérica são fatores determinantes nas propriedades físicas do material ${ }^{(13)}$. Atualmente, muitos compósitos são produzidos a partir da moagem ou frezagem do quartzo ou vidro, que podem ser de silicato de lítio-alumínio ou vidro de sílica que contém bário, estrôncio, zinco ou zircônia ${ }^{(41,42)}$. Há também as partículas de sílica submicrométricas de tamanho coloidal $(0,04 \mu \mathrm{m})$ obtidas por um processo pirolítico ou de $\operatorname{precipitação~}^{(9)}$.

O processo de obtenção das partículas inorgânicas determina o seu tamanho e, desta maneira, as resinas compostas podem ser classificadas em três grupos principais conforme o tamanho médio das partículas de carga: tradicional, híbrida e microparticulada. As resinas tradicionais são resinas compostas por partículas de vidro com tamanho de 1 a $50 \mu \mathrm{m}$. As resinas híbridas combinam partículas pequenas ou da categoria tradicional (cerca de 75\%) com partículas de sílica coloidal (cerca de $8 \%)^{(9,13)}$.

As resinas híbridas ainda podem ser subdivididas em três tipos: híbrida de partícula grande, de partícula média e de minipartícula. A híbrida de partícula grande, de partícula média e a de minipartícula combinam partículas com tamanho que variam de 1 a $20 \mu \mathrm{m}$, de 0,1 a $10 \mu \mathrm{m}$ e 0,1 a $2 \mu \mathrm{m}$, respectivamente, com partículas de sílica coloidal de $0,04 \mu \mathrm{m}{ }^{(9)}$.

E, por último, as resinas microparticuladas que podem ser homogêneas, que se constituem somente por partículas de sílica coloidal com tamanho médio de 0,04 $\mu \mathrm{m}$, ou heterogêneas, que combinam partículas de sílica coloidal de $0,04 \mu \mathrm{m}$ com partículas prépolimerizadas contendo sílica coloidal de $0,04 \mu \mathrm{m}{ }^{(9)}$. Os cimentos resinosos possuem partículas que variam de $0,04 \mu \mathrm{m}$ a $3 \mu \mathrm{m}$ e são classificados da mesma forma que as resinas compostas.

Todas as partículas inorgânicas são submetidas a um tratamento antes de serem misturados a matriz polimérica. Este tratamento consiste no recobrimento das superfícies externas da partícula por um agente de união silânico. Embora titanatos e zirconatos possam 
ser empregados como agentes de união, organossilanos, como o $\gamma$-metacriloxipropil trimetoxissilano, são os mais usados (Figura 2.1.D). Este organossilano é uma molécula bifuncional que em uma extremidade possui características de um radical metacrilato, enquanto na outra extremidade possui um grupo silanol que é capaz de interagir e se unir às superfícies cerâmicas.

$$
\mathrm{CH}_{2}=\mathrm{CCH}_{3} \mathrm{CO}_{2}\left(\mathrm{CH}_{2}\right)_{3} \mathrm{Si}\left(\mathrm{OCH}_{3}\right)_{3}
$$

Figura 2.1.D - Molécula do $\gamma$-metacriloxipropil trimetoxissilano

Após discorrer sobre a matriz orgânica, partículas de carga e o agente de união presente nos compósitos, é importante conhecer o processo de polimerização das resinas. A polimerização por adição é o tipo de reação química que converte os monômeros em polímeros nos cimentos resinosos ${ }^{(41)}$. Trata-se de uma reação intermolecular repetitiva em que as moléculas de monômeros se unem formando uma cadeia polimérica por meio de ligações covalentes ${ }^{(43)}$. Este tipo de reação geralmente envolve monômeros que contém ligações duplas de carbono $(\mathrm{C}=\mathrm{C})$. Estas ligações possuem alta energia e são relativamente instáveis, desta maneira conseguem reagir facilmente com outras moléculas. Este tipo de monômero requer uma molécula, denominada iniciador, para iniciar a reação química. Este o iniciador deve ser ativado, o que pode ocorrer pela interação deste com a luz, o calor ou com um agente químico ${ }^{(41)}$.

A primeira etapa de uma polimerização é a ativação do iniciador, que passa a constituir um radical livre (molécula com uma ligação simples de carbono e um elétron desemparelhado). Em seguida, o iniciador irá se unir ao monômero, fazendo com que sua ligação dupla de carbono se quebre. Desta forma, o radical livre passa a ser a cadeia polimérica em formação, com um dos átomos da ligação dupla quebrada apresentando o 
elétron não-pareado. O radical livre é muito reativo e reage sequencialmente com outros monômeros. Este tipo de reação se inicia em vários locais da matriz orgânica; desta forma, há numerosas cadeias poliméricas se formando simultaneamente ${ }^{(41)}$. Embora a viscosidade aumente numa velocidade muito rápida durante o crescimento das cadeias poliméricas, estas podem deslizar umas sobre as outras na fase chamada de pré-gel. O estágio de propagação continua, as cadeias moleculares se tornam maiores, as ligações cruzadas começam a predominar, e o material atinge o ponto gel, a partir do qual a mobilidade das cadeias é bastante reduzida ${ }^{(43)}$. Finalmente, alguns monômeros permanecem não-reagidos ou com algumas ligações não-reagidas (ligações duplas pendentes), a viscosidade da mistura aumenta e, assim, a reação entra no estágio final ou fase pós-gel, quando pára ou termina, alcança seu maior módulo de elasticidade e o material torna-se rígido ${ }^{(41,43)}$.

A polimerização de monômeros nos cimentos resinosos resulta em uma estrutura com monômeros não-reagidos ou com ligações duplas pendentes e com ligações cruzadas. Quanto maior a densidade de ligações cruzadas em uma resina polimerizada, maior será a sua resistência mecânica. Desta forma, é desejável que a resina atinja alto grau de conversão, mas sempre haverá uma concentração significante de ligações duplas de carbono não-reagidas. Isto acontece devido à limitação da mobilidade das partes reativas impostas pela formação de ligações cruzadas ${ }^{(44)}$, decorrente da alta velocidade da reação e do aumento da viscosidade do material $^{(41)}$.

Para que esta polimerização resulte com uma pequena quantidade de monômeros nãoreagidos, é importante que a sua ativação seja eficiente. Desta maneira, os cimentos resinosos podem ser classificados conforme o seu sistema de ativação em quimicamente ativados, fotoativados ou com dupla ativação (dual). Os cimentos quimicamente ativados são compostos por duas pastas: base e catalisadora. Cada pasta contém uma combinação de monômeros e partículas inorgânicas. A pasta base contém em torno de 0,5\% de uma amina 
terciária ativadora, como o dimetil-p-toluidina $N, N^{\prime}$. Já a catalisadora contém cerca de $1 \%$ de iniciador, como o peróxido de benzoíla $(\mathrm{PB}){ }^{(13)}$. Como não dependem da luz para desencadear a reação de polimerização, são indicados para restaurações que, devido a sua espessura ou composição, impedem parcial ou totalmente a passagem de luz. Porém, estes cimentos possuem como desvantagem a instabilidade de cor e a incorporação de bolhas durante a mistura das pastas, que reduz as suas propriedades mecânicas. Além disso, impossibilita o controle do tempo de trabalho pelo operador ${ }^{(10)}$.

Já os cimentos resinosos fotoativados são sistemas de pasta única que contém monômeros, carga inorgânica e um sistema iniciador que é instável na presença de luz. O sistema de iniciação dos radicais livres é constituído de um fotoiniciador, como uma diquetona, e uma amina iniciadora, como o dimetilaminoetil metacrilato (DMAEMA). A CQ é a diquetona mais usada. Apenas pequenas quantidades de CQ e DMAEMA são necessárias: $0,2 \%$ ou menos em peso e $0,15 \%$ em peso, respectivamente ${ }^{(9,13)}$.

$\mathrm{Na}$ presença de radiação luminosa com comprimento de onda entre 470 e $480 \mathrm{~nm}^{(12-}$ 14), a CQ é ativada e levada ao estado de "triplet". Neste estado, a CQ se combina com duas moléculas de uma amina terciária, formando um complexo foto-excitado (“exciplex"). Em seguida, a CQ remove um próton de cada molécula de amina e o "exciplex" se quebra em radicais livres os quais podem reagir com a dupla ligação carbono-carbono da molécula de monômero desencadeando a reação de polimerização. Se um número suficiente de moléculas de CQ não for levado ao estado "triplet", a resina não será adequadamente polimerizada. Assim, a irradiância utilizada para a polimerização pode afetar a extensão e a velocidade da reação de polimerização ${ }^{(43)}$.

Quanto maior a irradiância fornecida por um aparelho de fotoativação, mais fótons serão produzidos. E, quanto maior o número de fótons atingindo a resina, mais moléculas de CQ irão se transformar no estado "triplet" para reagir com a amina e formar radicais livres ${ }^{(45)}$. 
Logo, as propriedades físicas do material melhoram com o aumento da irradiância, em um mesmo tempo de exposição, da mesma forma que melhoram com o aumento do tempo de exposição sob a mesma irradiância ${ }^{(46)}$. Assim, o grau de conversão, a profundidade de polimerização e as propriedades mecânicas das resinas são mais dependentes da dose de energia (multiplicação da irradiância pelo tempo de exposição) utilizada ${ }^{(46)}$.

É conveniente ressaltar que outros tipos de fotoiniciadores são utilizados nas resinas compostas ${ }^{(47)}$, mas este assunto será abordado na segunda parte desta revisão de literatura. As vantagens do sistema de fotoativação incluem a facilidade de uso, pois permite o controle do tempo de trabalho, o acabamento imediato ${ }^{(10)}$ e a estabilidade de cor ${ }^{(7)}$. Por outro lado, a espessura, a opacidade, a cor ou a composição da restauração poderão atenuar a intensidade de luz que atinge o cimento resinoso ${ }^{(10,19,22)}$.

E, finalmente, o cimento resinoso dual é um sistema de duas pastas, onde a pasta base contém geralmente a CQ, a amina terciária alifática (por exemplo: DMAEMA) e a amina terciária aromática (por exemplo: dimetil-p-toluidina $N, N^{\prime}$ ). Já a pasta catalisadora contém o PB ${ }^{(9,12)}$. Quando as duas pastas são misturadas e depois expostas à luz, a fotoativação é promovida pela interação amina/CQ, e a ativação química é causada pela interação amina/PB ${ }^{(9)}$. Este cimento combina as vantagens do quimicamente ativado com as do fotoativado. Desta forma, é esperado que o componente químico complemente a polimerização do cimento em locais onde ocorre a atenuação parcial ou total da luz ${ }^{(10)}$. No entanto, se a amina catalisadora não for totalmente reagida pode ocorrer uma alteração da cor do cimento dual, tendendo para o amarelo ${ }^{(1)}$, e, como conseqüência, comprometer a estética de restaurações mais translúcidas. Sendo assim, como a pasta base deste cimento apresenta a mesma composição de um cimento resinoso fotoativado, esta pode ser utilizada isoladamente em restaurações mais delgadas (até $1 \mathrm{~mm}$ de espessura) ${ }^{(18)}$, que irão permitir a transmissão de luz. Esta situação proporciona uma versatilidade no uso ao cimento dual. 
Os sistemas de ativação e as diferentes composições dos cimentos resinosos proporcionam propriedades que são consideradas essenciais: resistência mecânica $(7,8)$, módulo de elasticidade intermediário ao do material restaurador e ao do dente ${ }^{(8)}$, limite de proporcionalidade elevado ${ }^{(8)}$, resiliência ${ }^{(8)}$, baixa solubilidade ${ }^{(7)}$, adesão à estrutura dentária

(7) e biocompatibilidade ${ }^{(7)}$. E, para que estas propriedades sejam alcançadas em cimentos fotoativados ou duais, é imprescindível conhecer as características dos aparelhos fotoativadores e compreender os fenômenos ópticos que ocorrem na interação entre os diferentes tipos de fonte de luz e os materiais restauradores estéticos para se alcance estas propriedades e o sucesso da cimentação adesiva de uma peça protética.

\subsection{Fontes de luz e sua transmissão através de materiais restauradores}

Este item abordará as fontes de luz disponíveis para a fotoativação de compósitos e as características estruturais dos materiais restauradores estéticos. Além disso, será feita uma explanação sobre os fenômenos ópticos e sobre a interação da luz com a matéria.

Classificam-se as fontes de luz para ativação de compósitos em quatro tipos: (I) QTH que irradia tanto a luz ultravioleta quanto do espectro visível, a qual é filtrada para promover a saída de um feixe de comprimento de onda entre 400 e $500 \mathrm{~nm}$ e, ainda, minimizar o calor gerado; (II) o LED, que emite radiação no comprimento de onda azul do espectro de luz visível, entre 440 e $480 \mathrm{~nm}$; (III) o arco de plasma (PAC), que utiliza um gás xenônio ionizado para produzir um plasma, gerando, assim, uma luz branca de alta intensidade que 
também é filtrada para reduzir o calor e permitir que o comprimento na faixa do azul seja emitido; e (IV) o laser de argônio, que emite uma variedade de comprimentos de onda (454, $458,466,472,477,488$ e $497 \mathrm{~nm})^{(9,45)}$.

Na presente pesquisa os aparelhos para a fotoativação selecionados foram um QTH e um LED. As razões pelo qual o PAC e o laser argônio não foram eleitos são: o uso limitado pelos clínicos e o seu alto custo. Este uso limitado está diretamente relacionado às desvantagens apresentadas por estes aparelhos. Como o PAC possui uma potência elevada, altos níveis de ozônio podem ser gerados. Além disso, emite muita radiação ultravioleta e infravermelha, assim cuidados relacionados à filtragem e eliminação da radiação devem ser rigorosamente seguidos. São aparelhos que utilizam fios preenchidos com um líquido para transmitir a radiação e se alguma dobra permanente se formar no fio, este é inutilizado. O conserto do PAC, caso necessite de alguma manutenção, não pode ser feita no consultório, pois requer equipamentos específicos e técnicos especializados, fazendo com que aumente o custo para o clínico ${ }^{(45)}$.

Com relação ao laser argônio, o comprimento de onda emitido que possui maior potência é o $488 \mathrm{~nm}$. No entanto, a energia do fóton emitido pelo QTH em um comprimento de onda de 488 nm não é diferente da energia emitida pelo PAC ou laser de argônio no mesmo comprimento de onda. A diferença é que há mais fótons neste comprimento de onda quando emitido pelo laser do que pelo QTH e PAC. Mas, apesar do laser de argônio emitir uma radiação colimada e energia coerente, ao atingir a superfície de uma resina composta, o espalhamento e refletância que ocorre nas partículas de carga fazem com que a sua colimação e coerência seja perdida. Além disso, como o diâmetro da fibra que transmite a radiação é muito pequeno $(50 \mathrm{~nm})$ e esta só emite uma potência de $250 \mathrm{~mW}$, são necessárias várias fibras. Mas, a irradiância resultante da união de várias fibras fica extremamente alta e inviável. Desta forma, os fabricantes recomendam que a ponteira do laser fique afastada da 
superfície da resina. Há, também, componentes para promover a difusão da radiação e aumentar o diâmetro da ponta, porém reduzem drasticamente a irradiância emitida. Portanto, estes fatores diminuem a popularidade no uso do PAC e do laser de argônio pelos clínicos ${ }^{(45)}$.

Diante do exposto, o aparelho mais comumente utilizado é o QTH. Apesar de fornecer uma irradiância e um comprimento de luz apropriado para a ativação da CQ, a polimerização do compósito pode ser insatisfatória devido a flutuações na voltagem, deterioração do bulbo da lâmpada, do refletor ou do filtro, contaminação da ponteira ou, ainda, por efeitos deletérios causados pela desinfecção da ponteira do aparelho.

Uma desvantagem dos QTHs em relação aos LEDs é a sua vida útil, onde o primeiro possui de 30 a 100 horas e o segundo apresenta milhares de horas de funcionamento ${ }^{(17,35)}$, e esta característica está tornando os LEDs o aparelho de fotoativação de primeira escolha dos cirurgiões-dentistas. No entanto, fabricantes de resinas compostas introduziram recentemente diferentes fotoiniciadores na matriz orgânica para atuarem sozinhos ou sinergicamente com a CQ. Dentre eles estão os derivados de óxido de acilfosfino (MAPO ou óxido de monoacilfosfina e BAPO ou óxido de bis-acilfosfina) e de $\alpha$-diquetona (fenilpropanodiona). Diferente da CQ, o pico de absorção destes compósitos está mais perto da região ultravioleta (UV) e se estende ligeiramente para a região da luz visível. Sendo assim, os QTH são mais eficientes na ativação destes compostos, pois possuem uma faixa de emissão espectral mais ampla do que os LEDs convencionais. Por outro lado, os LEDs possuem uma faixa espectral mais estreita que concentra toda a energia liberada próxima ao pico de absorção da CQ (470 $\mathrm{nm}$ ), sendo assim, mais eficientes na polimerização de compósitos que possuem a CQ como fotoiniciador $^{(47)}$.

Contudo, a emissão espectral, como um fator isolado, não garante a superioridade de um aparelho fotoativador. A dose de energia emitida tem um papel muito importante na polimerização de um compósito, como já foi mencionado na primeira parte deste capítulo. 
Este fato foi comprovado pelos valores de dureza e grau de conversão superiores de uma resina composta fotoativada por um QTH que emitiu uma dose de energia de $22 \mathrm{~J} / \mathrm{cm}^{2}$ do que por um LED que emitiu $14,4 \mathrm{~J} / \mathrm{cm}^{2(31)}$.

Os LEDs podem ser classificados em três gerações distintas, devido ao avanço tecnológico ocorrido nos últimos anos ${ }^{(48)}$. A primeira geração consiste em chips de baixa potência que promovem um grau de polimerização menor quando comparados aos QTH convencionais. Com este tipo de LED é necessário utilizar tempos de exposição mais longos para se obter um grau de polimerização similar aos QTH. No entanto, com estes LEDs há uma menor liberação de calor. Já a segunda geração dispõe de modelos que utilizam um único chip de alta potência com uma área superficial maior que emite somente a faixa de comprimento de onda correspondente à cor azul do espectro visível, apresentando, assim, um melhor desempenho quando comparados à primeira geração. A capacidade de polimerização dos LEDs de segunda geração é similar aos QTHs convencionais usando o mesmo tempo de exposição, porém podem gerar mais calor. Já a terceira geração de LEDs é caracterizada por incorporar o mesmo chip da segunda geração com um ou mais chips de baixa potência que emitem uma segunda freqüência na faixa espectral do violeta. Este tipo de LED possui uma tecnologia denominada "Periodic Level Shifting" (PLS) ou "micro-pulsing" que mantém uma potência elevada (em torno de $1500 \mathrm{~mW} / \mathrm{cm}^{2}$ ) com pulsos periódicos de potência mais alta (em torno de $2000 \mathrm{~mW} / \mathrm{cm}^{2}$ ). O objetivo desta tecnologia é diminuir o superaquecimento interno que pode danificar o aparelho e diminuir os níveis de temperatura transmitida ao dente $(35,48)$

A importância de obter LEDs de terceira geração pode ser explicada pela comparação dos valores de dureza de várias resinas compostas fotoativadas por dois LEDs de segunda geração (FreeLight 2; LEDemetron I), um LED de terceira geração (UltraLume 5) e um QTH (Optilux 401) ${ }^{(35)}$. Os autores desta pesquisa, após obterem a emissão espectral dos aparelhos, 
notaram que os LEDs de segunda geração possuíam uma faixa espectral mais estreita quando comparados com o LED de terceira geração e o QTH. Esta faixa mais ampla dos últimos aparelhos citados (Figura 2.2.A) permitiu a melhor polimerização de uma resina (Vit-1escence, Ultradent Producyts, Inc.) que possui um fotoiniciador que é ativado por uma luz com comprimento abaixo de $420 \mathrm{~nm}^{(35)}$.

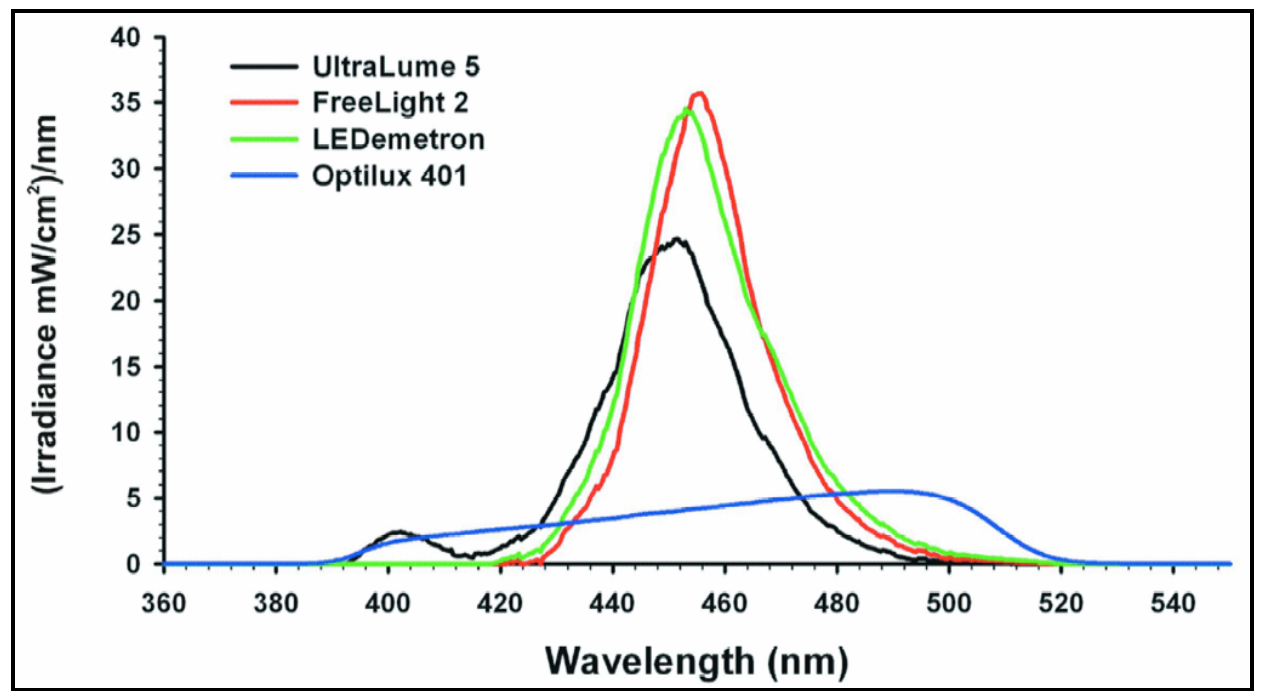

Figura 2.2.A - Emissão espectral dos aparelhos de fotoativação utilizados na pesquisa de Price, R.B.T.; Felix, C.A.; Andreou, P. ${ }^{(35)}$

Estes resultados foram obtidos para resinas compostas de uso direto, no caso dos cimentos resinosos que são fotoativados através de materiais restauradores, as características da radiação emitida pelo aparelho fotoativador podem ser alteradas devido a interposição e atenuação dos materiais rstauradores. Assim, para descrever os fenômenos óticos que envolvem as interações entre a luz (radiação eletromagnética) e a matéria, torna-se mais conveniente visualizar a radiação a partir de uma perspectiva quântico-mecânica. Neste sentido, a radiação, em vez de se consistir em ondas, é composta por grupos ou pacotes de energia chamados fótons. Assim, compreende-se que a intensidade da radiação ou irradiância, 
expressa em watts por medida de área, é a energia total emitida por unidade de tempo através de uma unidade de área perpendicular à direção da propagação ${ }^{(34)}$.

Quando a luz segue de um meio para outro, como por exemplo, quando a luz de um aparelho de fotoativação atinge a superfície de um material restaurador, uma parte da radiação luminosa pode ser transmitida através do meio, uma parte será absorvida e uma parte será refletida na interface dos dois meios. Desta forma, a intensidade do feixe incidente, $\mathrm{I}_{0}$, sobre a superfície do meio sólido deve ser igual à soma das intensidades dos feixes transmitido $\left(\mathrm{I}_{T}\right)$, absorvido $\left(\mathrm{I}_{A}\right)$ e refletido $\left(\mathrm{I}_{R}\right)$ (Equação 1$)^{(34)}$. Deste modo, a transmitância, a absorbância e a refletância referem-se à fração de luz relacionada com a transmissão $\left(\mathrm{I}_{T} / \mathrm{I}_{0}\right)$, absorção $\left(\mathrm{I}_{A} / \mathrm{I}_{0}\right)$ e reflexão $\left(\mathrm{I}_{R} / \mathrm{I}_{0}\right)$ que ocorre em um material ${ }^{(34)}$.

$$
\text { Equação 1: } \quad I_{0}=I_{T}+I_{A}+I_{R}
$$

Os materiais capazes de transmitir a luz com pouca absorção e reflexão são transparentes. Já os materiais translúcidos são aqueles em que a luz é transmitida de maneira difusa, isto é, a luz é dispersa no interior do material, num grau em que os objetos não são claramente distinguíveis quando observados através de uma amostra desse material ${ }^{(33,34)}$. Aqueles materiais que não transmitem a luz visível são conhecidos por opacos ${ }^{(34)}$.

O grau de translucidez de um material pode ser medido ao calcular a razão de contraste (RC), que é a razão entre a refletância de um objeto colocado sobre um fundo preto e a refletância do mesmo objeto colocado sobre um fundo branco ${ }^{(49)}$. Quando a RC é igual a zero o material é transparente e quando a RC é igual a 1 o material é opaco ${ }^{(50)}$.

Quando a luz é transmitida para o interior de materiais transparentes, ocorre uma diminuição da sua velocidade, esse fenômeno é conhecido por refração. O índice de refração (n), de um material é definido como sendo a razão entre a velocidade da luz no vácuo $(c)$ e a velocidade da luz no meio ( $v$ ) (Equação 2). A magnitude de $n$ irá depender do comprimento de onda da luz ${ }^{(34)}$. 


$$
\text { Equação 2: } \quad n=\frac{c}{v}
$$

Este retardo da luz ocorre devido à polarização eletrônica, isto é, o campo elétrico da luz interage com a nuvem eletrônica que circunda cada átomo dentro de sua trajetória, de tal modo a deslocar a nuvem eletrônica em relação ao núcleo do átomo. Desta maneira, o tamanho dos átomos ou íons constituintes possui uma influência considerável sobre a velocidade da luz em um sólido. Em geral, quanto maior for um átomo ou íon, maior será a polarização eletrônica, menor será a velocidade, e maior será o índice de refração. Por exemplo, as adições de bário e chumbo (na forma de óxidos: $\mathrm{BaO}$ e $\mathrm{PbO}$ ) ao vidro, que são íons grandes, irão aumentar significativamente o valor de $n^{(34)}$.

Quando a radiação luminosa passa de um meio para outro com índice de refração diferente, uma parte da luz é dispersa na interface dos dois meios, mesmo se ambos os materiais forem transparentes. A refletância $(R)$ representa aquela fração da luz incidente que é refletida na interface $\left(\mathrm{I}_{\mathrm{R}} / \mathrm{I}_{0}\right)$. Se a luz incide perpendicularmente à interface, a refletância é representada pela Equação 3, onde $n_{1}$ e $n_{2}$ são os índices de refração dos dois meios.

$$
\text { Equação 3: } \quad R=\left(\frac{n_{2}-n_{1}}{n_{2}+n_{1}}\right)^{2}
$$

Se a luz incidente não incide em direção perpendicular à interface, o valor de $R$ irá depender do ângulo de incidência ${ }^{(34)}$. Um estudo revelou que a refletância de uma luz visível incidente sobre uma superfície dentária ou cerâmica ou de um compósito varia entre 30 e 90\% e que esta reflexão será maior quando o ângulo entre a luz incidente e a superfície do material for pequeno, isto é, o material terá uma maior refletância a partir da incidência de uma luz rasante ${ }^{(51)}$.

Quando a luz é transmitida de um vácuo ou do ar para o interior de um sólido (s), temse a Equação 4, uma vez que o índice de refração é muito próximo à unidade. Dessa forma, quanto maior o índice de refração de um sólido, maior será a sua refletividade. Da mesma 
forma que o índice de refração de um sólido depende do comprimento de onda da luz incidente, a refletância também varia em função do comprimento de onda ${ }^{(34)}$.

$$
\text { Equação 4: } \quad R=\left(\frac{n_{s}-1}{n_{s}+1}\right)^{2}
$$

O grau de translucidez e opacidade de um material dependem em grande parte de suas características internas de refletância e transmitância. Quando um feixe de luz transmitido tem sua direção defletida, exibe uma aparência difusa, como resultado de múltiplos eventos de espalhamento. A opacidade advém quando o espalhamento é tão intenso que virtualmente nenhuma fração do feixe incidente é transmitida, sem deflexão, para a porção mais profunda. (34).

O espalhamento da luz também ocorre em materiais bifásicos em que uma fase está dispersa no interior da outra. A dispersão do feixe ocorre através dos contornos entre as fases quando existe uma diferença no índice de refração para as duas fases; quanto maior for esta diferença, maior será o espalhamento. Os poros residuais, originados na fabricação ou no processamento do material, também espalham a radiação luminosa de maneira efetiva ${ }^{(34)}$. Portanto, a quantidade de luz que é absorvida, refletida ou transmitida dependem da quantidade de cristais, da composição da matriz, do tamanho das partículas do material e do comprimento de luz incidente ${ }^{(33)}$.

Há dois efeitos de espalhamento: o Rayleigh e o Mie, ambos são determinados de acordo com o comprimento de onda da luz incidente e as dimensões do material que promove o espalhamento. O espalhamento Rayleigh ocorre quando o tamanho das partículas do material é similar ou menor que o comprimento de onda da luz incidente. Já o espalhamento Mie ocorre quando o tamanho das partículas são maiores que o comprimento de onda ${ }^{(31)}$.

Uma pesquisa relatou que o espalhamento promovido por porcelanas odontológicas de diferentes cores é do tipo Rayleigh ${ }^{(32)}$. Já outro trabalho, que verificou a transmitância da luz 
em uma resina composta de uso direto em função do comprimento de onda da luz incidente, mostrou que este material também promove um espalhamento do tipo Rayleigh ${ }^{(31)}$. Estas informações são valiosas, pois podem explicar as diferenças nas propriedades físicas de um mesmo compósito que é fotoativado com aparelhos que emitem radiação luminosa com diferentes faixas de comprimentos de onda.

Portanto, a penetração da luz visível nos materiais odontológicos é um fator importante na fotoativação das reações de polimerização dos cimentos resinosos e nos aspectos óticos da estética dentária ${ }^{(51)}$. A absorção e o espalhamento da luz incidente realizados pelas partículas inorgânicas do material restaurador indireto também podem determinar a atenuação da luz que chega ao cimento resinoso. Sendo que atenuação é a redução da intensidade de luz incidente ou transmitida em porcentagem ${ }^{(52)}$. Esta atenuação é função inversa com o tamanho do comprimento de onda da luz, isto é, a transmissão de luz aumenta com o aumento do comprimento de onda ${ }^{(26,32)}$.

No caso de resinas compostas, o espalhamento da luz, que está diretamente relacionado com o grau opacidade, aumenta quando o tamanho da partícula inorgânica do material se aproxima da metade do comprimento de onda da luz incidente. Portanto, como a maioria das unidades fotoativadoras emite luz com comprimentos de ondas entre 450 a 500 $\mathrm{nm}$, as resinas que possuem carga inorgânica de aproximadamente $250 \mathrm{~nm}$ apresentarão um maior espalhamento de luz e consequentemente um aspecto mais opaco. Mesmo as resinas microparticuladas que possuem carga inorgânica com tamanho médio de $40 \mathrm{~nm}$, formam aglomerados relativamente grandes $(240 \mathrm{~nm})$ e assim, apresentarão um coeficiente de transmissão de luz mais baixo do que uma resina híbrida ${ }^{(52,53)}$. No caso de partículas grandes ( $\cong 10^{4} \mathrm{~nm}$ ) ocorre reflexão quando a luz incide e refração e absorção quando a luz atravessa. Como materiais com este tamanho de partículas possuem um número reduzido de partículas por unidade de volume, consequentemente, exibem menor espalhamento e opacidade ${ }^{(33)}$. 
A relação entre o espalhamento da luz incidente e o tamanho das partículas de resinas compostas foi comprovada também através da profundidade de polimerização utilizando-se o ensaio de microdureza Knoop ${ }^{(53)}$. Os autores verificaram que as resinas que alcançaram a maior profundidade de polimerização eram àquelas com partículas grandes (5-10 $\mu \mathrm{m})$. As que apresentaram a menor profundidade de polimerização foram as que possuíam um tamanho médio de partículas de $0,04 \mu \mathrm{m}$. E, as resinas com valores intermediários de profundidade de polimerização foram aquelas com partículas de 1 a $1,5 \mu \mathrm{m}$. Estes resultados podem ser explicados pelo fato de que as partículas de $\mathrm{SiO}_{2}$ nas resinas microparticuladas $(0,04 \mu \mathrm{m})$ produzem aglomerados com tamanho de aproximadamente $0,24 \mu \mathrm{m}$, o que permite um elevado espalhamento e reduz a profundidade de polimerização ${ }^{(53)}$.

Já, com relação às cerâmicas, a variação da translucidez pode ser explicada pelo índice de refração destes materiais e pelo volume de conteúdo cristalino. Quanto maior a diferença entre os índices de refração das partículas e a matriz do material, maior será o espalhamento de luz ${ }^{(33,54)}$. Para exemplificar este fenômeno, foi pesquisado alguns materiais que foram ordenados conforme a translucidez em ordem decrescente ${ }^{(33)}$ : Vitadur Alpha (porcelana para dentina) $>$ Empress $>$ In-Ceram Spinell, Empress $2>$ Procera $>$ In-Ceram Alumina $>$ InCeram Zircônia, liga de ouro-paládio 52 SF. Uma das explicações para esta ordenação que os autores encontraram é que a matriz de porcelana, a leucita (presente no Empress) e o dissilicato de lítio (Empress 2) apresentam índices de refração de 1,50, 1,51 e 1,55, respectivamente, sendo semelhantes entre si. Já o óxido de zircônia, a alumina e o spinell possuem respectivamente índices diferentes: 2,20;1,76 e 1,72, o que se contrastam muito do índice da matriz de porcelana. Além disso, o Empress e o Empress 2 possuem menor conteúdo cristalino em sua matriz do que o In-Ceram e o Procera ${ }^{(33)}$.

Considera-se, portanto, que cerâmicas que contêm menos fase cristalina são mais translúcidas que aquelas que contêm mais fase cristalina ${ }^{(33,49)}$. No entanto, os resultados de 
um estudo não comprovaram esta tendência ${ }^{(49)}$. Os autores compararam a translucidez, através da RC, e a porosidade da cerâmica Eris com a porcelana Duceram LFC. Verificaram que a cerâmica $(\mathrm{RC}=0,584)$ apresentou uma $\mathrm{RC} 17 \%$ menor que a porcelana $(\mathrm{RC}=0,702)$, portanto, a cerâmica Eris foi mais translúcida. Os autores também explicaram estes resultados através do índice de refração e pela distribuição do tamanho dos poros. O índice refração das porcelanas (aproximadamente 1,5$)$ e dos poros $(n=1,0)$ resulta em um índice de refração relativo de 1,5 , que provavelmente é maior que os índices de refração das fases secundárias das cerâmicas. O espalhamento da luz é dependente do tamanho do poro, assim o espalhamento máximo ocorre quando o tamanho do poro possui a mesma magnitude do comprimento de onda incidente $(0,4$ a $0,7 \mu \mathrm{m})$. Apesar da porosidade da porcelana Duceram LFC ter sido a menor, esta porcelana apresentou o maior RC, porém a distribuição dos poros poderia estar desfavorável para a transmissão de luz nesta porcelana ${ }^{(49)}$.

A translucidez das cerâmicas também pode ser afetada pela sua espessura, microestrutura e pelo número de ciclos de queima realizados no seu processamento ${ }^{(49)}$. Esta afirmação foi comprovada por uma pesquisa ${ }^{(55)}$, na qual se aplicou uma porcelana de dentina sob cerâmicas de infra-estrutura. A opacidade dos espécimes de infra-estrutura aumentou após a aplicação da porcelana. As possíveis razões para este aumento incluem a presença da estrutura da porcelana com uma variedade de componentes cristalinos, o aumento na espessura dos espécimes, a refletância na interface entre a infra-estrutura e a porcelana, porosidade entre as camadas e qualquer mudança nos constituintes do material de infraestrutura devido aos ciclos de queima adicionais. Além disso, também foi detectada uma redução significante na translucidez depois do glaseamento dos espécimes ${ }^{(55)}$. Esta redução ocorre, pois a alta fluidez do glase fecha as porosidades presentes na superfície do material, resultando em uma superfície lisa que aumenta a reflexão da luz ${ }^{(49)}$. 
A transmissão de luz através de materiais estéticos pode ser aferida por dois métodos: a transmissão direta ou especular (Figura 2.2.B), que detecta o feixe de luz transmitido sem alteração de direção; a transmissão total ou difusa (Figura 2.2.C), que utiliza uma esfera integradora para a sua aferição e inclui toda a luz que passa pelo material de forma difusa ${ }^{(14,}$ 32).

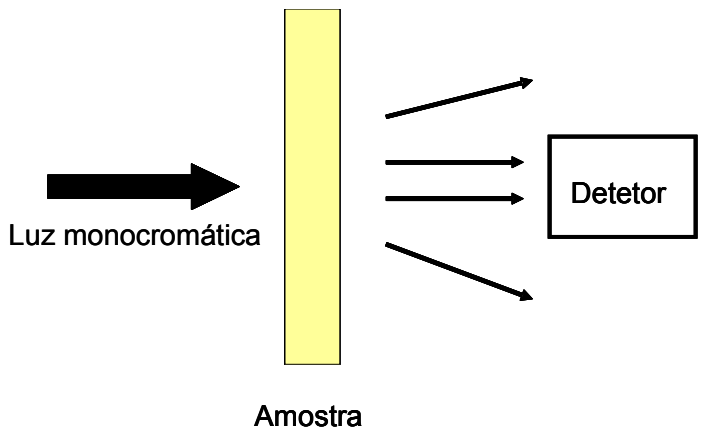

Figura 2.2.B - Método de avaliação da transmissão direta ou especular da luz ${ }^{(32)}$

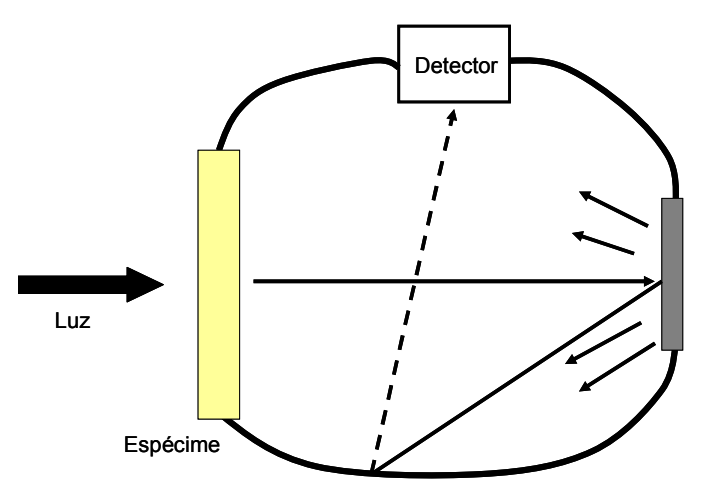

Figura 2.2.C Método de avaliação da transmissão total ou difusa da luz ${ }^{(32)}$

Em uma pesquisa ${ }^{(32)}$, após a avaliação da transmissão de luz através de cinco porcelanas, foi verificado que a quantidade de luz transmitida diretamente através dos espécimes de porcelana foi menor que $1 \%$, enquanto que a quantidade de transmissão total foi em média 26,8\%. Estes resultados mostram que a translucidez da porcelana pode ser explicada pela presença de opacificadores, como o óxido de estanho, que funcionam como centros de dispersão de luz ${ }^{(32)}$.

Outro fator que afeta a translucidez das cerâmicas é a espessura do material. Neste sentido, a equação de Lambert-Beer determina a quantidade de luz que passa através de um material translúcido: $I=I_{o} t_{c}^{X}$, onde $I$ é a intensidade de luz que passa através do espécime; $I_{o}$ é a intensidade do feixe de luz incidente; $t_{c}$ é uma constante para o material e, $x$ é a espessura do espécime. $t_{c}$ é definida como um coeficiente de transmissão, que é a razão entre a 
intensidade do feixe de luz incidente e a intensidade que passa através do espécime por unidade de espessura ${ }^{(32,56)}$.

Após compreender o processo de polimerização e a composição dos compósitos, as características das fontes de luz e os fenômenos óticos que ocorrem nos materiais restauradores estéticos, buscou-se na literatura, pesquisas que mostram o resultado da interação entre estes fatores. No próximo capítulo desta revisão da literatura será listada uma série de pesquisas que isolaram um ou mais fatores envolvidos na cimentação adesiva para verificar sua interferência na polimerização do cimento resinoso.

\subsection{Fatores que interferem na polimerização dos cimentos resinosos}

Dentre os fatores que interferem na polimerização dos cimentos resinosos sobre

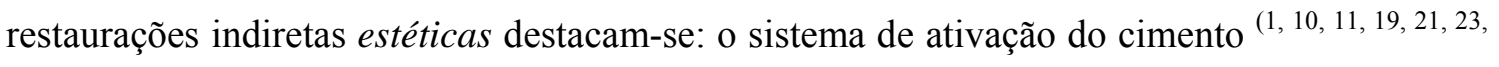
38, 57) , a espessura ${ }^{(1,15,18,20,21,24,38)}$, a cor ${ }^{(15,19)}$, a translucidez / opacidade ${ }^{(24)}$ e a composição

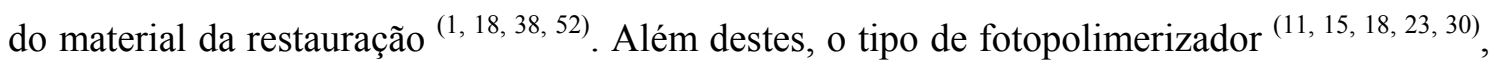
suas diferentes programações ${ }^{(11,17)}$, o tempo de exposição à luz ${ }^{(19,23,28,30)}$, a distância entre a fonte de luz e a película de cimento ${ }^{(24)}$ e o tempo após a polimerização ${ }^{(20,23)}$, são variáveis que também irão influenciar de alguma forma o grau de polimerização dos cimentos resinosos.

Em uma pesquisa ${ }^{(22)}$ foi examinada a microdureza Knoop de dois tipos de cimentos resinosos, um fotoativável e um dual, que foram fotoativados através de blocos constituídos 
por: uma porcelana feldspática e uma vitrocerâmica, com diversas espessuras $(0,5 ; 1 ; 2 ; 3$ e 4 mm). Os tempos de exposição à luz também variaram (30, 60, 90 e 120 segundos). Foi verificado que ambos os cimentos atingiram a dureza máxima quando fotoativados através dos discos de espessuras de 0,5 e $1 \mathrm{~mm}$ com o tempo de exposição recomendado pelo fabricante (60 s). E ainda, foi notado que nenhum cimento resinoso foi devidamente polimerizado sob os blocos de porcelana feldspática de 3 e $4 \mathrm{~mm}$, mesmo dobrando o tempo de exposição recomendado pelo fabricante. Ambos os cimentos apresentaram um melhor desempenho quando fotoativados através da vitrocerâmica. Estas diferenças nos resultados ao comparar os materiais cerâmicos interpostos não foram explicadas pelos pesquisadores ${ }^{(22)}$.

Já em outro estudo ${ }^{(38)}$ foi compararado o efeito da ativação química isoladamente e da dupla ativação nos valores de microdureza Knoop de sete cimentos resinosos duais em diferentes tempos de armazenamento (1 hora, 24 horas e 1 semana). Após esta etapa, foi verificada a influência de espaçadores de cerâmica e de resina composta, com diferentes espessuras $(1,2,3,4,5$ e $6 \mathrm{~mm})$, no grau de dureza dos mesmos cimentos resinosos. Com relação ao tipo de sistema de ativação dos cimentos, todos apresentaram valores de dureza inferiores ao utilizar somente a ativação química. E ainda, a maioria dos cimentos demonstrou um pequeno aumento na dureza com o tempo de armazenamento para ambos os sistemas de $\operatorname{ativação~}^{(38)}$.

Além disso, os sete cimentos analisados foram divididos em dois grupos. No primeiro, representados pelos cimentos Dicor, Twin-Look, Porcelite Dual Cure e Duo, após uma semana de armazenamento, foi observado um alto grau de dureza dos espécimes que foram somente quimicamente ativados, isto é, ocorreu uma redução de apenas 2 a $6 \%$ nos valores de dureza comparados com os mesmos cimentos que receberam dupla ativação. Já, no segundo grupo, representado pelos cimentos Sono-Cem, Dual e Dentist bonding porcelain kit, os espécimes quimicamente ativados apresentaram uma redução de $25 \%$ nos valores de dureza 
em relação aos de dupla ativação, no mesmo intervalo de tempo. Os autores atribuem estas diferenças às formulações dos cimentos resinosos testados, onde no primeiro grupo há uma quantidade suficiente de componente de ativação química para polimerizar o cimento em locais onde há déficit de luz ${ }^{(38)}$.

Na segunda etapa da pesquisa, os valores de dureza de todos os cimentos diminuíram com o aumento da espessura do espaçador. Reduções significativas no grau de dureza dos cimentos foram verificadas após uma hora e após um dia da fotoativação através de espaçadores com $1 \mathrm{~mm}$ ou mais de espessura. Após uma semana de armazenamento, reduções significantes só foram detectadas com espaçadores de $3 \mathrm{~mm}$ ou mais. Estes resultados também permitiram a separação dos cimentos nos mesmos dois grupos da primeira etapa. No primeiro grupo, a redução nos valores de dureza em relação ao valor máximo obtido sem a presença do espaçador foi de 19 a 29\% com espaçadores cerâmicos, e de 24 a $56 \%$ com os de resina composta, ambos com $6 \mathrm{~mm}$ de espessura. No segundo grupo de cimentos, nestas mesmas condições, a redução na dureza foi de 64 a 100\%, independentemente do material interposto. Estas reduções foram atribuídas à atenuação da luz causada pelo aumento da opacidade do espaçador, mas os autores não esclareceram as diferenças obtidas entre os espaçadores cerâmicos e de resina composta apresentadas no primeiro grupo ${ }^{(38)}$.

Duas pesquisas ${ }^{(21,58)}$ obtiveram resultados semelhantes, onde a dureza dos cimentos duais foi significativamente reduzida quando o material foi polimerizado através de inlays com mais de $2 \mathrm{~mm}$ de espessura, assim a ativação química destes cimentos não foi suficiente para compensar a atenuação da transmissão da luz causada pelo aumento da espessura das inlays ${ }^{(21,58)}$. Porém, ao comparar a dureza dos cimentos duais com a dos fotoativáveis, um outro estudo concluiu que o componente químico de ativação do sistema dual beneficia as propriedades do cimento, pois resultou em valores superiores ${ }^{(10)}$. 
Além dos valores de dureza do cimento resinoso, outras propriedades mecânicas foram avaliadas para comparar a dupla ativação e somente a fotoativação destes materiais. Neste sentido, foi relatado que a profundidade de polimerização do cimento resinoso com catalisador foi maior, independentemente do tipo de luz e da programação das unidades fotoativadoras $^{(11)}$.

Em outro estudo, os valores de resistência de união foram semelhantes ao comparar um cimento dual e um fotoativável na cimentação de restaurações cerâmicas de até $2 \mathrm{~mm}$, independentemente do tempo de armazenamento ${ }^{(1)}$. Já, em outra pesquisa, a resistência de união por cisalhamento de um cimento dual foi significativamente maior do que o mesmo cimento sem a ativação por luz. Com este resultado, os autores concluíram que o componente químico de um cimento dual não promove a sua completa polimerização em regiões onde a luz não pôde alcançar ${ }^{(59)}$.

Além do sistema de ativação do cimento e da espessura e da composição do material sobreposto ao cimento, a cor do material restaurador, representada pelo seu croma (saturação) e valor (brilho), podem influenciar as propriedades mecânicas do cimento resinoso. Assim, uma cerâmica com um alto croma e um baixo valor, como por exemplo, a cor C4, transmitirá menos luz, minimizando a polimerização do cimento resinoso dual. Isto se agrava ainda mais nos cimentos fotoativáveis $(15,19)$.

O croma e a espessura das restaurações também foram alterados em outra pesquisa ${ }^{(58)}$ para verificar a sua influência na dureza de um cimento resinoso. A conclusão foi a mesma dos autores acima citados, ou seja, quanto maior o croma, menor a transmissão de luz e, consequentemente, menor a dureza do cimento. Porém, um fato chama atenção, ao comparar o cimento que foi fotoativado através da restauração de $4 \mathrm{~mm}$ de espessura e de menor croma (A1) com o grupo controle, no qual foi deixado uma distância de $4 \mathrm{~mm}$ entre a ponta do 
fotoativador e o cimento, os resultados de dureza foram estatisticamente semelhantes entre si (58).

O tempo de espera após a exposição à luz para realizar um ensaio laboratorial para verificar o grau de conversão de cimentos resinosos, em alguns estudos, não influenciou significativamente os seus resultados ${ }^{(1,28)}$. Esta impossibilidade de continuar a reação de polimerização é devido ao aumento da viscosidade da resina causado pela polimerização inicial e pela dificuldade dos radicais se movimentarem na matriz orgânica ${ }^{(28)}$. No entanto, outras pesquisas demonstraram que os cimentos resinosos duais que são avaliados após $24 \mathrm{~h}$ da fotoativação possuem valores de conversão maiores do que os que foram avaliados imediatamente após a mesma ${ }^{(20,23)}$, gerando uma controvérsia sobre este assunto.

Além dos fatores já mencionados, o tipo de luz de um aparelho fotoativador pode interferir no grau de polimerização dos cimentos resinosos. Como já foi mencionado, há basicamente quatro tipos de aparelhos de fotoativação comercialmente disponíveis com características distintas: o QTH, o LED, o PAC e o laser argônio ${ }^{(9)}$. Ao verificar a influência dos diferentes tipos de unidades fotoativadoras no grau de conversão dos cimentos resinosos sob restaurações indiretas estéticas, pesquisas têm mostrado que a luz emitida pelo PAC apresenta resultados similares ou superiores, usando tempos de exposição mais curtos que os QTH $^{(18,23,30)}$. E, que os valores de dureza Rockwell de um cimento resinoso fotoativado com um LED e com um QTH convencional através uma porcelana com diferentes cores e espessuras foram superiores ao utilizar o LED ${ }^{(15)}$.

No entanto, a dureza universal e profundidade de polimerização de em um cimento resinoso ativado por um PAC $\left(1700 \mathrm{~mW} / \mathrm{cm}^{2}\right.$ por $\left.10 \mathrm{~s}\right)$ através de restaurações cerâmicas foi inferior à polimerização convencional $\left(800 \mathrm{~mW} / \mathrm{cm}^{2}\right.$ por $\left.40 \mathrm{~s}\right)$ e softstart $\left(100 \mathrm{a} 800 \mathrm{~mW} / \mathrm{cm}^{2}\right.$ por $40 \mathrm{~s}$ ) com luz halógena nas mesmas condições ${ }^{(11)}$. Confirmando que as propriedades mecânicas são mais dependentes da dose de energia do que da irradiância dos aparelhos ${ }^{(43)}$. 
Esta relação também foi confirmada com os resultados de outro trabalho ${ }^{(17)}$, no qual foi comparada a resistência de união de um cimento resinoso à dentina e à cerâmica, utilizando diferentes protocolos de polimerização. Os protocolos utilizados foram: modo contínuo com QTH $\left(600 \mathrm{~mW} / \mathrm{cm}^{2}\right.$ por $\left.40 \mathrm{~s}\right)$; modo contínuo com LED $\left(1100 \mathrm{~mW} / \mathrm{cm}^{2}\right.$ por 10s); modo pulsátil $\left(1100 \mathrm{~mW} / \mathrm{cm}^{2}\right.$, com flashes de $1 \mathrm{~s}$ e intervalo de $250 \mathrm{~ms}$, durante $\left.10 \mathrm{~s}\right)$; modo exponencial com LED (de 0 a $1100 \mathrm{~mW} / \mathrm{cm}^{2}$, sendo que a irradiância foi aumentando gradativamente nos primeiros $10 \mathrm{~s}$ e depois manteve $1100 \mathrm{~mW} / \mathrm{cm}^{2}$ por mais $10 \mathrm{~s}$ ). Os maiores valores de resistência foram os obtidos com os protocolos de irradiação contínua do QTH e exponencial do LED, pois apresentaram a maior dose de energia $\left(24 \mathrm{~J} / \mathrm{cm}^{2}\right.$ e em torno de $22 \mathrm{~J} / \mathrm{cm}^{2}$, respectivamente) em relação aos outros protocolos $\left(11 \mathrm{~J} / \mathrm{cm}^{2}\right)^{(17)}$.

Frente às inúmeras pesquisas relatadas anteriormente, que resultam em conclusões divergentes, somada a rapidez na introdução de novos materiais resinosos para cimentação, os autores de um trabalho ${ }^{(57)}$ propuseram quatro requisitos que um cimento resinoso deveria apresentar para ser considerado um "all-purpose”. São eles: (1) o grau de conversão de um cimento fotoativável deve ser equivalente ao do material dual nas mesmas condições; (2) o grau de conversão do cimento dual sob uma restauração de porcelana de $3 \mathrm{~mm}$ de espessura deve ser igual ou maior ao de um cimento quimicamente ativado; (3) o grau de conversão de um cimento dual que não foi exposto à luz deve ser equivalente àquela de pasta única que foi fotoativado, ambos sob um espaçador de porcelana de $3 \mathrm{~mm}$ de espessura; (4) em locais onde a luz não pôde alcançar, o grau de conversão cimento dual deve ser o mesmo ao obtido com exposição direta da luz. Os autores constataram, após avaliarem seis cimentos resinosos duais, que nem todos alcançaram o grau de conversão desejado nas situações propostas, assim, concluíram que a escolha de um cimento deve estar baseada na situação clínica ${ }^{(57)}$.

Após revisar as características dos cimentos resinosos, os aparelhos de fotoativação, as propriedades óticas dos materiais restauradores de uso indireto e os fatores que interferem na 
polimerização do cimento, é importante compreender os ensaios laboratoriais que poderão estimar o desempenho clínico dos cimentos resinosos frente a estas variáveis.

\subsection{Ensaios laboratoriais para avaliar o grau de conversão de compósitos}

O grau de conversão fornece a porcentagem de ligações duplas de carbono que foram convertidas em ligações simples durante o processo de polimerização de uma resina composta. Este grau dos cimentos resinosos pode ser verificado por meio de ensaios laboratoriais diretos ou indiretos. Os diretos são aqueles que utilizam equipamentos específicos, como o espectroscópio infra-vermelho (IR) ou o Raman, os quais irão fornecer o grau de conversão monômero/polímero de uma resina composta em porcentagem a partir da quantidade de ligações duplas remanescentes após a polimerização. Já os indiretos são ensaios mecânicos laboratoriais, pois o grau de conversão está diretamente relacionado com as propriedades mecânicas do material ${ }^{(31)}$.

Dentre os ensaios diretos, estão aqueles que utilizam um espectrômetro para investigar o grau de conversão de polímeros através de uma técnica vibracional, a qual registra a freqüência de vibração dos monômeros ${ }^{(60)}$. O teste de Fourier Transformed Infra Red (FTIR), que utiliza um espectrômetro de luz infra-vermelha, é o mais antigo e tem sido o mais

utilizado $^{(23,28,57,61)}$. Por ser uma técnica que verifica o grau de conversão através da absorção da luz, em compósitos com partículas inorgânicas maiores podem ocorrer absorções intensas que irão interferir a leitura dos dados. Além desta desvantagem, há a necessidade de preparar 
os corpos-de-prova com espessuras muito delgadas, dificultando o seu uso para materiais friáveis ou para avaliar uma interface entre dois substratos diferentes ${ }^{(60,62)}$.

Um outro tipo mais recente de espectrômetro é do tipo Raman que é utilizado nos testes Raman, FT-Raman e Micro-Raman. Este equipamento verifica o grau de conversão de polímeros através do espalhamento da luz causado pela incidência de um laser nas suas moléculas. Pode ser utilizado um laser de Nd:YAG ou de He-Ne, como os comprimentos de onda destes lasers são $1063 \mathrm{~nm} \mathrm{e} \mathrm{632,8} \mathrm{nm,} \mathrm{respectivamente.} \mathrm{A} \mathrm{luz} \mathrm{gerada} \mathrm{pelo} \mathrm{laser} \mathrm{é}$ incapaz de iniciar a reação de polimerização das resinas compostas. Além disso, os espécimes utilizados neste espectrômetro não necessitam de nenhuma preparação específica, portanto qualquer tipo de geometria pode ser empregado. Entretanto, como possui uma alta capacidade de detectar fluorescência dos materiais pode ocorrer interferências nas freqüências de interesse ${ }^{(60,62)}$.

Para resinas compostas odontológicas, a região do espectro de interesse, fornecido por estes ensaios diretos, está compreendida entre $1500 \mathrm{~cm}^{-1}$ e $1800 \mathrm{~cm}^{-1}$. Nesta região, estão localizados os picos das freqüências dos grupos alifático $(\mathrm{C}=\mathrm{C}$ e $\mathrm{C}=\mathrm{O})$ e aromático $(\Phi)$ dos monômeros e das cadeias de ligações cruzadas (Figura 2.4.A). E são estes picos que fornecerão as referências para o cálculo do grau de conversão do polímero que está sendo estudado. Portanto, a vibração $\mathrm{C}=\mathrm{C}$ será sempre observada na freqüência $1640 \mathrm{~cm}^{-1}$ e a $\mathrm{C}=\mathrm{O}$ geralmente em torno de $1720 \mathrm{~cm}^{-1}$. Para os sistemas resinosos, que contém vibrações de ligações aromáticas, dois picos serão observados: um mais fraco em $1582 \mathrm{~cm}^{-1}$ e um mais forte a $1610 \mathrm{~cm}^{-1}{ }^{(62)}$. O cálculo do grau de conversão de uma resina composta será explicado detalhadamente no capítulo de material e métodos. 


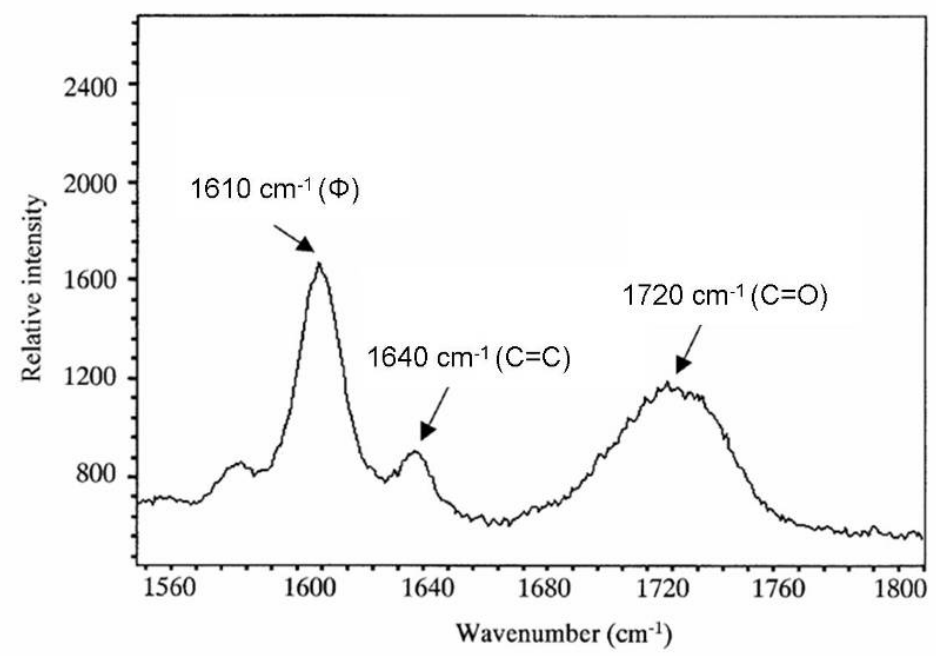

Figura 2.4.A - Espectro fornecido pelo ensaio FT-Raman, indicando os picos de interesse para o cálculo do grau de conversão ${ }^{(60)}$

Apesar dos métodos diretos serem o mais sensíveis para determinar o grau de conversão de um polímero, é necessário equipamentos específicos e dispendiosos ${ }^{(11,63)}$. Assim, os ensaios mecânicos são amplamente utilizados para comparar o grau de polimerização entre diferentes polímeros. Entre eles, os valores obtidos através do ensaio de microdureza mostram uma forte correlação com os valores obtidos através das técnicas vibracionais $^{(31)}$.

Em um estudo prévio com resinas sem carga ${ }^{(64)}$, os valores de dureza e grau de conversão apresentaram uma correlação linear. No entanto, o autor enfatiza que não se pode correlacionar um valor específico de grau de conversão com um valor de dureza, pois a dureza pode variar de acordo com o conteúdo da carga e a composição da matriz. Mesmo assim, esta associação entre dureza e espectroscopia é vantajosa, pois a técnica vibracional (Raman) é mais sensível para detectar diferenças nos primeiros estágios da reação de polimerização, enquanto que o ensaio de microdureza possui maior sensibilidade para identificar pequenas mudanças depois que a cadeia polimérica já está com as ligações cruzadas formadas ${ }^{(31)}$. 
O ensaio de microdureza consiste em uma endentação realizada por uma ponta de diamante no material em teste, sob uma carga estática, durante um período de tempo. Depois da remoção da ponta, é obtida uma impressão microscópica que será analisada. Como no ensaio de microdureza Knoop é utilizado um diamante em forma de pirâmide romboédrica, a impressão fornecida possui uma diagonal maior e uma menor. O resultado é obtido medindose a diagonal maior. Já no ensaio de microdureza Vickers é empregado um diamante em forma de pirâmide de base quadrada, resultando em uma impressão com duas diagonais do mesmo tamanho. E o valor da dureza é obtido pela média das medidas das duas diagonais ${ }^{(63)}$.

Em materiais poliméricos, após a remoção da carga ocorre uma recuperação elástica do material. No caso do ensaio Vickers, esta recuperação ocorre nas duas diagonais, mascarando o resultado (Figura 2.4.B). Em contrapartida, no ensaio Knoop as tensões são distribuídas de um modo que as dimensões do menor eixo se encontrarão sujeitas a alterações por relaxamento e as dimensões do maior eixo, que é o eixo de referência para o cálculo da dureza, se manterão inalteradas ${ }^{(63,65)}$. A partir destas informações, pode-se concluir que a microdureza é definida como a resistência a uma deformação permanente ${ }^{(63)}$ e que o ensaio de microdureza Knoop é o mais indicado para este tipo de material, pois independe da ductibilidade do mesmo ${ }^{(9,65)}$. 


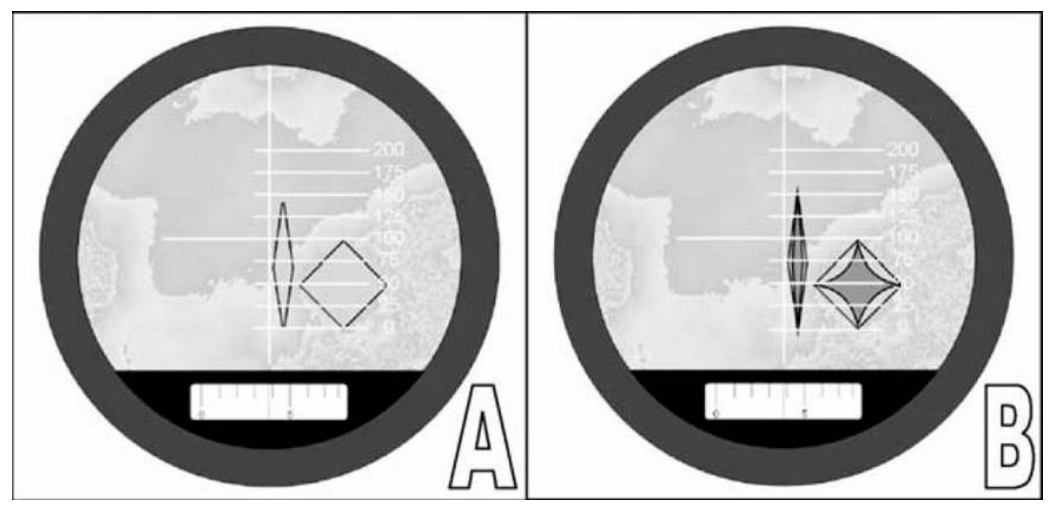

Figura 2.4.B - Representação esquemática da impressão Knoop romboédrica e da impressão Vickers piramidal: (A) impressão original com o diamante posicionado; (B) impressão original após a remoção do diamante - recuperação elástica é verificada ${ }^{(63)}$

Além do tipo de teste de dureza, o local da endentação é de extrema importância, pois geralmente encontram-se valores de dureza maior no centro do material do que nas suas extremidades ou bordas. Isto pode ser explicado pelo fato de que no centro do material, o radical livre do monômero está envolto tridimensionalmente por possíveis parceiros reativos, enquanto que um radical livre localizado na extremidade do corpo-de-prova (cp) encontrará somente parceiros reativos localizados de um lado da esfera hipotética em que o radical livre é o centro ${ }^{(10)}$.

Outro ensaio mecânico muito utilizado para avaliar a resistência mecânica de um polímero é o ensaio de resistência à flexão. Uma vantagem deste em relação ao ensaio de resistência à tração é que não há a necessidade de prender o cp na máquina de ensaio, tornando-o de fácil execução. A resistência à flexão de um material é descrita como a quantidade de força necessária para dobrar ou quebrar o mesmo ${ }^{(12)}$.

Há basicamente três tipos de ensaios laboratoriais para determinar a resistência à flexão de um material: flexão biaxial, flexão em quatro pontos e flexão em três pontos. Existem três tipos de ensaio de flexão biaxial: pistão sobre três bolas, bola sobre anel e anel sobre anel. O ensaio de pistão sobre três bolas e o bola sobre anel são semelhantes e possuem a desvantagem de não distribuir uniformemente as cargas aplicadas, isto é, ficam 
concentradas sobre o pistão. Além disso, é um ensaio passível de erro no posicionamento do cp. Já o teste anel sobre anel requer um cp com dimensões e volume maiores, e com isso, aumenta a probabilidade do espécime apresentar defeitos intrínsecos que poderão mascarar os resultados. Os ensaios de resistência à flexão biaxial são mais utilizados em materiais totalmente friáveis como as cerâmicas ${ }^{(66)}$.

O ensaio de resistência à flexão de quatro pontos é o mais indicado para testar a resistência de corpos-de-prova de maior extensão e volume, pois é menos sensível a defeitos presentes nos corpos-de-prova ${ }^{(12,67)}$.

Já o ensaio de flexão de três pontos pode ser realizado em materiais frágeis, dúcteis ou resistentes. Nos cimentos resinosos, que são materiais frágeis, as deformações são muito pequenas. Desta forma, para determinar a tensão de flexão, considera-se a força registrada no limite de ruptura. Os resultados obtidos por este ensaio dependem da distância entre o ponto onde a força é aplicada e o apoio, da distância entre apoios e das dimensões do cp ${ }^{(65)}$. Durante o ensaio de resistência à flexão de três pontos cria-se um eixo neutro no espécime. Abaixo do ponto em que é aplicada a carga e acima do eixo neutro, o espécime está sob compressão, enquanto que a porção contrária do espécime está sob tensão. Portanto, este ensaio avalia a propriedade mecânica de uma área limitada diretamente abaixo da aplicação da carga ${ }^{(12)}$.

Segundo a norma ISO $4049^{(68)}$, as dimensões do cp devem ser 25 × 2 × 2 mm. Estas dimensões proporcionam algumas desvantagens: (I) grande quantidade de material utilizado; (II) é necessário irradiar o material fotopolimerizável em três locais diferentes do cp; (III) torna-se um procedimento demorado. Com isso, foi realizada uma pesquisa ${ }^{(69)}$ comparando os valores de resistência à flexão de vários corpos-de-prova com dimensões diferentes. Concluíram, portanto, que o emprego de espécimes com dimensões menores $(10$ × 2 × 2 ou 10 x $2 \times 1 \mathrm{~mm}$ ) fornece resultados semelhantes aos obtidos utilizando espécimes padronizados $(\text { ISO } 4049)^{(69)}$. 
Diante do que foi exposto, os ensaios laboratoriais selecionados para avaliar as propriedades físicas do cimento resinoso na presente pesquisa foram o método FT-Raman, a microdureza Knoop e a resistência à flexão de três pontos. 


\section{PROPOSIÇÃO}

Apresentam-se os seguintes objetivos para esta pesquisa:

I. Avaliar a transmitância relativa dos seguintes materiais restauradores indiretos: uma vitrocerâmica (IPS Eris - Ivoclar-Vivadent); uma vitrocerâmica reforçada por dissilicato de lítio e recoberta por uma vitrocerâmica (IPS Empress 2 + IPS Eris - Ivoclar-Vivadent); uma resina composta microhíbrida (Sinfony - 3M ESPE); uma resina composta microparticulada (SR Adoro - Ivoclar-Vivadent), através da análise de imagens digitais obtidas por uma câmera CCD, utilizando um QTH (Optilux ${ }^{\mathrm{TM}}$ 501, SDS Kerr) e um LED (L.E.Demetron 1, SDS Kerr) como fonte de luz, e da espectrometria de luz visível.

II. Obter a emissão espectral com os valores de irradiância relativa e absoluta na faixa de luz visível dos dois aparelhos de fotoativação já citados.

III. Verificar a influência da interposição dos materiais restauradores supracitados nas propriedades mecânicas (resistência à flexão e microdureza Knoop) e no grau de conversão (verificado pelo método FT-Raman) de um cimento resinoso (Nexus 2 - SDS Kerr), após irradiação com o QTH ou o LED anteriormente citados.

IV. Verificar a correlação estatística entre as médias das propriedades físicas do cimento e as médias de transmitância relativa dos materiais restauradores, além de realizar análises de correlação entre as médias de microdureza e GC do cimento. 


\section{MATERIAL E MÉTODOS}

Foi obtida a emissão espectral de dois aparelhos de fotoativação: um QTH e um LED. Em seguida, foram confeccionados discos com $2 \mathrm{~mm}$ de espessura com os seguintes materiais restauradores estéticos de uso indireto: vitrocerâmica, vitrocerâmica reforçada por dissilicato de lítio, resina composta microhíbrida e resina composta microparticulada. E, foi verificada a transmitância relativa (TR) da luz destes materiais. Após esta etapa, foram confeccionados corpos-de-prova (cps) de um cimento resinoso, utilizando dois sistemas de ativação (fotoativado ou dual), que foram fotopolimerizados sob os discos de materiais restauradores, utilizando-se dois tipos de aparelhos fotoativadores.

Desta maneira, foram estudados três fatores que podem afetar o grau de conversão (GC) e as propriedades mecânicas do cimento resinoso: o aparelho de fotoativação, o tipo do cimento e o material restaurador indireto.

Foi verificado o GC do cimento resinoso através do método direto FT-Raman e também sua a microdureza Knoop e resistência à flexão.

Portanto, este capítulo foi dividido em cinco partes: (I) obtenção da emissão espectral dos aparelhos de fotoativação; (II) confecção dos discos dos materiais restauradores indiretos estéticos; (III) avaliação da TR dos materiais restauradores indiretos; (IV) confecção dos cps de cimento resinoso; (V) avaliação das propriedades físicas dos cimentos resinosos. 


\subsection{Obtenção da emissão espectral dos aparelhos de fotoativação}

Foi obtida a emissão espectral dos dois aparelhos de fotoativação: um QTH (Optilux ${ }^{\mathrm{TM}}$ 501, SDS Kerr, Orange, EUA) e um LED (L.E.Demetron 1, SDS Kerr, Orange, EUA) que foram utilizados para verificar a TR dos materiais restauradores indiretos estéticos e na confecção dos cps de cimento resinoso (Figura 4.1.A e Figura 4.1.B). A emissão espectral, nesta pesquisa, foi representada por dois gráficos que correlacionaram o comprimento de onda da luz emitida pelo aparelho com a irradiância relativa e absoluta do mesmo. 


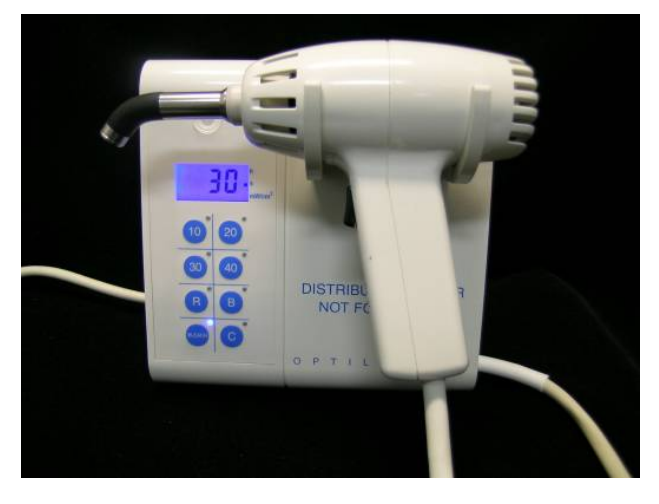

Figura 4.1.A - Aparelho de fotoativação de lâmpada halógena de quartzo-tungstênio (Optilux ${ }^{\mathrm{TM}}$ 501, SDS Kerr)

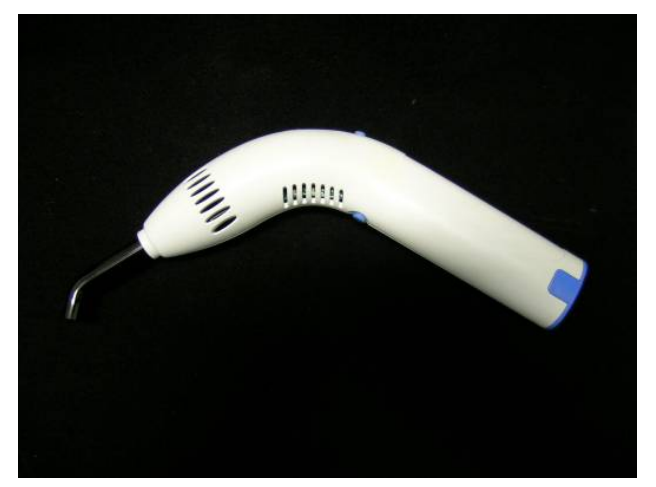

Figura 4.1.B - Diodo emissor de luz para fotoativação (L.E.Demetron 1, SDS Kerr)

\subsection{1 irradiância relativa}

A irradiância relativa é aquela em que a irradiância máxima em um determinado comprimento de onda emitido pelo aparelho é considerado com o valor de uma unidade. Para a obtenção da emissão espectral com a irradiância relativa dos aparelhos de fotoativação foi utilizado um espectroradiômetro (Photo Research, modelo PR-705, série 75033201, Chatsworth, EUA) e uma esfera integradora (Optronic, modelo OL IS-670, série 96100046, Orlando, EUA). Foram realizadas três leituras de cada aparelho (Figura 4.1.C e Figura 4.1.D). O intervalo espectral foi de 380 a $780 \mathrm{~nm}$, variando a cada $2 \mathrm{~nm}$. 


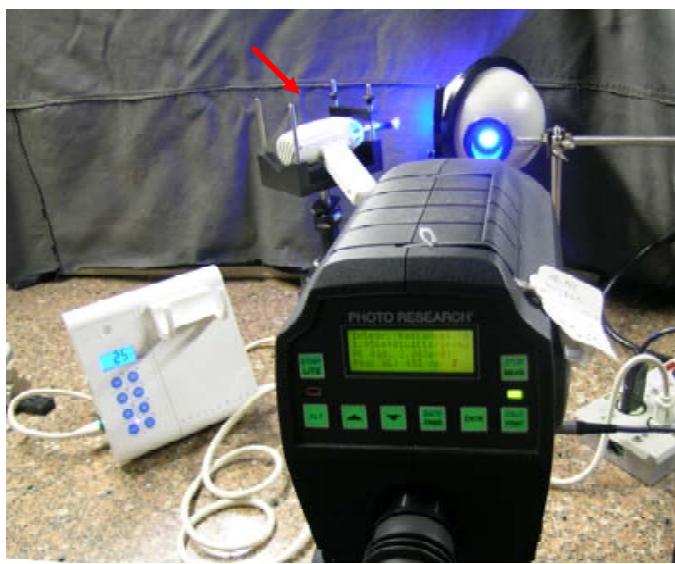

Figura 4.1.C - Espectroradiômetro e esfera integradora em funcionamento para obtenção da emissão espectral com irradiância relativa do QTH (OptiluxTM 501, SDS Kerr), indicado pela seta

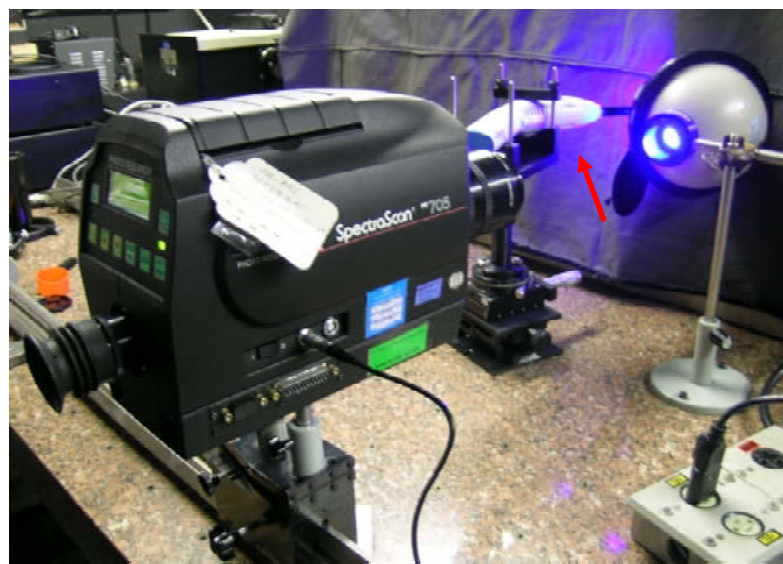

Figura 4.1.D - Espectroradiômetro e esfera integradora em funcionamento para obtenção da emissão espectral com irradiância relativa do LED (L.E.Demetron 1, SDS Kerr), indicado pela seta

4.1.2 irradiância absoluta

Já a irradiância absoluta $\left(\mathrm{mW} / \mathrm{cm}^{2}\right)$ foi obtida através de um espectroradiômetro (Minolta CO., modelo CS-1000, série 18011001, Japão). O centro do aparelho de fotoativação foi instalado na mesma altura do centro do espectroradiômetro a uma distância de $53 \mathrm{~cm}$ (Figura 4.1.E e Figura 4.1.F). A superfície da ponteira do aparelho de fotoativação e a lente do espectroradiômetro ficaram paralelas entre si. Foram realizadas três leituras de cada aparelho. O intervalo espectral também foi de 380 a 780 nm, porém variando a cada nanômentro. 


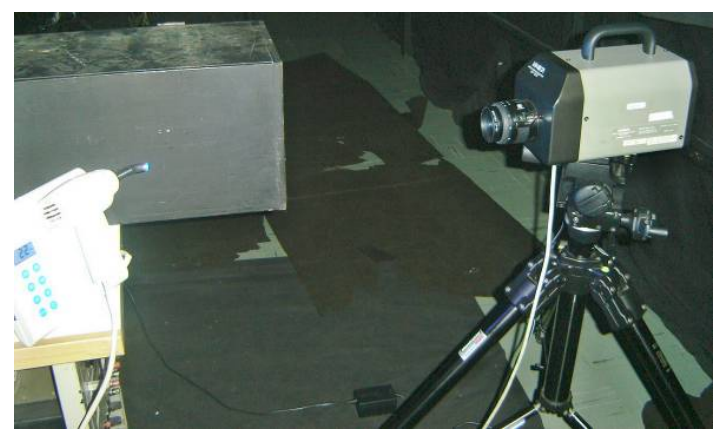

Figura 4.1.E - Espectroradiômetro posicionado para obtenção da emissão espectral com irradiância relativa dos aparelhos de fotoativação de luz halógena (Optilux ${ }^{\mathrm{TM}}$ 501, SDS Kerr)

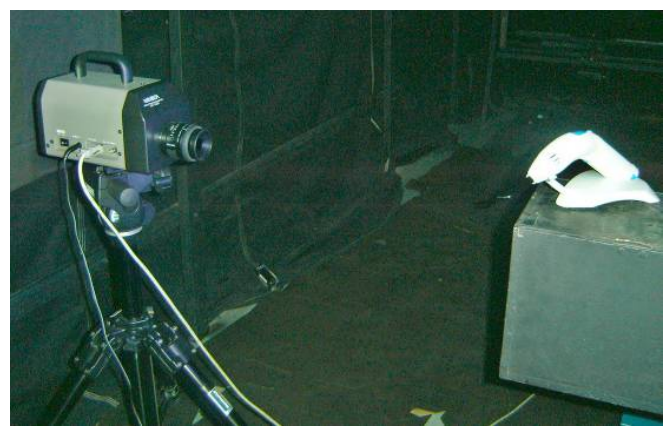

Figura 4.1.F - Espectroradiômetro posicionado para obtenção da emissão espectral com irradiância relativa do LED (L.E.Demetron 1, SDS Kerr)

\subsection{Confecção dos discos de materiais restauradores indiretos estéticos}

Foram confeccionados vinte discos (11 mm de diâmetro e $2 \pm 0,06 \mathrm{~mm}$ de espessura) de diferentes materiais restauradores, sendo dez discos de cerâmica e dez de resina composta de uso indireto. Dos dez discos de cerâmica, cinco eram constituídos de uma cerâmica vítrea, IPS Eris e os outros cinco de uma cerâmica vítrea reforçada por dissilicato de lítio, IPS Empress 2, com espessura de $0,8 \mathrm{~mm}$, recoberto com 1,2 $\mathrm{mm}$ da vitrocerâmica IPS Eris. Já dos dez discos de resina composta, cinco eram constituídos de uma resina microhíbrida, Sinfony, e os outros cinco de uma resina microparticulada, SR Adoro. As informações referentes aos materiais utilizados estão dispostas na Tabela 4.2.A. 
Todos os discos foram preparados na cor A2 da escala Vita (Vita Zahnfabrik, Bad Säckingen, Alemanha), de acordo com as especificações dos respectivos fabricantes, e tiveram suas espessuras aferidas com um paquímetro digital (Starrett, Brasil) com precisão de $0,01 \mathrm{~mm}$.

Tabela 4.2.A - Materiais restauradores indiretos estéticos testados*

\begin{tabular}{|c|c|c|c|c|}
\hline Material & Fabricante & Composição básica & $\begin{array}{l}\text { Tamanho e } \\
\text { volume das } \\
\text { partículas }\end{array}$ & Lote \\
\hline $\begin{array}{l}\text { IPS Eris for } \\
\text { E2 }\end{array}$ & $\begin{array}{l}\text { Ivoclar-Vivadent, } \\
\text { Leichtenstein. }\end{array}$ & $\begin{array}{c}\text { Componente vítreo de silicato } \\
\text { de zinco alcalino transparente } \\
\text { e cerâmica vítrea contendo } \\
\text { fluorapatita. }\end{array}$ & $\begin{array}{l}\text { Não } \\
\text { informado. }\end{array}$ & H25269 \\
\hline $\begin{array}{c}\text { IPS } \\
\text { Empress2 }\end{array}$ & $\begin{array}{l}\text { Ivoclar-Vivadent, } \\
\text { Leichtenstein. }\end{array}$ & $\begin{array}{l}\text { Cerâmica vítrea reforçada por } \\
\text { dissilicato de lítio. }\end{array}$ & $\begin{array}{c}0,5-0,4 \mu \mathrm{m} \\
70 \pm 5 \%\end{array}$ & J06266 \\
\hline Sinfony & $\begin{array}{l}\text { 3M ESPE, } \\
\text { Seefeld, } \\
\text { Alemanha. }\end{array}$ & $\begin{array}{c}\text { Resina composta microhíbrida } \\
\text { a base de UDMA, livre de } \\
\text { Bis-GMA e TEGDMA. }\end{array}$ & $\begin{array}{c}\text { Vidro de } \\
\text { estrôncio: } \\
0,6 \mu \mathrm{m}, 40 \% \text {. } \\
\text { Sílica } \\
\text { pirogênica: } \\
0,06 \mu \mathrm{m}, 5 \% \text {. }\end{array}$ & 253241 \\
\hline SR Adoro & $\begin{array}{l}\text { Ivoclar-Vivadent, } \\
\text { Leichtenstein. }\end{array}$ & $\begin{array}{c}\text { Resina composta } \\
\text { microparticulada a base de } \\
\text { UDMA, livre de Bis-GMA e } \\
\text { TEGDMA. }\end{array}$ & $\begin{array}{c}\text { Dióxido de } \\
\text { sílica: } 0,01 \text { - } \\
0,1 \mu \mathrm{m}, 46- \\
47 \% \text {. }\end{array}$ & H2236 \\
\hline
\end{tabular}

*Informações fornecidas pelos fabricantes.

A seguir será descrito detalhadamente o processamento dos materiais utilizados para a confecção dos discos de materiais restauradores indiretos estéticos. 


\subsection{1 confecção dos discos de cerâmica IPS Eris}

O pó cerâmico foi misturado à água destilada em um béquer de vidro sob vibração a fim de se obter uma barbotina homogênea. Em seguida, os corpos verdes foram conformados em uma matriz de carbeto-tungstênio com dimensões de $14,9 \mathrm{~mm}$ de diâmetro e 2,9 mm de profundidade. $\mathrm{O}$ preenchimento da matriz foi feito em duas etapas sob intensa vibração manual para evitar a incorporação de bolhas de ar. O excesso de água foi removido com papel absorvente e o excesso da pasta foi removido com uma lâmina de vidro. Em seguida, o disco foi retirado da matriz e posicionado sobre uma base refratária para ser levado ao forno Keramat I (Knebel, Porto Alegre, Brasil) onde foi sinterizado conforme o ciclo sugerido pelo fabricante (Tabela 4.2.B). Apenas três espécimes serão levados ao forno a cada ciclo de queima.

Tabela 4.2.B - Ciclos de sinterização da cerâmica IPS Eris*

\begin{tabular}{l|l}
\hline Etapa & Temperatura e/ou Tempo \\
\hline Secagem A (elevador sobe da posição inicial até próximo à & $403{ }^{\circ} \mathrm{C}$ \\
entrada da mufla) & \\
Secagem B (elevador está dentro da mufla, sem fechamento) & $403{ }^{\circ} \mathrm{C}$ \\
Temperatura inicial & $403{ }^{\circ} \mathrm{C}$ \\
Taxa de aquecimento & $60{ }^{\circ} \mathrm{C} / \mathrm{min}$ \\
Temperatura máxima & $755{ }^{\circ} \mathrm{C}$ \\
Tempo de queima à vácuo (29 mmHg) & $2 \mathrm{~min}$ \\
Temperatura de desligamento da bomba de vácuo & $755{ }^{\circ} \mathrm{C}$ \\
Tempo de resfriamento 1 & $2 \mathrm{~min}$ \\
Tempo de resfriamento 2 & $2 \mathrm{~min}$ \\
Tempo de resfriamento 3 & $2 \mathrm{~min}$ \\
\hline
\end{tabular}

* Segundo as orientações do fabricante.

Após a sinterização, os discos foram desgastados com uma ponta diamantada cilíndrica até ficarem com $11 \mathrm{~mm}$ de diâmetro (PM82G, KG Sorensen, São Paulo, Brasil). Além disso, os discos foram colados sobre uma placa de aço e usinados em uma retificadora 
plana (MSG-600, Mitutoyo, São Paulo, Brasil) com rebolo diamantado grosso até apresentarem $2 \mathrm{~mm}$ de espessura.

Em seguida, foi pincelada a pasta para o glaseamento (IPS Empress Universal Glazing Paste Ivoclar-Vivadent, Leichtenstein, lote H13115) sobre uma das superfícies do disco. E realizado a sinterização no forno Keramat I (Knebel, Porto Alegre, Brasil), conforme o ciclo sugerido pelo fabricante (Tabela 4.2.C). A outra face do disco foi condicionada com ácido fluorídrico a 10\% (Condicionador de porcelana, Dentsply, York, EUA) por 60 segundos, que em seguida foram lavadas em água corrente por 60 segundos e no ultra-som (Thornton T14, Inpec Eletrônica Ltda, Vinhedo, Brasil) por mais 60 segundos.

Tabela 4.2.C - Ciclos de sinterização da IPS Empress Universal Glazing Paste*

\begin{tabular}{l|l}
\hline Etapa & Temperatura e/ou Tempo \\
\hline Secagem A (elevador sobe da posição inicial até próximo à & $403{ }^{\circ} \mathrm{C}$ \\
entrada da mufla) & \\
Secagem B (elevador está dentro da mufla, sem fechamento) & $403{ }^{\circ} \mathrm{C}$ \\
Temperatura inicial & $403{ }^{\circ} \mathrm{C}$ \\
Taxa de aquecimento & $60{ }^{\circ} \mathrm{C} / \mathrm{min}$ \\
Temperatura máxima & $735{ }^{\circ} \mathrm{C}$ \\
Tempo de queima à vácuo (29 mmHg) & $2 \mathrm{~min}$ \\
Temperatura de desligamento da bomba de vácuo & $734{ }^{\circ} \mathrm{C}$ \\
Tempo de resfriamento 1 & $2 \mathrm{~min}$ \\
Tempo de resfriamento 2 & $2 \mathrm{~min}$ \\
Tempo de resfriamento 3 & $2 \mathrm{~min}$ \\
\hline Segundo as orientações do fabricante.
\end{tabular}


4.2.2 confecção dos discos de cerâmica de IPS Empress 2 + IPS Eris

O sistema IPS Empress 2 utiliza a técnica da cera perdida. Para a confecção dos padrões de cera em forma de disco, foi necessária utilização de uma matriz de silicone com as cavidades vazadas para que a cera pudesse ser vertida. Um silicone de adição (Elite Double 8, Zhermack, Rovigo, Itália) foi dosado e um frasco graduado com a mesma quantidade de líquido branco (A - ativador) e do rosa (B - base). A mistura foi realizada durante 10 segundos, até a obtenção de uma cor homogênea e despejada sobre uma réplica metálica dos discos (12 mm de diâmetro e $2 \mathrm{~mm}$ de espessura). Após 30 minutos, o molde foi removido manualmente com o auxílio de uma espátula romba.

Uma cera especial para a técnica de prensagem (Pro-mod VKS, Al Dente, Alemanha) foi usada para a confecção dos padrões de cera em forma de disco. A cera foi aquecida com uma lamparina a álcool e vertida sobre as cavidades do molde de silicone previamente confeccionado. Depois de resfriada a cera, os excessos foram removidos com uma espátula LeCron e os discos de cera finalizados foram então conectados a canais de alimentação de cera (sprues).

Os espécimes encerados foram fixados em uma base plástica de forma cilíndrica, formadora do conduto de alimentação padronizado para a acomodação das pastilhas e do punção. Em cada anel grande (200 g de revestimento) pode ser colocado até 1,4 g de cera, o que equivale a 4 discos com seus sprues. Uma lâmina de papel, própria do sistema, foi adaptada à base plástica, de maneira a formar um cilindro estabilizado inferiormente pela base e superiormente por um anel plástico próprio para este fim (Figura 4.2.A e Figura 4.2.B). Nesta etapa, foram colocados pontos de cera na face interna do papel para que servissem de 
orientação na fase de desinclusão. Tais pontos se apresentaram como dois orifícios na face externa do cilindro de revestimento, evitando danos aos espécimes. O complexo base/papel/anel plástico foi preenchido pelo revestimento até sua totalidade.

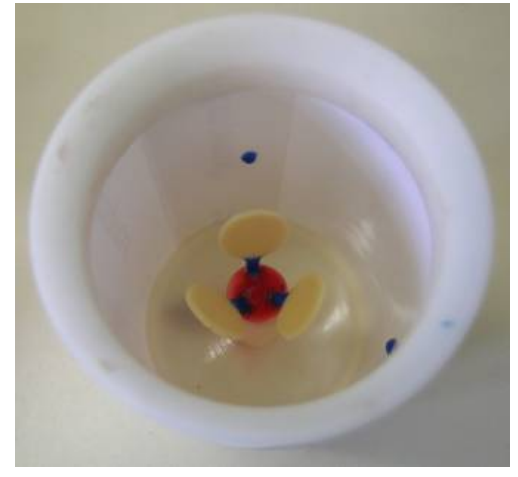

Figura 4.2.A - Espécimes encerados fixados na base plástica, com a lâmina de papel e $\mathrm{o}$ anel plástico adaptados

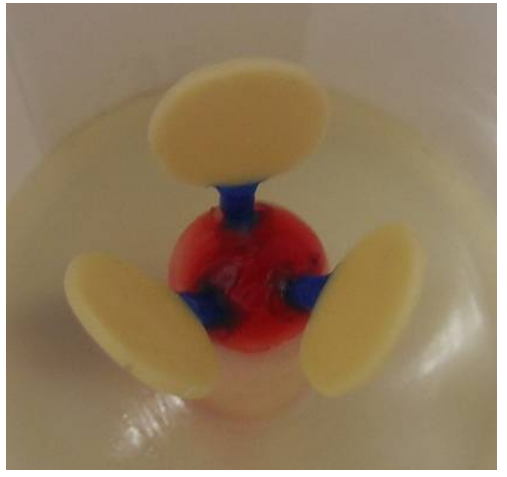

Figura 4.2.B - Detalhe dos espécimes encerados

O revestimento fosfatado, próprio para a técnica da estratificação (IPS PressVEST Speed, Ivoclar-Vivadent, Liechtenstein Alemanha, lote JL3026) foi proporcionado em uma relação pó/líquido de $200 \mathrm{~g}$ para $32 \mathrm{ml}$ de líquido de revestimento e $22 \mathrm{~m}$ de água destilada para o IPS Empress 2. O revestimento foi espatulado mecanicamente a vácuo por 60 segundos, sendo que a inclusão foi realizada manualmente, sob vibração mecânica.

Após a presa do revestimento (1 hora), a base plástica formadora do conduto, o papel e o anel plástico superior foram removidos do cilindro, para que este fosse levado ao forno para perda da cera.

Em forno de anel (Mastercasting, Dental Pioneira, São Paulo, Brasil), a cera foi volatilizada e o revestimento termicamente expandido até $850^{\circ} \mathrm{C}$, por 1 hora. $\mathrm{O}$ conjunto composto de cilindro de revestimento, pastilha de cerâmica e embolo de alumina foi introduzido no forno para prensagem a quente próprio do sistema (EP600, Ivoclar-Vivadent, Schaan, Liechtenstein). O ciclo de prensagem encontra-se na Tabela 4.2.D. Ao atingir a 
temperatura de $920^{\circ} \mathrm{C}$ para o IPS Empress 2, a pastilha era prensada lentamente pelo êmbolo, em um processo de escoamento viscoso, para dentro do molde, em um processo com duração aproximada de 40 minutos.

Tabela 4.2.D - Ciclos térmicos para a cerâmica IPS Empress 2*

\begin{tabular}{l|l}
\hline Etapa & Temperatura e/ou Tempo \\
\hline Temperatura inicial do forno & $700{ }^{\circ} \mathrm{C}$ \\
Taxa de aquecimento & $60{ }^{\circ} \mathrm{C} / \mathrm{min}$ \\
Temperatura de injeção & $920{ }^{\circ} \mathrm{C}$ \\
Tempo na temperatura de injeção & $20 \mathrm{~min}$ \\
Velocidade mínima de descida para interrupção de injeção & $300 \mu \mathrm{m} / \mathrm{min}$ \\
\hline Segundo as orientações do fabricante.
\end{tabular}

O cilindro foi resfriado até a temperatura ambiente e logo após realizou-se a desinclusão dos espécimes. O primeiro passo da desinclusão foi a marcação do punção de alumina para que ele pudesse ser separado do resto do conjunto, ser limpo ser utilizado novamente nas prensagens seguintes. Com um disco de carbeto de silício ( $\mathrm{SiC}$ ) montado em um motor elétrico, o cilindro foi cortado respeitando-se os pontos de orientação previamente executados e removendo-se os pedaços de revestimento com a ajuda de uma tesoura de ouro. Com uma ponta diamantada em alta rotação (\#740, Vortex, São Paulo, Brasil), fez a remoção do revestimento restante na porção mais próxima dos espécimes Os canais de alimentação também foram removidos da mesma maneira.

Os discos foram colados sobre uma placa de aço e usinados em uma retificadora plana (MSG-600, Mitutoyo, São Paulo, Brasil) com rebolo diamantado grosso até apresentarem 0,8 mm de espessura.

Para que os discos apresentassem 2 mm, foi aplicado a cerâmica IPS Eris sobre o disco de IPS Empress 2. O pó cerâmico do IPS Eris foi misturado à água destilada em um béquer de vidro sob vibração a fim de se obter uma barbotina homogênea e aplicado com um pincel sobre o disco de IPS Empress 2, com uma espessura superior a $2 \mathrm{~mm}$ para que fosse 
compensada a contração da cerâmica. Em seguida, o disco foi posicionado sobre uma base refratária para ser levado ao forno Keramat I (Knebel, Porto Alegre, Brasil) onde foi sinterizado conforme o ciclo sugerido pelo fabricante (Tabela 4.2.B).

Após a sinterização, os discos foram desgastados com uma ponta diamantada cilíndrica até ficarem com $11 \mathrm{~mm}$ de diâmetro (PM82G, KG Sorensen, São Paulo, Brasil). Além disso, os discos foram colados sobre uma placa de aço e usinados em uma retificadora plana (MSG-600, Mitutoyo, São Paulo, Brasil) com rebolo diamantado grosso até apresentarem $2 \mathrm{~mm}$ de espessura.

Em seguida, foi pincelada a pasta glase (IPS Empress Universal Glazing Paste IvoclarVivadent, Leichtenstein, lote H13115) sobre uma superfície do disco. E realizado a sinterização no forno Keramat I (Knebel, Porto Alegre, Brasil), conforme o ciclo sugerido pelo fabricante (Tabela 4.2.C). A outra face do disco foi condicionada com ácido fluorídrico a 10\% (Condicionador de porcelana, Dentsply, York, EUA) por 60 segundos, que em seguida foram lavadas em água corrente por 60 segundos e no ultra-som (Thornton T14, Inpec Eletrônica Ltda, Vinhedo, Brasil) por mais 60 segundos.

\subsection{3 confecção dos discos da resina indireta Sinfony}

Para a confecção dos cinco discos de Sinfony foi utilizada uma matriz de polioximetileno bipartida com $11 \mathrm{~mm}$ de diâmetro e $2 \mathrm{~mm}$ de espessura (Figura 4.2.C e Figura 4.2.D). A pasta de escolha foi a dentina na cor A2 (DA2). Foram inseridos pequenos 
incrementos da resina dentro da matriz sobre uma placa de vidro com auxílio de um pincel. Cada incremento foi fotoativado por $5 \mathrm{~s}$ com o aparelho de fotoativação Visio Alfa (3M ESPE, Seefeld, Alemanha). A última camada resina foi colocada dentro da matriz e pressionada com uma lâmina de vidro e foi fotoativada através da lâmina de vidro durante 40 s com o aparelho de fotoativação Visio Alfa (3M ESPE, Seefeld, Alemanha). Após esta fotopolimerização inicial, o disco foi levado ao aparelho Visio Beta Vario (3M ESPE, Seefeld, Alemanha) por 1 min de luz mais 14 min de luz mais vácuo (programa número 01) para a polimerização final.

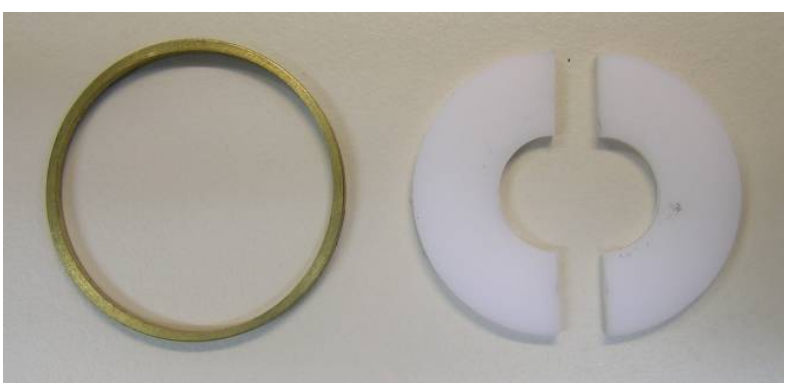

Figura 4.2.C - Foto da matriz de polioximetileno bipartida aberta, com anel metálico de estabilização ao lado, para confecção dos discos de resina composta Sinfony e SR Adoro

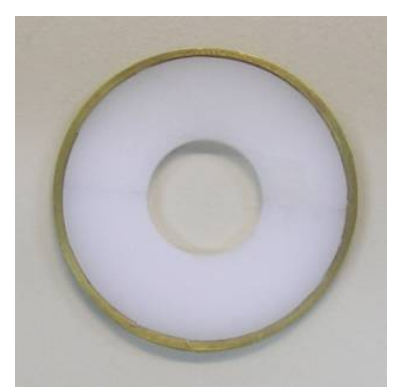

Figura 4.2.D - Foto da matriz de polioximetileno bipartida fechada para confecção dos discos de resina composta Sinfony e SR Adoro

Os excessos ao redor dos discos foram removidos com uma ponta diamantada cilíndrica em baixa rotação (PM82G, KG Sorensen, São Paulo, Brasil). A face que não estava voltada para a luz de fotoativação foi jateada com óxido de alumínio na granulação de $100 \mu \mathrm{m}$ (Microetcher Model II, Danville Engineering Inc., Califórnia, EUA) e lavada no ultra-som (Thornton T14, Inpec Eletrônica Ltda, Vinhedo, Brasil) por 60 segundos. Já a face voltada para a luz foi mantida intacta, pois a lisura de superfície obtida com a lâmina de vidro foi considerada satisfatória. 


\subsection{4 confecção dos discos da resina indireta SR Adoro}

Para a confecção dos cinco discos de SR Adoro também foi utilizado uma matriz de polioximetileno bipartida (Figura 4.2.C e Figura 4.2.D) com $11 \mathrm{~mm}$ de diâmetro e $2 \mathrm{~mm}$ de espessura. A pasta de escolha foi a Dentin/Body na cor A2. Um único incremento da resina foi colocado dentro da matriz e pressionado entre uma placa de vidro e uma lâmina de vidro. A resina foi fotoativada através da lâmina de vidro durante $40 \mathrm{~s}$ com o aparelho de fotoativação Quick (Ivoclar-Vivadent, Leichtenstein). Após esta fotopolimerização inicial, o disco foi levado ao aparelho Targis Power Upgrade (Ivoclar-Vivadent, Leichtenstein) por 25 min (programa número 03) para a sua polimerização final.

Os excessos ao redor dos discos foram removidos com uma ponta diamantada cilíndrica em baixa rotação (PM82G, KG Sorensen, São Paulo, Brasil). A face que não estava voltada para a luz de ativação foi jateada com óxido de alumínio na granulação de $100 \mu \mathrm{m}$ (Microetcher Model II, Danville Engineering Inc., Califórnia, EUA) e lavada no ultra-som (Thornton T14, Inpec Eletrônica Ltda, Vinhedo, Brasil) por 60 segundos. Já a face voltada para a luz foi mantida intacta, pois a lisura de superfície obtida com a lâmina de vidro foi considerada satisfatória. 


\subsection{Avaliação da TR dos materiais restauradores indiretos:}

A TR é uma propriedade óptica do material que indica, em porcentagem, quanto de luz atravessou o material em relação ao feixe incidente. Dois tipos de ensaio foram realizados para este fim: no primeiro, obteve-se a TR dos materiais restauradores indiretos estéticos utilizando como fonte de luz os aparelhos fotoativadores e uma câmera CCD (Charge Coupled Device) para captação das imagens; no segundo tipo de ensaio foi utilizado um espectrômetro. Cada ensaio será detalhadamente explicado a seguir.

4.3.1 TR obtida através da análise de imagens obtidas por uma CCD

Nesta etapa, foram utilizadas as mesmas unidades de fotoativação que foram analisadas no item I deste capítulo: um QTH (OptiluxTM 501, SDS Kerr, Orange, EUA) e um LED (L.E.Demetron 1, SDS Kerr, Orange, EUA); ambos com ponteira com $11 \mathrm{~mm}$ de diâmetro. Foram utilizados cinco discos de cada material restaurador.

A TR dos materiais restauradores foi obtida após a luz, proveniente dos aparelhos de fotoativação, atravessar os discos previamente confeccionados, utilizando uma câmera CCD (Charge Coupled Device, modelo KP-M1, Hitachi, Woodbury, EUA) e o software Global Lab

Image (Data Translation, Marlboro, EUA) para captura e análise das imagens. Durante a 
aferição, foi utilizado um encaixe de polioximetileno preto na ponta do fotoativador para os discos (Figura 4.3.A- I e II) sendo que a face polida destes ficou voltada para a luz. O ensaio foi realizado em ambiente totalmente escuro.
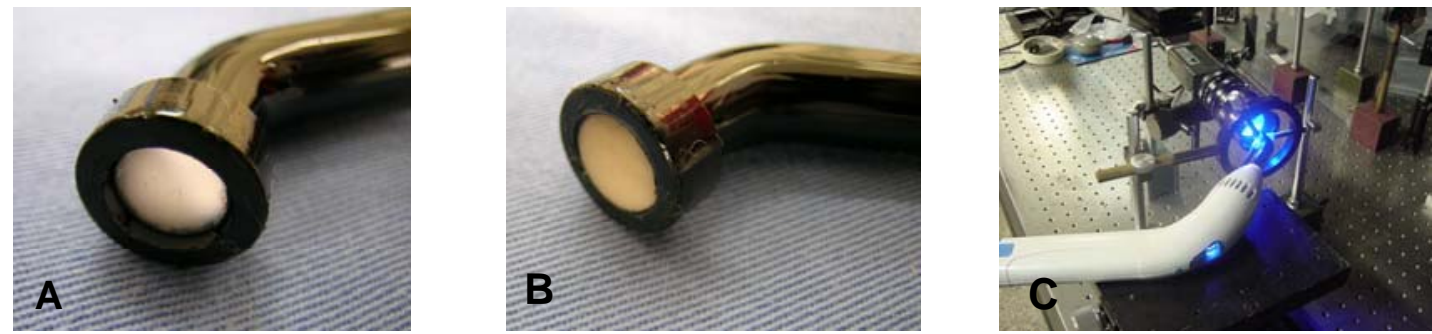

Figura 4.3.A - Encaixe polioximetileno na ponta do fotoativador: I, sem disco de material restaurador; II, com disco de cerâmica IPS Eris (Ivoclar-Vivadent). III, Fotoativador L.E.Demetron encaixado no equipamento para obtenção de imagens pela câmera CCD

O encaixe de polioximetileno foi fixado por um dispositivo de três pontos e posicionado centralmente à lente objetiva da câmera (Figura 4.3.A- III). Como a TR é uma medida relativa, houve a necessidade de registrar a imagem da luz dos aparelhos sem a interposição do material restaurador para obter um valor de referência. Porém, ao remover o disco, ocorria uma saturação da imagem, por isso foram utilizados filtros de poliéster metalizados (Winner Film, São Paulo, Brasil) com transmitâncias pré-determinadas.

Após a obtenção das imagens (Figura 4.3.B), estas foram transformadas em gráficos em três dimensões (Figura 4.3.C), utilizando-se o programa ImageJ (www.rsb.info.nih.gov/ij). Em seguida, com o programa MatLab (www.mathworks.com/matlabcentral), foi obtido o número de pixels abaixo de cada curva dos gráficos. A Equação 5 foi utilizada para o cálculo da TR, sendo r, o número de pixels obtido do gráfico de referência do grupo do material que está sendo analisado, d o número de pixels obtido do gráfico do disco analisado, e f a transmitância do filtro utilizado.

$$
\text { Equação 5: } \quad \mathrm{TR}=\frac{r}{d} \times f
$$



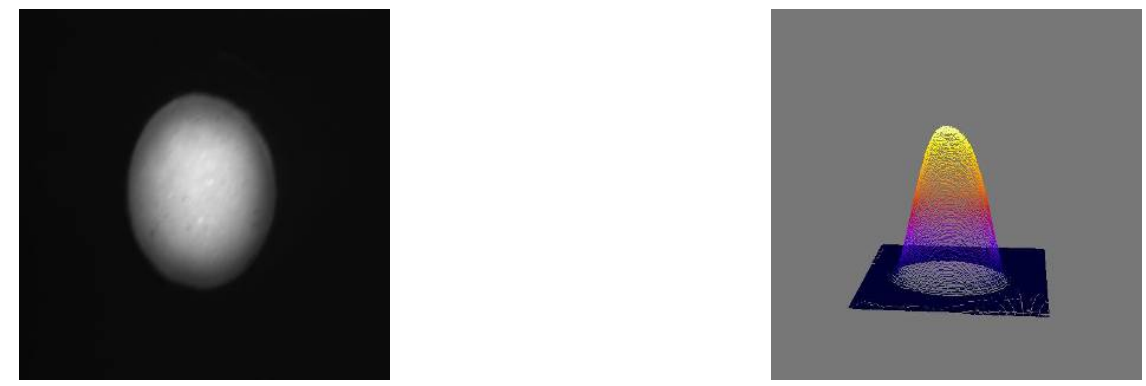
Figura 4.3.B - Imagem obtida pela câmera CCD e pelo
software Global Lab Image $\begin{gathered}\text { 4.3.C - Gráfico produzido pelo software } \\ \text { ImageJ }\end{gathered}$

Para o tratamento estatístico dos valores de TR foi utilizado o teste de análise de variância de dois fatores independentes, sendo aparelhos de fotoativação e tipo de materiais restauradores indiretos. As médias foram analisadas pelo teste de contraste de Tukey com nível de significância de 5\%.

\subsubsection{TR obtida através da espectrometria}

O ensaio realizado foi o de transmissão total, conforme descrito no capítulo de Revisão de Literatura, na faixa espectral de 380 a $780 \mathrm{~nm}$. O espectrômetro utilizado foi o Cintra 10 (GVC, Austrália) com uma esfera integradora acoplada. Esta esfera tem como função coletar tanto a energia transmitida de maneira direta quanto a energia difusa, que foi espalhada, dando a energia total transmitida ${ }^{(70)}$. 
Foram confeccionadas duas máscaras metálicas pintadas com tinta preta: uma para encaixar os discos de materiais restauradores indiretos estéticos e a outra sem nenhum material interposto posicionada no feixe de referência. Estas máscaras possuíam um furo com $4 \mathrm{~mm}$ de diâmetro. Os furos das duas máscaras estavam alinhados com a trajetória dos feixes emitidos pela fonte de luz do aparelho. Os discos foram posicionados em uma das máscaras de forma que a parte polida ficou voltada para o feixe de luz incidente. Foram utilizados cinco discos de cada material. O ensaio forneceu a TR do material a cada $2 \mathrm{~nm}$ de comprimento de onda, resultando em 200 dados por leitura. Foi realizada a média das cinco repetições e, assim, obtido o espectro de TR de cada material.

Com o objetivo de comparar a TR obtida entre os dois métodos (CCD e espectrômetro), selecionaram-se os valores de TR entre os comprimentos de onda 400 e 500 nm (faixa da luz azul), obteve-se a média de transmitância das repetições para cada material e realizou-se a análise de variância de 1 fator dos valores obtidos. As médias obtidas para cada material foram comparadas pelo teste de Tukey ao nível de significância de 5\%.

\subsection{Confecção dos cps de cimento resinoso:}

Duzentos e dezesseis cps do cimento resinoso Nexus 2 foram confeccionados

utilizando somente a pasta base na cor clear (sistema fotoativado) e outros duzentos e dezesseis cps, utilizando a pasta base, na mesma cor, espatulada com a pasta catalisadora de baixa viscosidade (sistema de dupla ativação) por 10 segundos. A composição básica destas 
pastas está na Tabela 4.4.A. Para o grupo de sistema dual, a quantidade exata de pasta base e catalisadora foi obtida com auxílio de uma balança digital com precisão de $0,0001 \mathrm{~g}$ (Adventure, Ohaus, China). Durante a pesagem, a pasta estava protegida da luz ambiente por um recipiente opaco. Os cps foram conformados a partir de uma matriz metálica bipartida de dimensões de 10 × 2 × 1 mm (Figura 4.4.A e Figura 4.4.B). Esta matriz foi colocada entre uma placa de vidro e o disco de material restaurador. Tiras de poliéster foram utilizadas para evitar o contato do cimento com os mesmos. Um encaixe de policetal preto foi usado para o correto posicionamento do espaçador e da ponta da unidade fotoativadora (Figura 4.4.C). Toda a confecção dos espécimes foi feita dentro de uma caixa de acrílico de cor alaranjada $(19$ × 20 × $32 \mathrm{~cm})$ para evitar uma possível influência de luz externa.

Tabela 4.4.A - Cimentos resinosos testados*

\begin{tabular}{c|c|c|c|c}
\hline Material & Fabricante & $\begin{array}{c}\text { Composição básica } \\
\text { da matriz }\end{array}$ & $\begin{array}{c}\text { Tamanho e volume das } \\
\text { partículas }\end{array}$ & Lote \\
\hline $\begin{array}{c}\text { Nexus 2 - pasta } \\
\text { base }\end{array}$ & SDS Kerr, & Bis-GMA & Dióxido de sílica: \\
$0,6 \mu \mathrm{m}, 47 \%$ & 436600 \\
$\begin{array}{c}\text { Nexus 2 - pasta } \\
\text { Catalizadora }\end{array}$ & & $\begin{array}{c}\text { Bis-GMA } \\
\text { TEGDMA }\end{array}$ & Não informado. & 432687 \\
\hline
\end{tabular}

*Informações fornecidas pelos fabricantes.

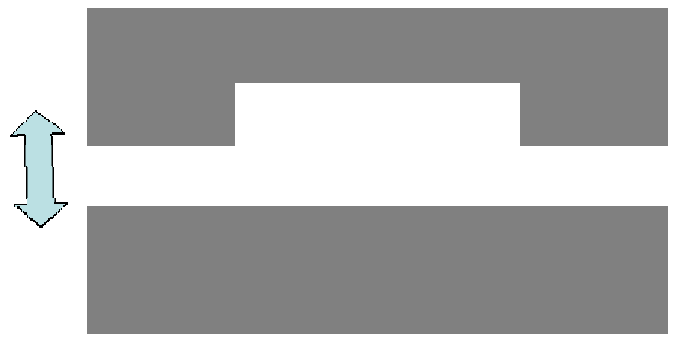

Figura 4.4.A - Desenho esquemático da matriz metálica bipartida aberta para confecção dos cps de cimento resinoso

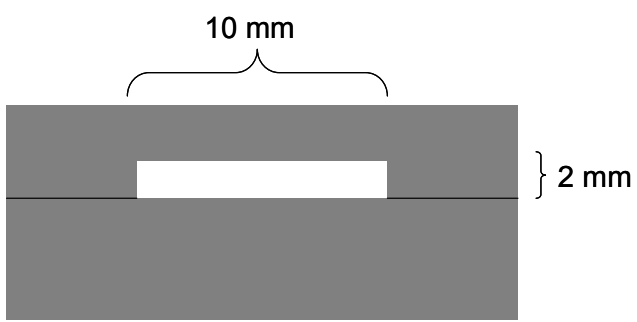

Figura 4.4.B - Desenho esquemático da matriz metálica bipartida fechada para confecção dos cps de cimento resinoso 


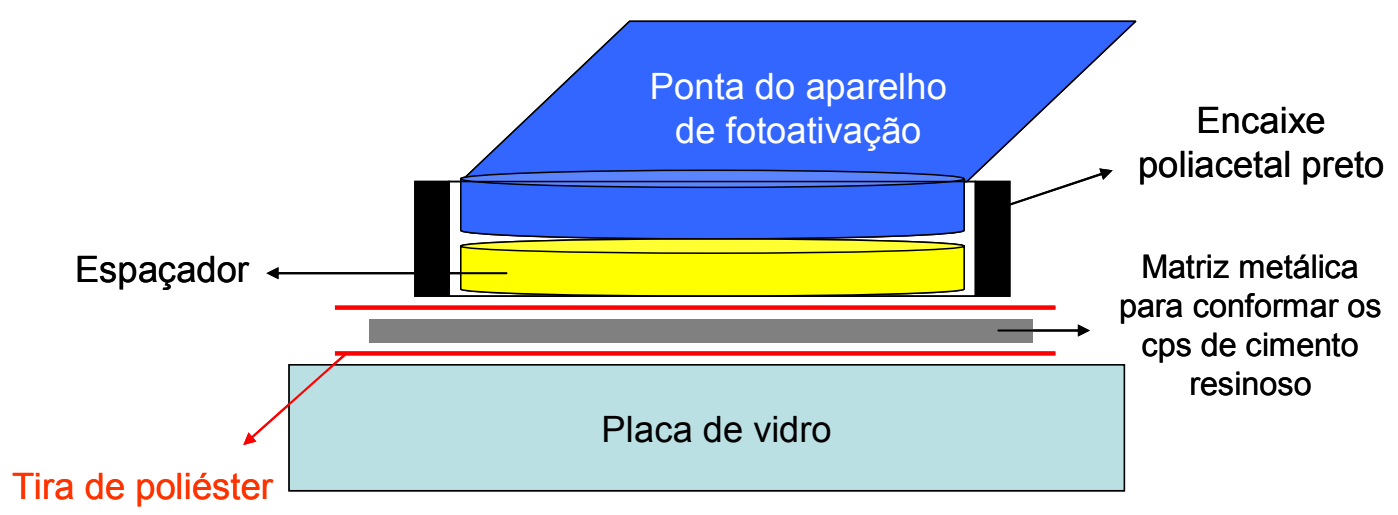

Figura 4.4.C - Desenho esquemático para a preparação dos cps de cimento resinoso

Tanto o grupo onde foi usado o cimento fotoativado quanto o que se usou o dual foram subdivididos em dois grupos de acordo com o tipo do fotoativador: QTH ou LED. Os cento e oito cps da cada grupo foram novamente divididos em seis subgrupos de acordo com o material do disco (Quadro 4.1). No subgrupo 1, a ponta do aparelho de fotoativação fícou encostada sobre a tira de poliéster que foi colocada sobre a superfície do cimento (espaço de 0 $\mathrm{mm}$ ); no subgrupo 2, a ponta do fotoativador ficou a $2 \mathrm{~mm}$ de distância do cimento, não havendo disco de material restaurador; no subgrupo 3, os cps foram fotopolimerizados através do disco de cerâmica IPS Eris; no subgrupo 4, os cps foram fotopolimerizados através de um disco confeccionado pela cerâmica IPS Empress 2 + IPS Eris; no 5, através de um disco de resina Sinfony; e finalmente, no subgrupo 6, os cps foram fotopolimerizados através de um disco de SR Adoro. Todos os espécimes foram irradiados por 60 segundos. 


\begin{tabular}{|c|c|c|c|}
\hline $\begin{array}{c}\text { Aparelho de } \\
\text { fotoativação } \\
\text { (modelo e fabricante) } \\
\end{array}$ & $\begin{array}{c}\text { Tipo de cimento } \\
\text { Nexus } 2 \text { - SDS Kerr }\end{array}$ & Espaçador & $\begin{array}{l}\text { Grupos experimentais } \\
\qquad(\mathrm{n}=18)\end{array}$ \\
\hline \multirow{12}{*}{$\begin{array}{c}\text { QTH } \\
\left(\text { Optilux }{ }^{\mathrm{TM}} 501 \text { - SDS }\right. \\
\text { Kerr) }\end{array}$} & \multirow{6}{*}{$\begin{array}{c}\text { Pasta base } \\
\text { (fotoativado) }\end{array}$} & Espaço de $0 \mathrm{~mm}$ & $1 \mathrm{~A}$ \\
\hline & & Espaço de $2 \mathrm{~mm}$ & $2 \mathrm{~A}$ \\
\hline & & IPS Eris & $3 \mathrm{~A}$ \\
\hline & & $\begin{array}{c}\text { IPS Empress } 2+\text { IPS } \\
\text { Eris }\end{array}$ & $4 \mathrm{~A}$ \\
\hline & & Sinfony & $5 \mathrm{~A}$ \\
\hline & & SR Adoro & $6 \mathrm{~A}$ \\
\hline & \multirow{6}{*}{$\begin{array}{l}\text { Pasta base }+ \\
\text { catalisadora } \\
(\text { dual })\end{array}$} & Espaço de $0 \mathrm{~mm}$ & $1 \mathrm{~B}$ \\
\hline & & Espaço de $2 \mathrm{~mm}$ & $2 \mathrm{~B}$ \\
\hline & & IPS Eris & $3 \mathrm{~B}$ \\
\hline & & $\begin{array}{c}\text { IPS Empress } 2+\text { IPS } \\
\text { Eris }\end{array}$ & $4 \mathrm{~B}$ \\
\hline & & Sinfony & $5 \mathrm{~B}$ \\
\hline & & SR Adoro & $6 \mathrm{~B}$ \\
\hline \multirow{12}{*}{$\begin{array}{c}\text { LED } \\
\text { (L.E.Demetron } 1 \text { - SDS } \\
\text { Kerr) }\end{array}$} & \multirow{6}{*}{$\begin{array}{l}\text { Pasta base } \\
\text { (fotoativado) }\end{array}$} & Espaço de $0 \mathrm{~mm}$ & $1 \mathrm{C}$ \\
\hline & & Espaço de $2 \mathrm{~mm}$ & $2 \mathrm{C}$ \\
\hline & & IPS Eris & $3 \mathrm{C}$ \\
\hline & & $\begin{array}{c}\text { IPS Empress } 2+\text { IPS } \\
\text { Eris }\end{array}$ & $4 \mathrm{C}$ \\
\hline & & Sinfony & $5 \mathrm{C}$ \\
\hline & & SR Adoro & $6 \mathrm{C}$ \\
\hline & \multirow{6}{*}{$\begin{array}{l}\text { Pasta base }+ \\
\text { catalisadora } \\
(\text { dual })\end{array}$} & Espaço de $0 \mathrm{~mm}$ & $1 \mathrm{D}$ \\
\hline & & Espaço de $2 \mathrm{~mm}$ & $2 \mathrm{D}$ \\
\hline & & IPS Eris & $3 \mathrm{D}$ \\
\hline & & $\begin{array}{c}\text { IPS Empress } 2+\text { IPS } \\
\text { Eris } \\
\end{array}$ & $4 \mathrm{D}$ \\
\hline & & Sinfony & $5 \mathrm{D}$ \\
\hline & & SR Adoro & $6 \mathrm{D}$ \\
\hline
\end{tabular}

Quadro 4.1- Delineamento experimental

Dezoito cps foram confeccionados para cada condição experimental, sendo que seis cps de cada condição foram utilizados para o ensaio de resistência à flexão, seis para o ensaio de microdureza Knoop e seis foram submetidos ao teste FT-Raman. Após a polimerização, a superfície voltada para a luz marcada foi identificada e os espécimes tiveram suas dimensões 
aferidas com um paquímetro digital (Starrett, Brasil) e ficaram armazenados em local escuro na água destilada por $24 \mathrm{~h}$ a $37^{\circ} \mathrm{C}$.

\subsection{Avaliação das propriedades físicas dos cimentos resinosos:}

Para a avaliação das propriedades físicas dos cimentos resinosos, foram selecionados os ensaios mecânicos de resistência à flexão e microdureza Knoop, e o método direto FTRaman para verificar o GC.

\subsection{1 ensaio de resistência à flexão}

Finalizado o período de armazenamento dos cps, foi realizado o ensaio de resistência à flexão em três pontos em máquina de ensaio universal (Kratos, Cotia, SP), com uma célula de carga de $100 \mathrm{kgf}$, em uma velocidade de $0,5 \mathrm{~mm} / \mathrm{min}$ e com uma distância de $6 \mathrm{~mm}$ entre os apoios. Os cps foram posicionados de forma que a face irradiada ficou voltada para o lado da

aplicação da carga. A resistência à flexão foi calculada através da Equação 6 , onde $\sigma$ é a 
resistência à flexão (em $\mathrm{MPa}), F$ é a carga aplicada no momento da fratura $(\mathrm{em} \mathrm{N}), l$ é a distância entre os apoios (em mm), $b$ é a largura e $h$ é a altura do espécime (ambas em mm) $(10,69)$.

$$
\text { Equação 6: } \sigma=\frac{3 F l}{2 b h^{2}}
$$

A análise de variância de três fatores independentes, sendo aparelhos de fotoativação, os tipos de cimento e os espaçadores, foi aplicada para os resultados de resistência à flexão. As médias calculadas foram analisadas pelo teste de contraste de Tukey com nível de significância de 5\%.

\subsection{2 ensaio de microdureza Knoop}

Após o período de armazenamento, os cento e quarenta e quatro cps destinados ao ensaio de microdureza Knoop foram colados com cianocrilato (Loctite Super Bonder, Henkel, Madison Heights, EUA) em tubos de PVC preenchidos com resina quimicamente ativada (JET, Clássico, São Paulo, Brasil), de forma que a face lateral (espessura) ficou voltada para cima. Esta face foi polida em uma politriz automática (Twin Variable Speed Grinder Polisher. EcoMet e Power Head AutoMet 2000, Buehler, Lake Bluff, EUA), sob constante irrigação com água, inicialmente com lixas d'água de granulações decrescentes de 400, 600, 1000, 
2000, 2400 e 4000, finalizando com um disco de feltro e pasta diamantada de granulação 1 $\mu \mathrm{m}$ (Buehler, Lake Bluff, EUA).

A superfície polida dos cps foi submetida ao ensaio de microdureza Knoop. Para tanto, foi dividida longitudinalmente em duas partes: uma próxima à face irradiada e a outra à face não-irradiada; e em três partes transversalmente: uma no meio do fragmento e as outras duas próximas à borda do $\mathrm{cp}$; totalizando seis regiões (Figura 4.5.A) que foram submetidas a uma endentação, sob carga de 100 gramas e tempo de penetração de 15 segundos ${ }^{(63)} \mathrm{O}$ microdurômetro utilizado foi o da Shimadzu, modelo HMV - 2T (Kioto, Japão), com o software C.A.M.S. Win versão 5.0.

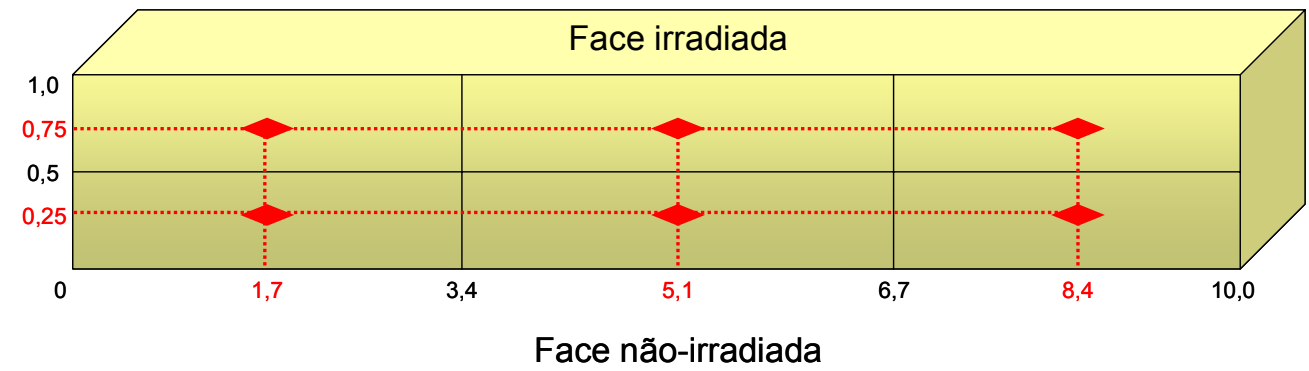

Figura 4.5.A - Desenho esquemático do cp de cimento resinoso com os respectivos locais das endentações (losangos em vermelho) para o ensaio de microdureza Knoop

Para o tratamento estatístico dos valores de microdureza Knoop a análise de variância de quatro fatores foi aplicada, sendo que os fatores independentes foram os aparelhos de fotoativação, os tipos de cimento e os espaçadores e o fator vinculado foi a zona de endentação no cp. O número de repetições foi igual a seis. As médias foram analisadas pelo teste de Tukey com nível de significância de 5\%. 


\subsubsection{GC pelo método FT-Raman}

Para determinar o GC do cimento resinoso aplicando o método FT-Raman, foram utilizados seis espécimes de cada condição experimental, sendo que em três cps foi analisado o GC da face irradiada e nos outros três cps foi analisado o GC da face não-irradiada. O espectrômetro da Bruker Optics (modelo RFS 100/S, Billerica, EUA) foi utilizado. Este aparelho constitui-se de um laser Nd:YAG com comprimento de onda de $1064 \mathrm{~nm}$ e potência de $100 \mathrm{~mW}$, com resolução do espectro de 4 cm-1 e com 64 co-adições. O divisor de feixes é de quartzo e a abertura possui $7 \mathrm{~mm}$. O detector é de germânio refrigerado com nitrogênio líquido a -180 oC.

Assim, após o período de armazenamento, os cps foram colados com cianocrilato (Loctite Super Bonder, Henkel, Madison Heights, EUA) em tubos de PVC preenchidos com resina quimicamente ativada (JET, Clássico, São Paulo, Brasil), de forma que a face que foi analisada ficou voltada para cima. Esta face foi polida em uma politriz automática (Twin Variable Speed Grinder Polisher. EcoMet e Power Head AutoMet 2000 - Buehler, Lake Bluff, EUA), sob constante irrigação com água, inicialmente com a lixa d'água de granulação 4000 por 2 min. Em cada espécime foram realizadas duas leituras: uma no centro e uma na borda do cp (Figura 4.5.B e Figura 4.5.C). 


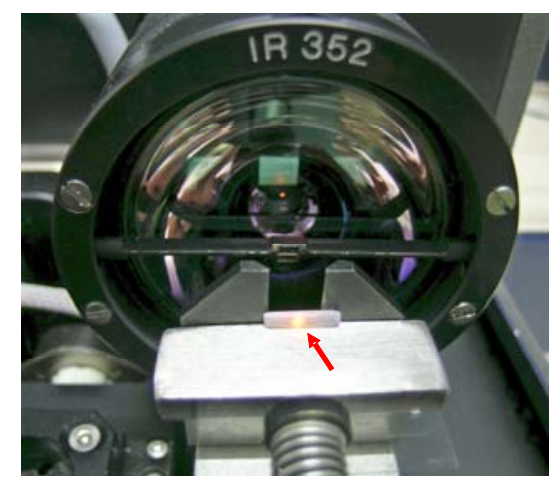

Figura 4.5.B - Espécime de cimento resinoso posicionado no espectrômetro para verificação do $\mathrm{GC}$ no centro do $\mathrm{cp}$ (seta)

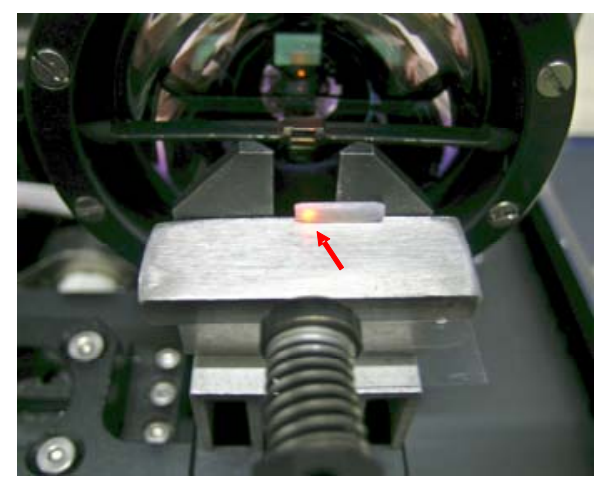

Figura 4.5.C - Espécime de cimento resinoso posicionado no espectrômetro para verificação do GC na borda do cp (seta)

O teste baseia-se na obtenção, análise e comparação dos espectros fornecidos pelo software OPUS (Bruker Optics, Billeria, EUA). Apesar de analisar um intervalo espectral de 100 a $3500 \mathrm{~cm}-1$, somente foram plotados espectros com o intervalo de 1000 a $2000 \mathrm{~cm}-1$, pois o pico da freqüência de vibração dos grupos alifáticos $(C=C)$ está em 1640 cm-1 e a 1610 cm-1 para os grupos aromáticos $(\Phi)$.

Iniciou-se o teste obtendo o espectro da pasta base não-irradiada e da pasta base recém-misturada com a catalisadora também não irradiada. Desta forma, criou-se um parâmetro para calcular o GC dos cps (Figura 4.5.D). Em seguida, fez-se a leitura dos cps (Figura 4.5.E). 
Para o cálculo do GC, traçou-se uma linha base, que passa pelos pontos mais baixos de cada espectro obtido. A partir do pico relacionado com grupos alifáticos, traçou-se uma perpendicular à abscissa do espectro. Mediu-se, em milímetros, a distância entre o pico e o ponto formado pela perpendicular e a linha base para se obter o valor de $\mathrm{I}_{\mathrm{C}=\mathrm{C}}$ destes grupos. Realizaram-se os mesmos procedimentos para determinar o valor de $\mathrm{I}_{\Phi}$, porém utilizando o pico relacionado aos anéis aromáticos. Calculou-se, assim, a razão $(R)$ entre $I_{C=C}$ e $I_{\Phi}$ de cada espectro. Para determinar o GC em porcentagem de cada cp, aplicou-se a fórmula ${ }^{(16)}$ :

$$
\mathrm{GC}=\left(1-\mathrm{R}_{\text {polimerizado }} / \mathrm{R}_{\text {não-polimerizado }}\right) \times 100 \text {. }
$$

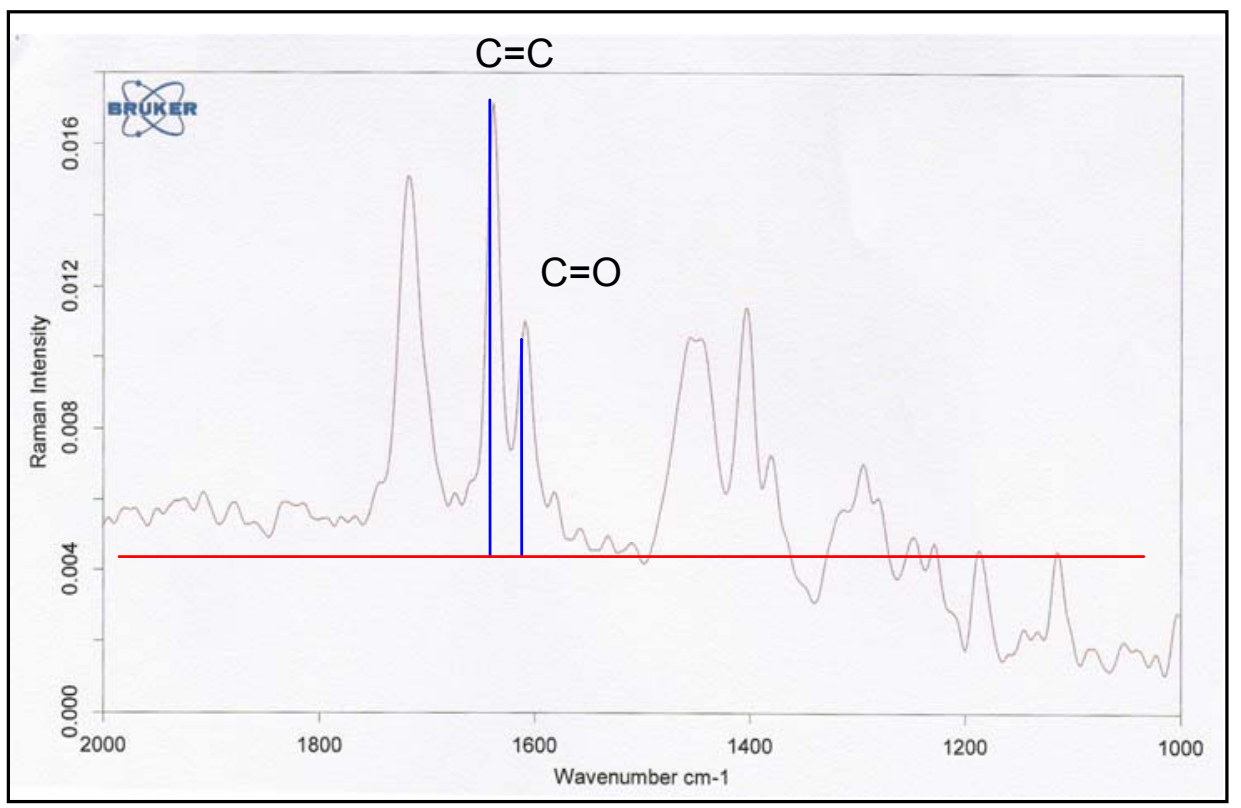

Figura 4.5.D - Espectro obtido pelo teste FT-Raman da pasta base do cimento resinoso não-irradiada 


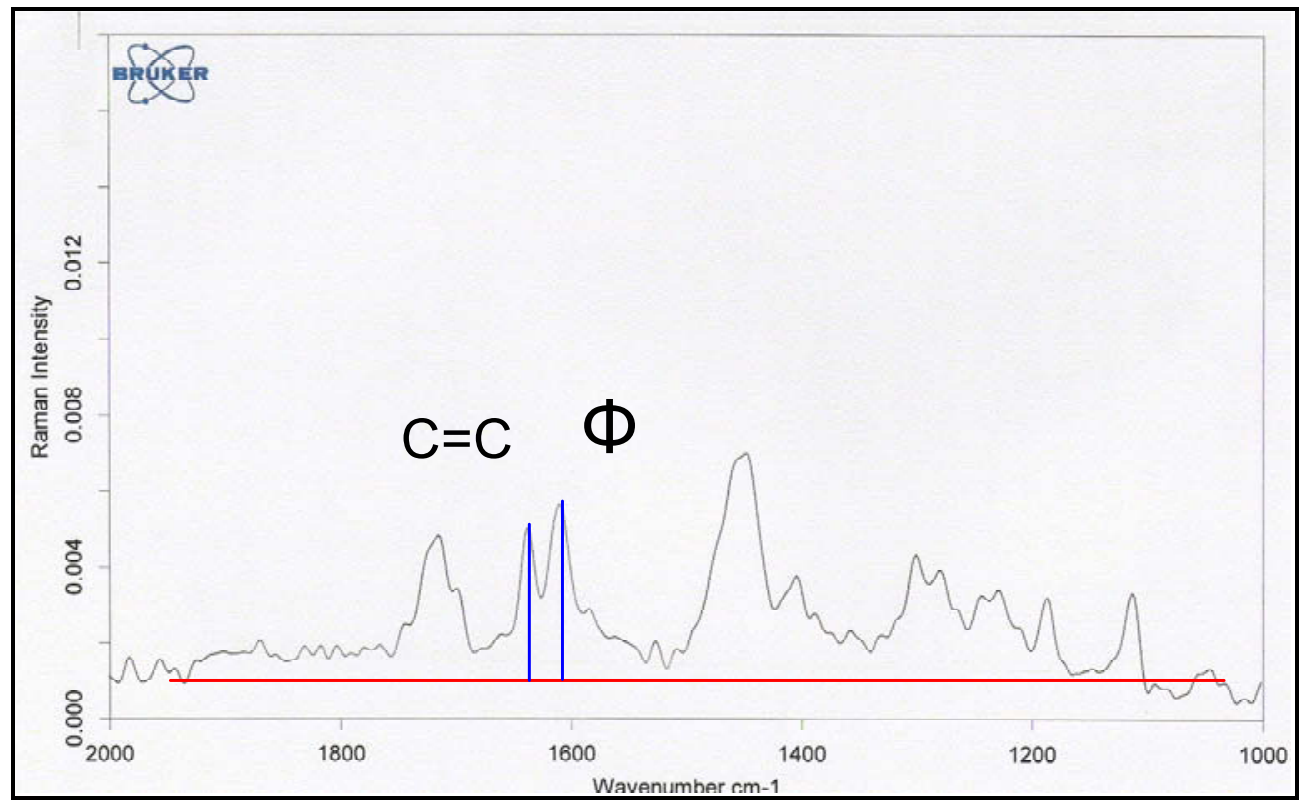

Figura 4.5.E - Espectro obtido pelo teste FT-Raman da pasta base do cimento resinoso irradiado

Os valores de GC obtidos foram submetidos à análise de variância de quatro fatores, sendo que os fatores independentes foram os aparelhos de fotoativação, os tipos de cimento e os espaçadores, o fator vinculado foi a região de análise no cp e o número de repetições foi igual a três. As médias foram analisadas pelo teste de Tukey com nível de significância de $5 \%$. 


\section{RESULTADOS}

Este capítulo será dividido em seis partes, conforme o ensaio laboratorial aplicado e tratamento estatístico dos dados. São elas: (I) emissão espectral dos aparelhos de fotoativação; (II) TR dos materiais restauradores indiretos estéticos; (III) resistência à flexão; (IV) microdureza Knoop; (V) GC pelo método FT-Raman; (VI) correlações e análises de regressão.

\subsection{Emissão espectral dos aparelhos de fotoativação}

\subsection{1 irradiância relativa}

Com a média obtida entre as três leituras da irradiância relativa (\%) do aparelho de fotoativação QTH e do LED em um intervalo de comprimento de onda de 380 a $780 \mathrm{~nm}$, foi construído o Gráfico 5.1.A que mostra a emissão espectral destes aparelhos. Nesta análise, o pico de irradiância do QTH foi no comprimento de onda igual a $492 \mathrm{~nm}$. Já para o LED o pico ocorreu no comprimento de onda igual a $452 \mathrm{~nm}$. 


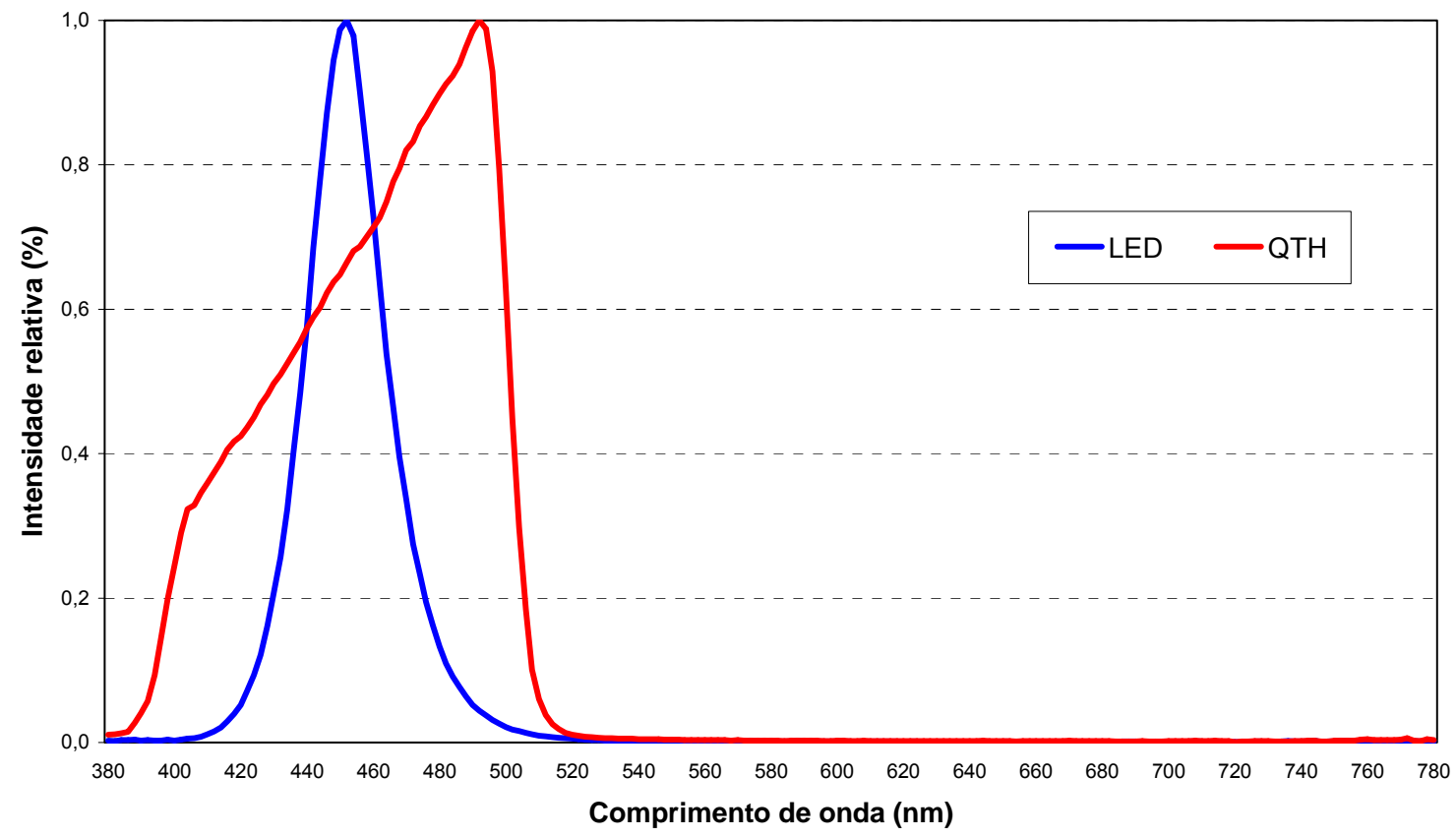

Gráfico 5.1.A - Emissão espectral dos valores de irradiância relativa dos aparelhos de fotoativação QTH (OptiluxTM 501, SDS Kerr) e LED (L.E.Demetron 1, SDS Kerr)

\subsection{2 irradiância absoluta}

Após calcular a média entre dos valores de irradiância das três leituras realizadas nos aparelhos de fotoativação, foi obtido o Gráfico 5.1.B que mostra a curva da emissão espectral do QTH e do LED. Foi calculado a integral das duas curvas para se obter a irradiância total dos aparelhos, onde o QTH e o LED apresentaram 739,6 e 1000,8 mW/ $\mathrm{cm}^{2}$ respectivamente. 


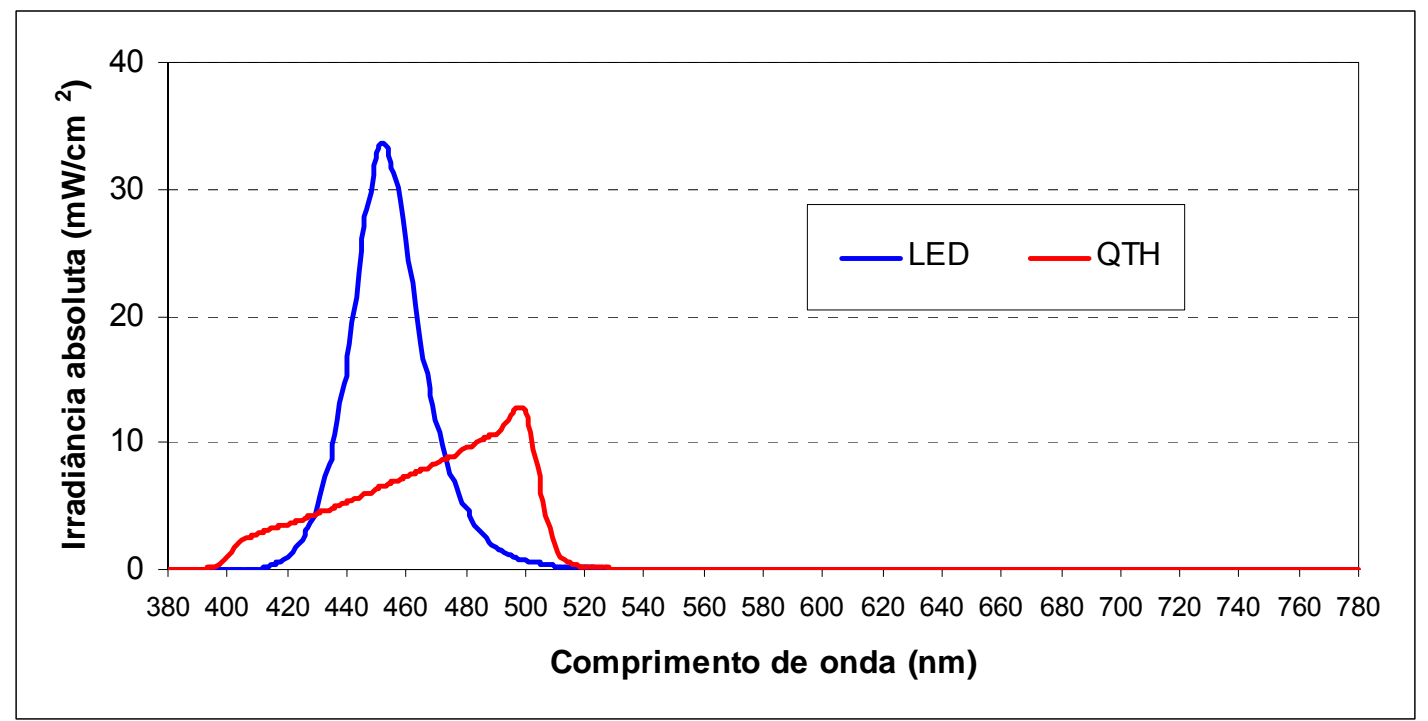

Gráfico 5.1.B - Emissão espectral dos valores de irradiância absoluta ( $\mathrm{mW} / \mathrm{cm} 2)$ dos aparelhos de fotoativação QTH (OptiluxTM 501, SDS Kerr) e LED (L.E.Demetron 1, SDS Kerr)

Além disso, foi calculada a integral das curvas que compreendiam entre 460 e $480 \mathrm{~nm}$, que correspondem à faixa de absorção da CQ. Nesta faixa, o QTH e o LED emitiram 175,6 e $277,1 \mathrm{~mW} / \mathrm{cm}^{2}$ respectivamente. 


\subsection{TR dos materiais restauradores indiretos estéticos}

5.2.1 TR obtida através da análise de imagens obtidas por uma CCD

A análise de variância dos resultados de TR demonstrou que houve diferença estatística entre os materiais restauradores indiretos estéticos $(p<0,001)$ e entre os dois aparelhos de fotoativação estudados $(p<0,05)$. Já a interação entre os materiais restauradores e os aparelhos de fotoativação não foi estatisticamente significantes (Tabela 5.2.A).

Tabela 5.2.A - Análise de variância dos resultados de TR dos materiais restauradores indiretos estéticos obtidos através da análise das imagens obtidas pela câmera CCD

\begin{tabular}{l|c|c|c|c}
\hline Fonte de variação & G.L. & Quadrados médios & R.Q.M. & \\
\hline Material restaurador (M) & 3 & 2,2145 & 41,36 & $* * *$ \\
Aparelho fotoativador (A) & 1 & 0,2755 & 5,15 & $*$ \\
Interação M x A & 3 & 0,0695 & 1,30 & n.s. \\
& & & & \\
Resíduo & 32 & 0,0535 & - & \\
Total & 39 & - & - & \\
\hline
\end{tabular}

Legenda:

n.s.: não significante

* $\quad$ significante ao nível de 5\% $(p<0,05)$

*** significante ao nível de $0,1 \%(p<0,001)$

Para o contraste das médias dos materiais restauradores, o teste de Tukey $(p=0,05 ; \Delta$ $=0,28)$ revelou que a maior média de TR foi obtida pela resina Sinfony $(3,1 \pm 0,25 \%)$. Os demais materiais restauradores não apresentaram diferenças entre si (Gráfico 5.2.A). Com relação ao fator aparelho de fotoativação (Gráfico 5.2.B), a média obtida com o LED (2,6 \pm $0,22 \%)$ foi maior que a obtida pelo QTH $(2,4 \pm 0,24 \%)$. 


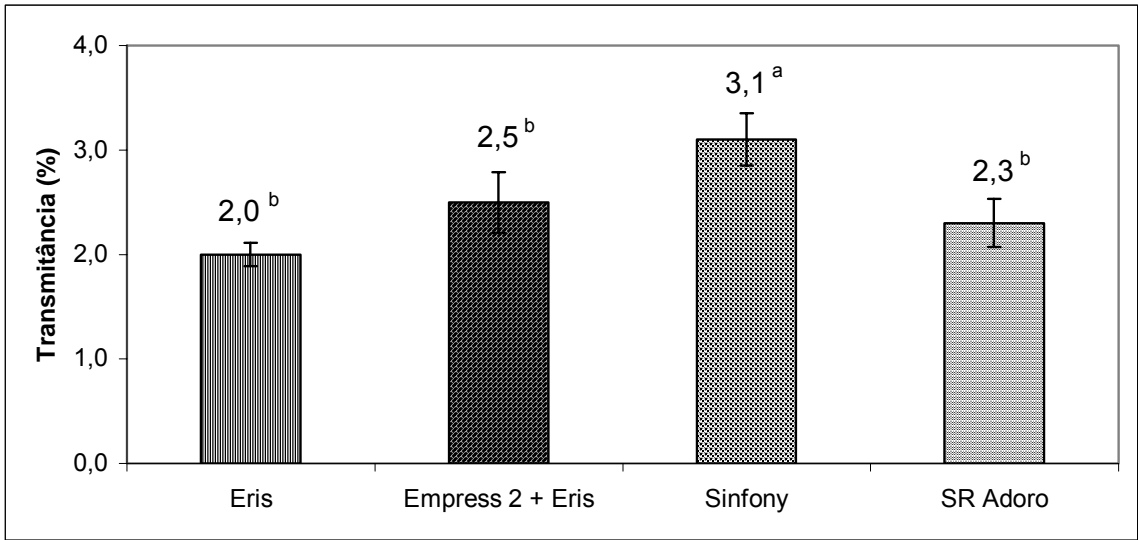

Gráfico 5.2.A - Médias da TR (\%) da luz através dos materiais restauradores indiretos estudados. Letras diferentes indicam diferença estatística entre os grupos

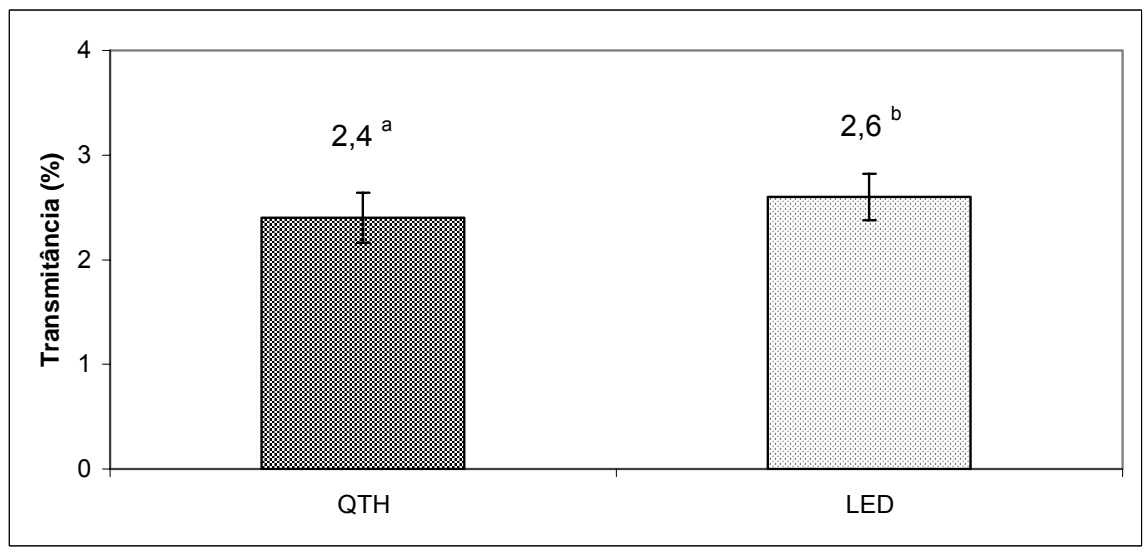

Gráfico 5.2.B - Médias da TR (\%) da luz através dos materiais restauradores indiretos ao utilizar os dois tipos de aparelhos de fotoativação (QTH e LED) como fonte de luz 
5.2.2 TR obtida através da espectrometria

Após o cálculo das médias de TR por comprimento de onda entre as cinco repetições de cada material restaurador indireto estético, foi obtido o Gráfico 5.2.C. Neste gráfico, notase nitidamente que conforme aumenta o comprimento de onda, aumenta a TR dos materiais.

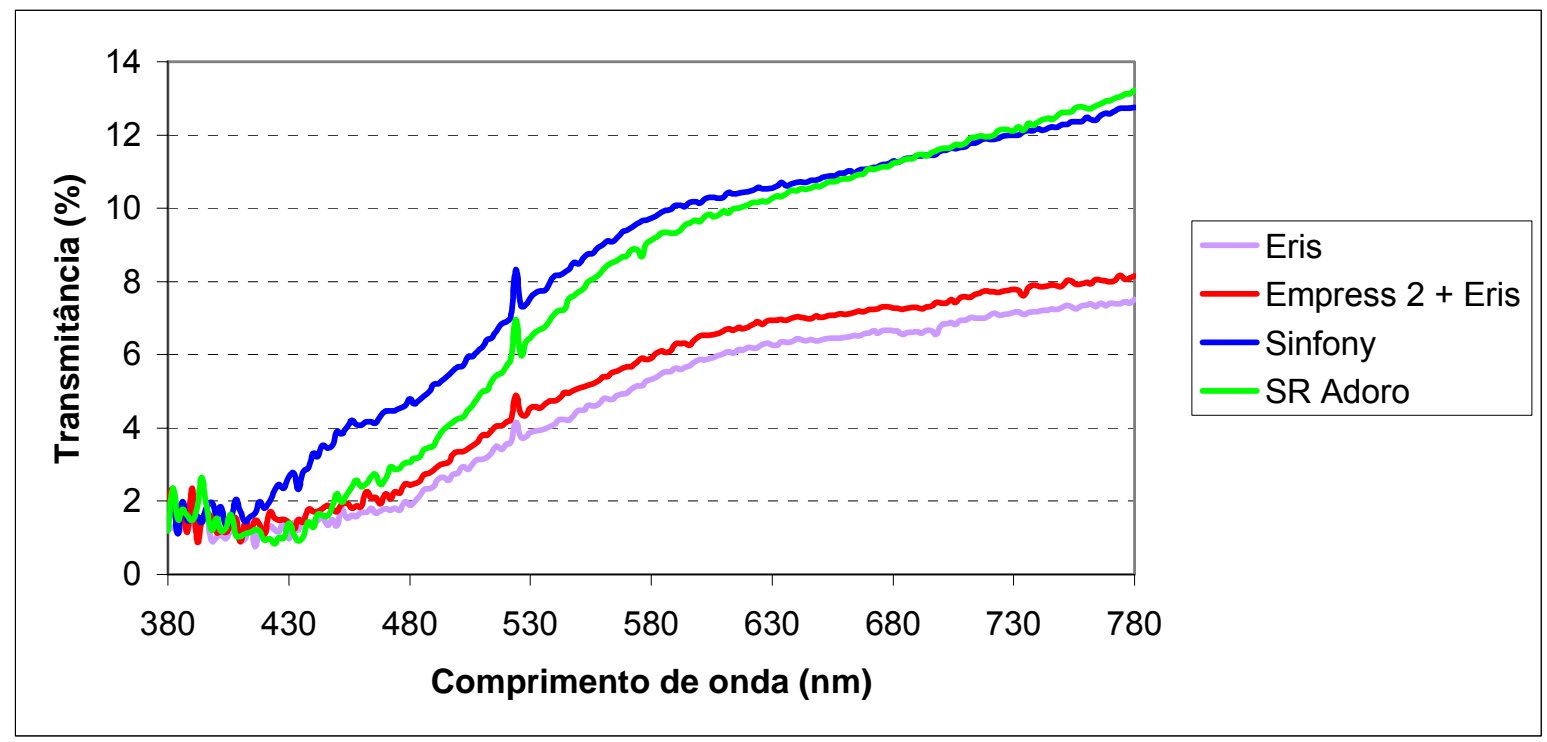

Gráfico 5.2.C - TR (\%) dos materiais restauradores indiretos estéticos por comprimento de onda

A análise de variância das médias de TR obtidas entre os comprimentos de onda de 400 a $500 \mathrm{~nm}$ (Tabela 5.2.B), mostrou que há diferença estatística entre os materiais restauradores estudados $(p<0,001)$. O teste de Tukey $(p=0,05 ; \Delta=0,444)$ revelou que a resina Sinfony novamente apresentou a maior média de TR $\left(3,5^{\mathrm{a}} \pm 0,22 \%\right)$ e que a cerâmica Eris obteve a menor média de TR $\left(1,6^{\mathrm{c}} \pm 0,21 \%\right)$. Não houve diferença estatística entre a resina SR Adoro $\left(2,2^{\mathrm{b}} \pm 0,22 \%\right)$ e ao conjunto cerâmico Empress $2+$ Eris $\left(1,9^{\mathrm{bc}} \pm 0,23 \%\right)$. Da 
mesma maneira, não houve diferença estatística entre as médias obtidas pela cerâmica Eris e pelo conjunto Empress $2+$ Eris.

Tabela 5.2.B - Análise de variância das médias de TR dos materiais restauradores indiretos estéticos obtidos entre os comprimentos de onda de 400 a $500 \mathrm{~nm}$ (espectrômetro)

\begin{tabular}{|c|c|c|c|c|}
\hline Fonte de variação & G.L. & Quadrados médios & R.Q.M. & \\
\hline Material restaurador & 3 & 3.3994 & 56.35 & $* * *$ \\
\hline Resíduo & 16 & 0,0603 & - & \\
\hline Total & 19 & - & - & \\
\hline
\end{tabular}

\subsection{Resistência à flexão}

A análise de variância (Tabela 5.3.A) dos resultados de resistência à flexão do cimento resinoso mostrou que houve diferença estatística significante entre os fatores principais, todos eles ao nível de $0,1 \%(p<0,001)$. Somente a interação entre espaçadores e tipo de cimento foi estatisticamente significante $(p<0,01)$. 
Tabela 5.3.A - Análise de variância dos resultados de resistência à flexão do cimento resinoso Nexus2

Legenda:

\begin{tabular}{l|c|c|c|c}
\hline Fonte de variação & G.L. & Quadrados médios & R.Q.M. & \\
\hline Espaçador (E) & 5 & $22.182,3320$ & 39,90 & $* * *$ \\
Tipo de cimento (C) & 1 & $78.141,3359$ & 140,55 & $* * *$ \\
Aparelho fotoativador (A) & 1 & $26.394,6660$ & 47,47 & $* * *$ \\
& & & & \\
Interação E x C & 5 & $2.393,8667$ & 4,31 & $* *$ \\
Interação C x A & 1 & 31,1092 & 0,06 & n.s. \\
Interação E x A & 5 & 952,7340 & 1,71 & n.s. \\
Interação E x C x A & 5 & 933,3110 & 1,68 & n.s. \\
& & & & \\
Resíduo & 120 & 555,9764 & - & \\
Total & 143 & - & - & \\
\hline
\end{tabular}

n.s.: não significante

** $\quad$ significante ao nível de $1 \%(p<0,01)$

*** significante ao nível de $0,1 \%(p<0,001)$

O teste de Tukey $(p=0,05 ; \Delta=19,7)$ aplicado entre as médias do fator principal espaçadores (Tabela 5.3.A) mostrou que quando o cimento resinoso foi ativado sem nenhum material interposto, deixando um espaço de $2 \mathrm{~mm}$, a sua resistência à flexão foi maior $\left(215,1^{\mathrm{a}}\right.$ $\pm 29,4 \mathrm{MPa})$. No entanto, a presença da resina Sinfony $\left(198,7^{\mathrm{ab}} \pm 17,2 \mathrm{MPa}\right)$ entre a fonte de luz e o cimento não diminuiu estatisticamente a resistência à flexão do cimento. Também não houve diferença estatística entre as médias das duas resinas indiretas. O grupo em que a ponta do fotoativador foi colocada a uma distância de $0 \mathrm{~mm}$ do cimento $\left(169,3^{\mathrm{c}} \pm 26,2 \mathrm{MPa}\right)$ não apresentou diferença estatística entre a resina SR Adoro $\left(186,8^{\mathrm{bc}} \pm 15,1 \mathrm{MPa}\right)$ e ao conjunto cerâmico Empress $2+$ Eris $\left(171,2^{\mathrm{c}} \pm 29,7 \mathrm{MPa}\right)$. A cerâmica Eris proporcionou uma menor média de resistência à flexão ao cimento $\left(126,8^{\mathrm{d}} \pm 19,5 \mathrm{MPa}\right)$. 


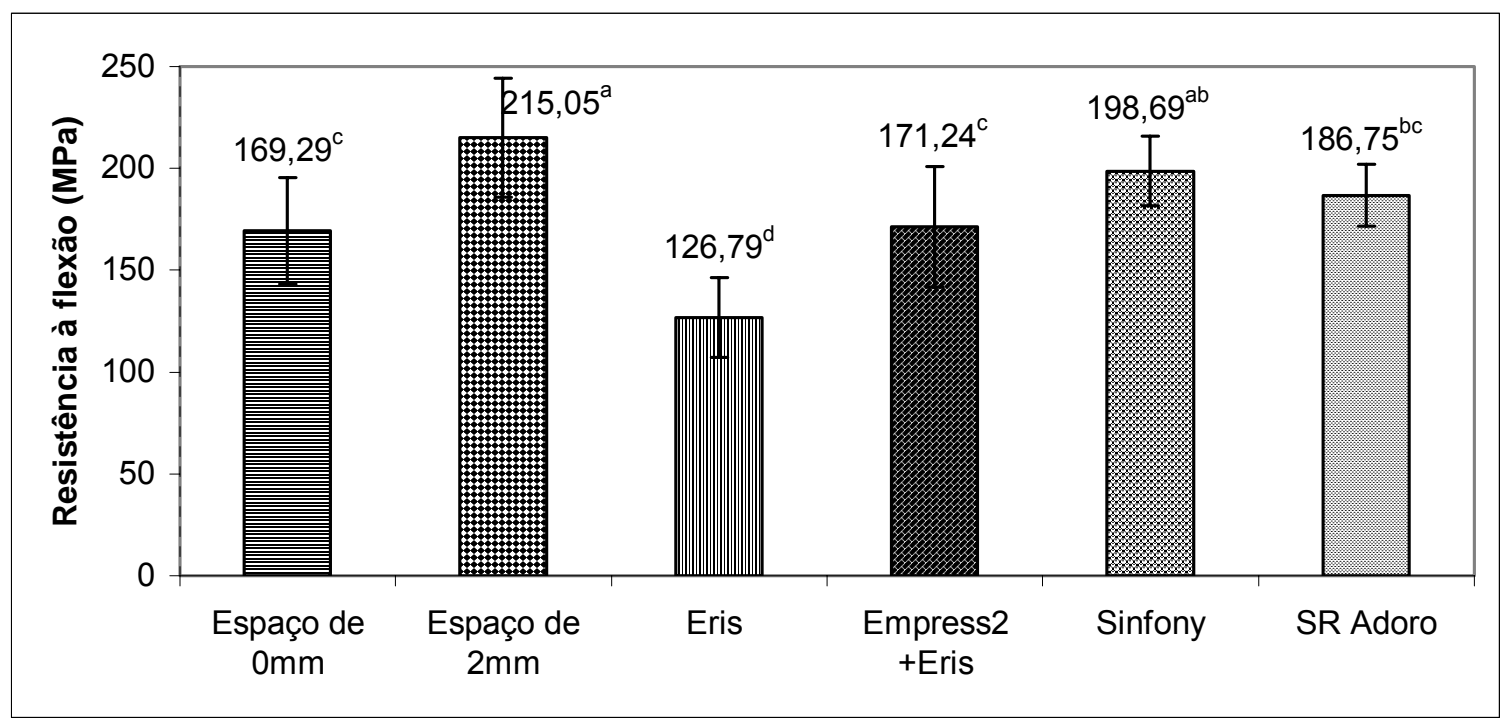

Gráfico 5.3.A - Médias de resistência à flexão do cimento resinoso quando fotoativado ao aplicar a luz diretamente sobre o cimento, sem nenhum material interposto, deixando 0 e $2 \mathrm{~mm}$ de espaço e através de diferentes materiais restauradores indiretos estéticos. Letras diferentes indicam diferença estatística entre os grupos

Quando analisado o fator tipo de cimento, o cimento resinoso dual (201,3 $\pm 22,8 \mathrm{MPa})$ apresentou uma resistência $23,2 \%$ superior ao cimento de pasta única $(154,7 \pm 24,3 \mathrm{MPa})$. Já para o fator aparelho de fotoativação, o QTH (191,5 \pm 21,2 $\mathrm{MPa})$ proporcionou uma resistência de 14,14\% superior comparado com o LED (164,4 $\pm 25,7 \mathrm{MPa})$.

Com relação à interação significante (Gráfico 5.3.B), percebe-se uma superioridade nos valores obtidos com o cimento de ativação dual. Nesta interação, os grupos que apresentaram os maiores valores de resistência à flexão foram: Espaço de $2 \mathrm{~mm}+$ dual $\left(232,5^{\mathrm{a}} \mathrm{MPa}\right)$; Sinfony + dual $\left(225,6^{\mathrm{ab}} \mathrm{MPa}\right)$; SR Adoro + dual $\left(214,1^{\mathrm{ab}} \mathrm{MPa}\right)$. Conforme o teste de Tukey $(p=0,05 ; \Delta=32,1)$, não houve diferença estatística entre as médias das duas resinas com o cimento dual, do conjunto Empress $2+$ Eris com o cimento dual e do grupo em que foi deixado um espaço de $2 \mathrm{~mm}$ com o cimento de pasta única (fotoativado). A interação da cerâmica Eris com o cimento fotoativado obteve a menor média de resistência à flexão foi $\left(92,9^{\mathrm{f}} \mathrm{MPa}\right)$. 


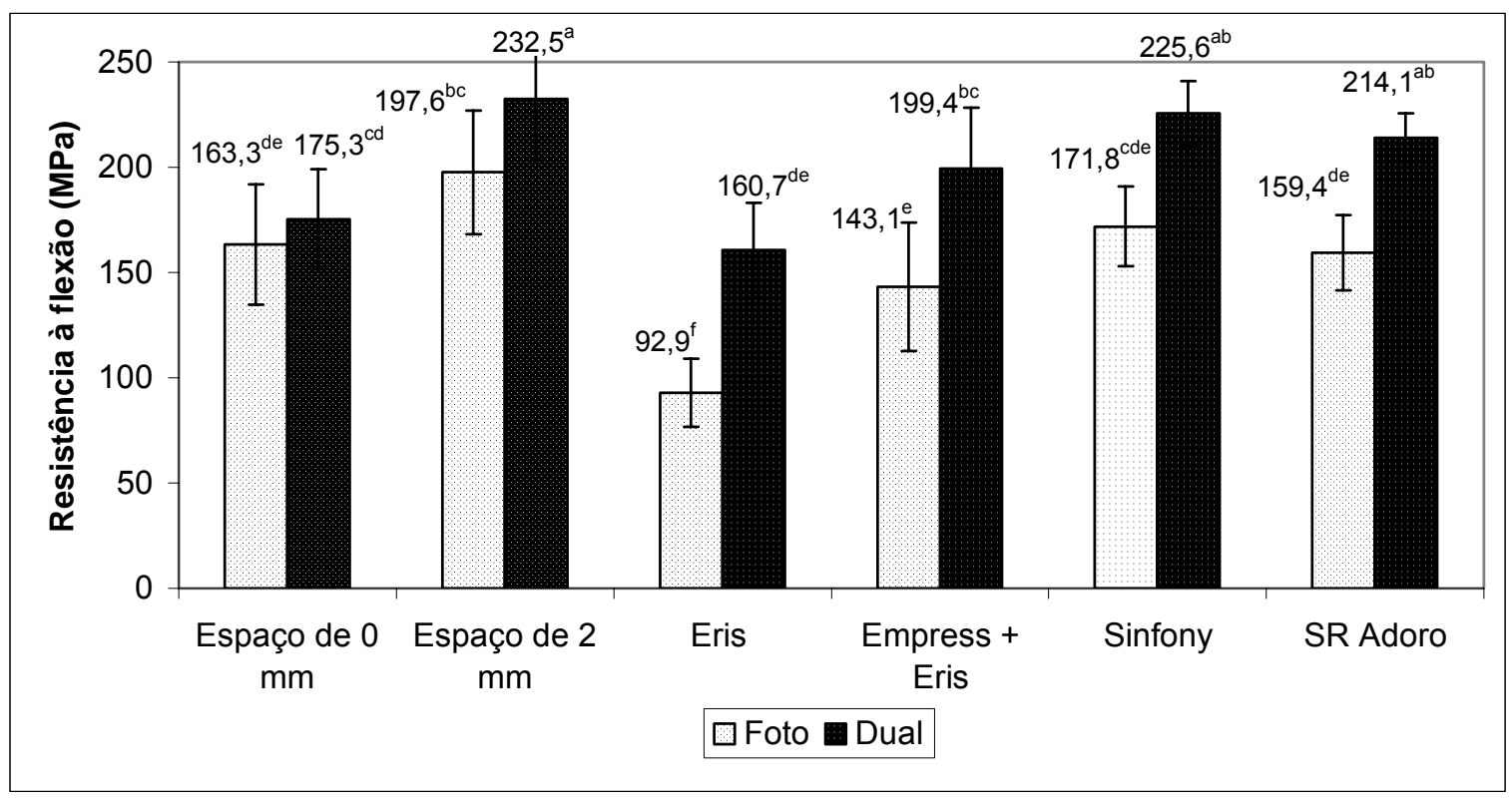

Gráfico 5.3.B - Médias de resistência à flexão do cimento resinoso quando fotoativado ao aplicar a luz diretamente sobre o cimento, sem nenhum material interposto, deixando 0 e $2 \mathrm{~mm}$ de espaço e através de diferentes materiais restauradores indiretos estéticos, utilizando-se dois tipos de cimento resinoso (foto e dual). Letras diferentes indicam diferença estatística entre os grupos

\subsection{Microdureza Knoop}

O tratamento estatístico dos valores de microdureza Knoop através da análise de variância (Tabela 5.4.A) demonstrou que todos os fatores principais e interações foram estatisticamente significantes ao nível de $0,1 \%$. Entretanto, o fator principal tipo de aparelho fotoativador, a interação tripla, tipo de aparelho, espaçador e zona de endentação e a interação quádrupla não foram estatisticamente significantes. 
Tabela 5.4.A - Análise de variância dos resultados de microdureza Knoop do cimento resinoso Nexus2

Legenda:

\begin{tabular}{|c|c|c|c|c|}
\hline Fator de variação & G.L. & Quadrados Médios & R.Q.M. & \\
\hline Aparelho fotoativador (A) & $\overline{1}$ & 31,8754 & 1,4536 & n.s. \\
\hline Tipo de cimento $(\mathrm{C})$ & 1 & $13.489,8546$ & 615,1826 & $* * *$ \\
\hline Espaçador (E) & 5 & $2.206,2577$ & 100,6128 & $* * *$ \\
\hline $\mathrm{A} \times \mathrm{C}$ & 1 & 497,8477 & 22,7035 & $* * *$ \\
\hline$A \times E$ & 5 & 548,1265 & 24,9964 & $* * *$ \\
\hline $\mathrm{C} \times \mathrm{E}$ & 5 & $1.150,4744$ & 52,4655 & $* * *$ \\
\hline $\mathrm{A} \times \mathrm{C} \times \mathrm{E}$ & 5 & 597,1966 & 27,2342 & $* * *$ \\
\hline Resíduo I & 120 & 21,9282 & - & \\
\hline Bloco-principal & 143 & 273,8548 & - & \\
\hline Zona de endentação (Z) & 3 & 627,2007 & 111,2328 & $* * *$ \\
\hline$A \times Z$ & 3 & 25,4078 & 4,5060 & $* * *$ \\
\hline $\mathrm{C} \times \mathrm{Z}$ & 3 & 268,1092 & 47,5487 & $* * *$ \\
\hline$E \times Z$ & 15 & 133,2892 & 23,6386 & $* * *$ \\
\hline $\mathrm{A} \times \mathrm{C} \times \mathrm{Z}$ & 3 & 30,0074 & 5,3218 & $* * *$ \\
\hline$A \times E \times Z$ & 15 & 9,7853 & 1,7354 & n.s. \\
\hline $\mathrm{C} \times \mathrm{E} \times \mathrm{Z}$ & 15 & 52,7054 & 9,3472 & $* * *$ \\
\hline$A \times C \times E \times Z$ & 15 & 10,8772 & 1,9290 & n.s. \\
\hline Resíduo II & 360 & 5,6386 & - & \\
\hline Sub-bloco & 432 & 18,4767 & - & \\
\hline Total & 575 & 81,9881 & - & \\
\hline
\end{tabular}

n.s.: não significante

*** significante ao nível de $0,1 \%(p<0,001)$

O cimento dual $(42,3 \pm 2,8 \mathrm{KHN})$ apresentou uma média de dureza $22,9 \%$ maior que a média de dureza dos cps feitos com somente uma pasta $(32,7 \pm 3,4 \mathrm{KHN})$. Com relação ao fator espaçador (Tukey ao nível de $5 \% ; \Delta=1,96$ ), o grupo em que foi deixado $2 \mathrm{~mm}$ de espaço entre a ponta do aparelho de fotoativação e a superfície do cimento, sem nenhum espaçador interposto, obteve a maior média de dureza entre os grupos $\left(44,1^{\mathrm{a}} \pm 2,3 \mathrm{KHN}\right) . \mathrm{O}$ grupo em que o cimento foi fotopolimerizado com a ponta do aparelho encostada diretamente sobre o cimento $\left(38,1^{\mathrm{b}} \pm 1,8 \mathrm{KHN}\right)$ e os grupos das resinas Sinfony $\left(39,6^{\mathrm{b}} \pm 2,9 \mathrm{KHN}\right)$ e SR Adoro $\left(39,8^{\mathrm{b}} \pm 2,7 \mathrm{KHN}\right)$ apresentaram médias estatisticamente semelhantes. Os grupos das cerâmicas Eris $\left(31,2^{\mathrm{c}} \pm 3,8 \mathrm{KHN}\right)$ e Empress $2+$ Eris $\left(32,7^{\mathrm{c}} \pm 4,5 \mathrm{KHN}\right)$ resultaram nas menores médias de dureza as quais foram semelhantes entre si.

Com relação às zonas de endentação, a região da face irradiada no centro do cp obteve a maior média de dureza $\left(39,6^{\mathrm{a}} \pm 2,9 \mathrm{KHN}\right)$. O contraste de Tukey $(p=0,05 ; \Delta=0,72)$ 
revelou diferença estatística entre as médias de dureza no centro do cp entre a superfície irradiada e não-irradiada $\left(38,1^{\mathrm{b}} \pm 3,7 \mathrm{KHN}\right)$. Mesmo se referindo à superfície irradiada, as bordas do $\mathrm{cp}\left(37,6^{\mathrm{b}} \pm 3,0 \mathrm{KHN}\right)$ apresentaram menor média de dureza do que no centro. Além disso, na mesma região de borda, porém $1 \mathrm{~mm}$ mais abaixo (face não-irradiada) as médias de dureza foram ainda menores $\left(34,6^{\mathrm{c}} \pm 2,8 \mathrm{KHN}\right)$.

$\mathrm{Na}$ interação cimento e aparelho de fotoativação (Tukey ao nível de $5 \% ; \Delta=1,44$ ), as médias calculadas com o LED e o cimento dual foram as maiores $\left(43,5^{\mathrm{a}} \pm 2,3 \mathrm{KHN}\right)$. Em seguida, o grupo do QTH com o cimento de ativação dupla obteve uma média $\left(41,2^{\mathrm{b}} \pm 3,2\right.$ $\mathrm{KHN})$ estatisticamente diferente da primeira. Tanto o grupo do QTH $\left(33,3^{\mathrm{c}} \pm 3,5 \mathrm{KHN}\right)$ como o grupo do $\operatorname{LED}\left(32,0^{\mathrm{c}} \pm 3,3 \mathrm{KHN}\right)$, que utilizaram o cimento fotoativado, apresentaram médias de dureza semelhantes entre si (Gráfico 5.4.A).

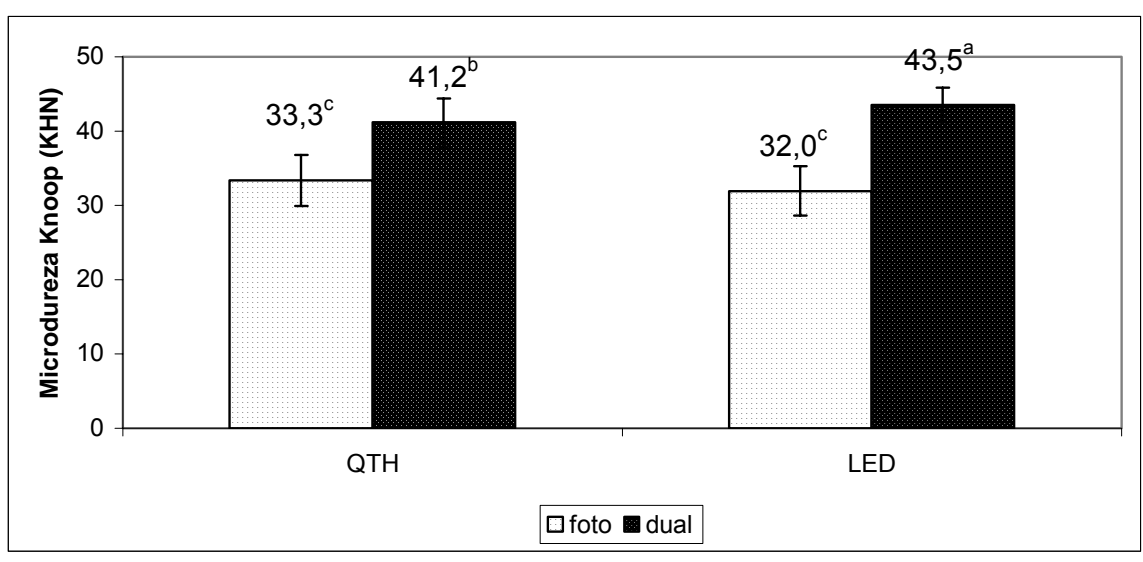

Gráfico 5.4.A - Médias de microdureza Knoop dos dois tipos de cimento resinoso (fotoativado e dual) quando fotopolimerizado pelos dois tipos de aparelhos de fotoativação (QTH e LED). Letras diferentes indicam diferença estatística entre os grupos

Já na interação espaçador e aparelho de fotoativação (Tukey ao nível de 5\%; $\Delta=$ 3,19 ), todos os grupos de espaçadores apresentaram médias semelhantes entre os aparelhos, com exceção do grupo em que o cimento foi ativado com a ponta do aparelho a uma distância 
de $0 \mathrm{~mm}$ da superfície do cimento e do grupo do conjunto cerâmico Empress $2+$ Eris (Gráfico 5.4.B).

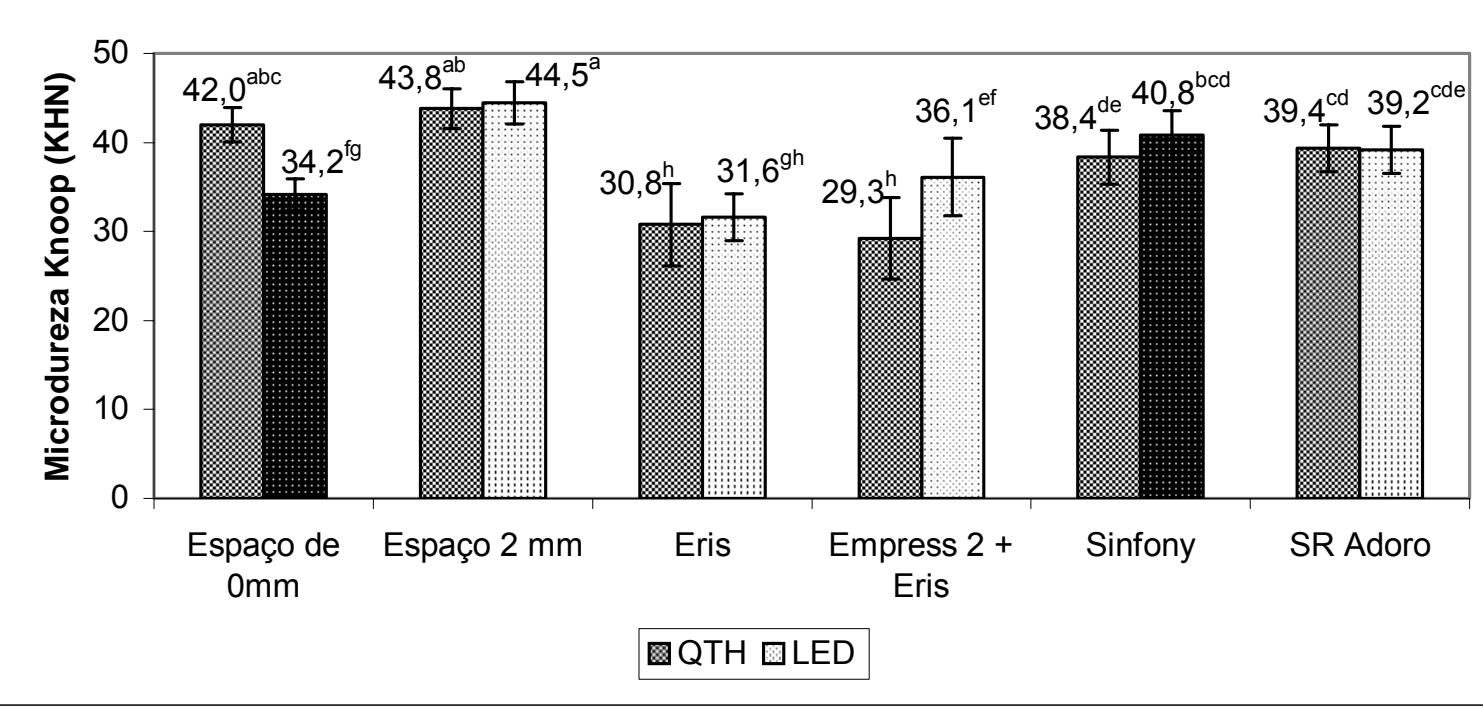

Gráfico 5.4.B - Médias de microdureza Knoop do cimento resinoso quando fotoativado ao aplicar a luz diretamente sobre o cimento, sem nenhum material interposto, deixando 0 e $2 \mathrm{~mm}$ de distância e através de diferentes materiais restauradores indiretos estéticos, utilizando-se dois tipos de aparelhos de fotoativação (QTH e LED). Letras diferentes indicam diferença estatística entre os grupos

Com relação à interação espaçadores e tipo de cimento (Tukey ao nível de 5\%; $\Delta=$ 3,19), há uma superioridade das médias dos grupos que utilizaram a dupla ativação do cimento, com exceção do grupo em que o cimento foi fotopolimerizado sem espaçador, deixando um espaço de $2 \mathrm{~mm}$ (Gráfico 5.4.C). Neste grupo, as médias de dureza obtidas foram semelhantes entre si independentemente do tipo de cimento utilizado. Nos grupos da cerâmica Eris, a ativação dupla do cimento $(40,3 \pm 2,5 \mathrm{KHN})$ aumentou em 45,2\% em relação ao cimento de pasta única $(22,1 \pm 4,7 \mathrm{KHN})$, compensando a falta da luz atenuada pela cerâmica. A maior média de dureza obtida foi com o grupo da resina SR Adoro e o cimento dual $(47,2 \pm 2,5 \mathrm{KHN})$. 


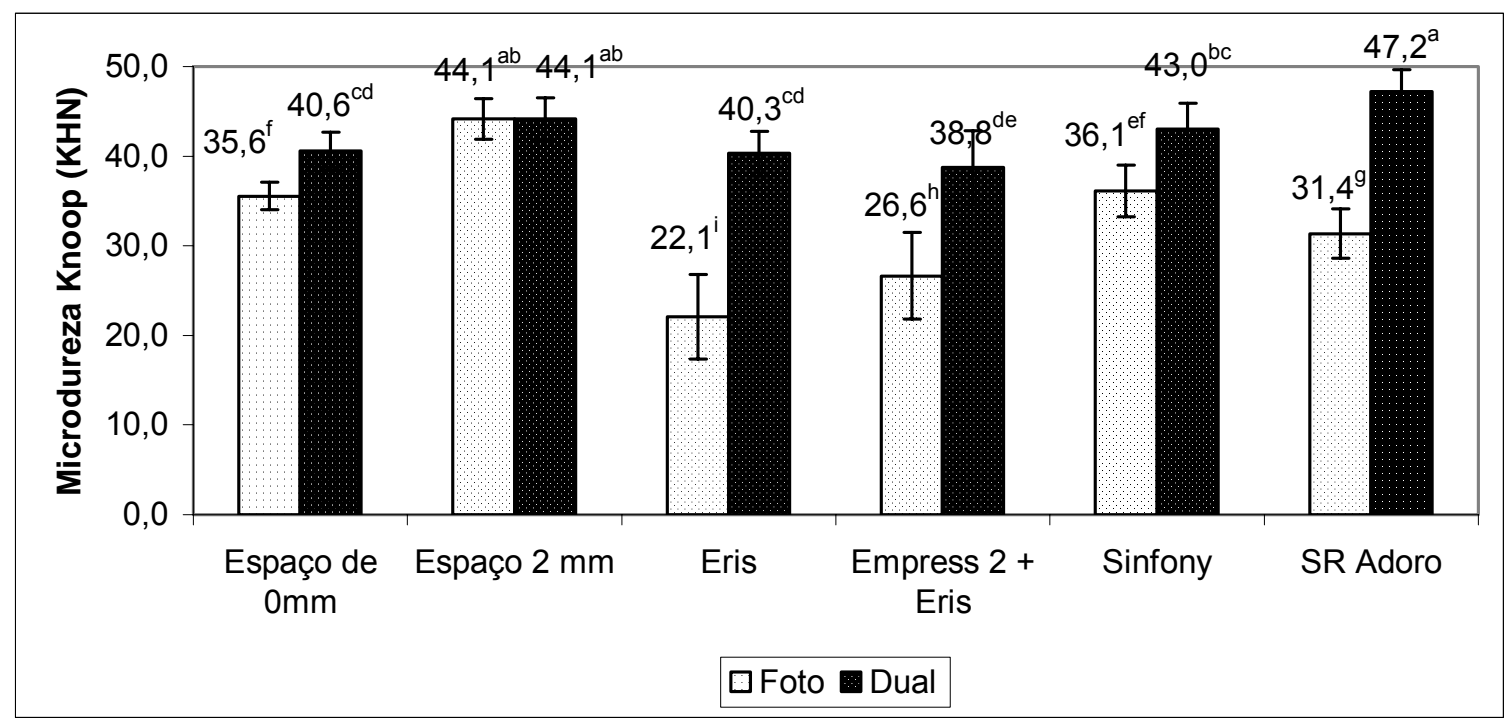

Gráfico 5.4.C - Médias de microdureza Knoop dos dois tipos de cimento resinoso (foto e dual) quando fotoativado ao aplicar a luz diretamente sobre o cimento, sem nenhum material interposto, deixando 0 e $2 \mathrm{~mm}$ de espaço e através de diferentes materiais restauradores indiretos estéticos. Letras diferentes indicam diferença estatística entre os grupos

Mesmo na interação entre tipo de cimento e zona de endentação (Gráfico 5.4.D), o benefício da ativação dupla do cimento está evidente. Em todos os grupos de zona de endentação, o teste de Tukey $(p=0,05 ; \Delta=1,21)$ revelou que o cimento dual apresentou médias superiores. Ao analisar as médias dos grupos de cimento dual, verifica-se que todas as zonas foram estatisticamente semelhantes entre si $\left(42,7^{\mathrm{a}} \pm 2,8 \mathrm{KHN} ; 42,4^{\mathrm{a}} \pm 2,4 \mathrm{KHN} ; 43,1^{\mathrm{a}}\right.$ $\pm 3,3 \mathrm{KHN})$, com exceção da zona localizada na borda da face não-irradiada $\left(41,1^{\mathrm{b}} \pm 2,7\right.$ $\mathrm{KHN}$ ). Porém, ao analisar as médias obtidas com o cimento fotoativado, percebe-se a nítida influência da distribuição não-uniforme da luz na ponta do aparelho de fotoativação, pois o grupo de maior média é o da zona da localizada no centro da face irradiada $\left(36,4^{\mathrm{c}} \pm 3,0\right.$ $\mathrm{KHN})$, seguida pela zona do centro da face não-irradiada $\left(33,2^{\mathrm{d}} \pm 4,1 \mathrm{KHN}\right)$, que não é estatisticamente diferente da zona da borda da face irradiada $\left(32,9^{\mathrm{d}} \pm 3,5 \mathrm{KHN}\right)$. E, finalmente, com a menor média a zona localizada na borda da face não-irradiada $\left(28,1^{\mathrm{e}} \pm 2,8\right.$ KHN). 


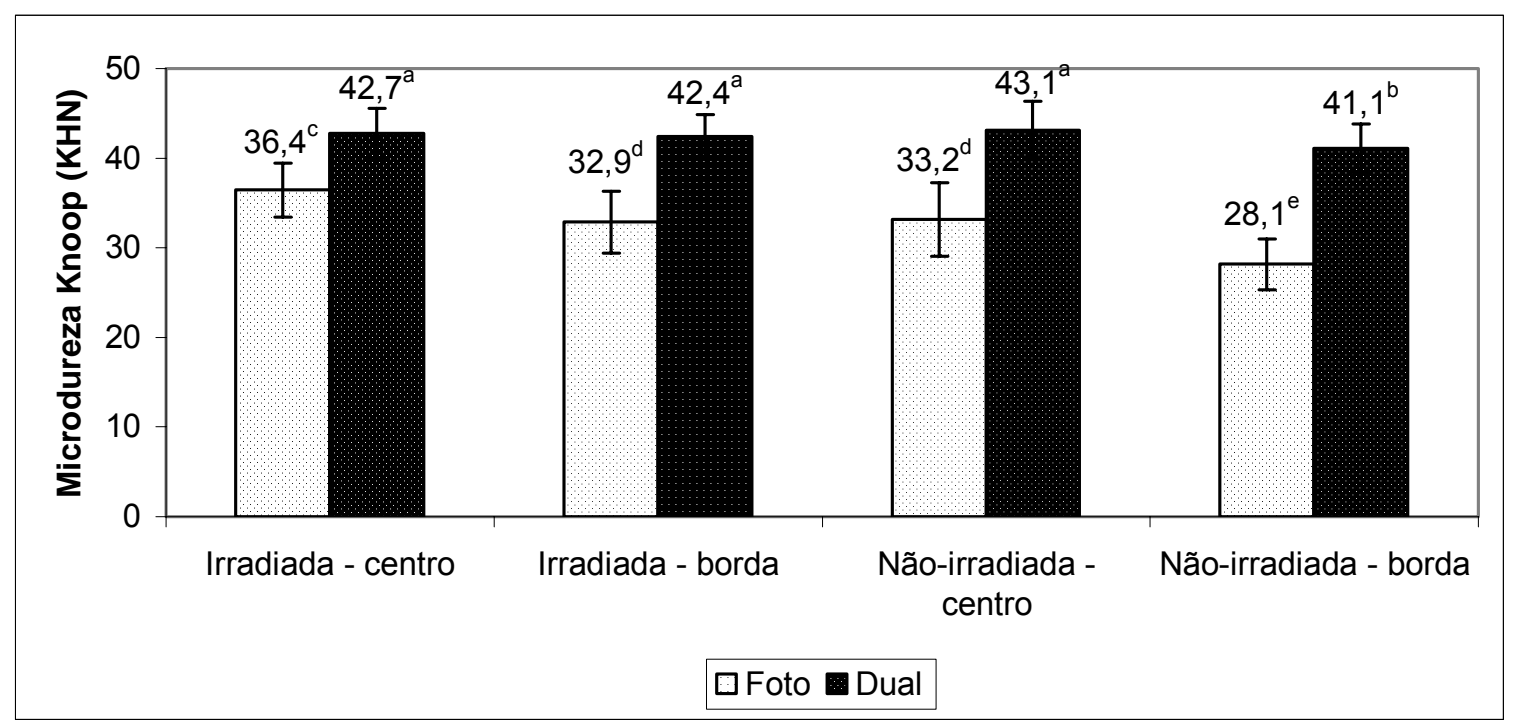

Gráfico 5.4.D - Médias de microdureza Knoop dos dois tipos de cimento resinoso (foto e dual) destacando as quatro zonas de endentação. Letras diferentes indicam diferença estatística entre os grupos

$\mathrm{Na}$ interação zona de endentação e tipo de aparelho de fotoativação, não houve diferença entre os aparelhos em todas as zonas, com exceção da zona localizada na borda da face irradiada, onde o $\operatorname{LED}(37,0 \pm 2,9 \mathrm{KHN})$ apresentou uma média de dureza 3,1\% superior em relação ao QTH (38,2 \pm 3,1 KHN). Estas diferenças foram constadas pelo teste de Tukey ao nível de $5 \%(\Delta=1,20)$. Com relação às zonas de endentação, as médias de dureza seguiram o mesmo comportamento da análise deste fator isoladamente.

Os resultados de dureza obtidos da interação tripla (Gráfico 5.4.E), espaçadores, tipo de cimento e aparelhos de fotoativação, mostraram novamente que a influência da ativação química (cimento dual) é marcante. Outro fato importante é que nos grupos em que foi deixado um espaço de $2 \mathrm{~mm}$ sem espaçador entre a ponta do aparelho e o cimento, as médias se mantiveram semelhantes entre si, independentemente do tipo de cimento e aparelho (Tukey ao nível de $5 \% ; \Delta=5,03)$. Já com a cerâmica Eris interposta a dureza do cimento praticamente dobrou quando se utilizou o cimento dual, isto é houve um aumento da dureza em 48,5\% ao utilizar o QTH (40,6 KHN) e 42\% com o LED (40,0 KHN). Uma outra situação que chama atenção são as médias obtidas pelo grupo de cimento de pasta única (fotoativado) 
que foi fotopolimerizada com a ponta do aparelho encostada sobre o mesmo, pois ao utilizar o LED (26,0 KHN) a média de dureza cai 42,4\% em relação ao QTH (45,1 KHN). E, finalmente, se verificou uma homogeneidade das médias ao utilizar o LED para fotopolimerizar o cimento dual em todos os grupos de espaçadores.

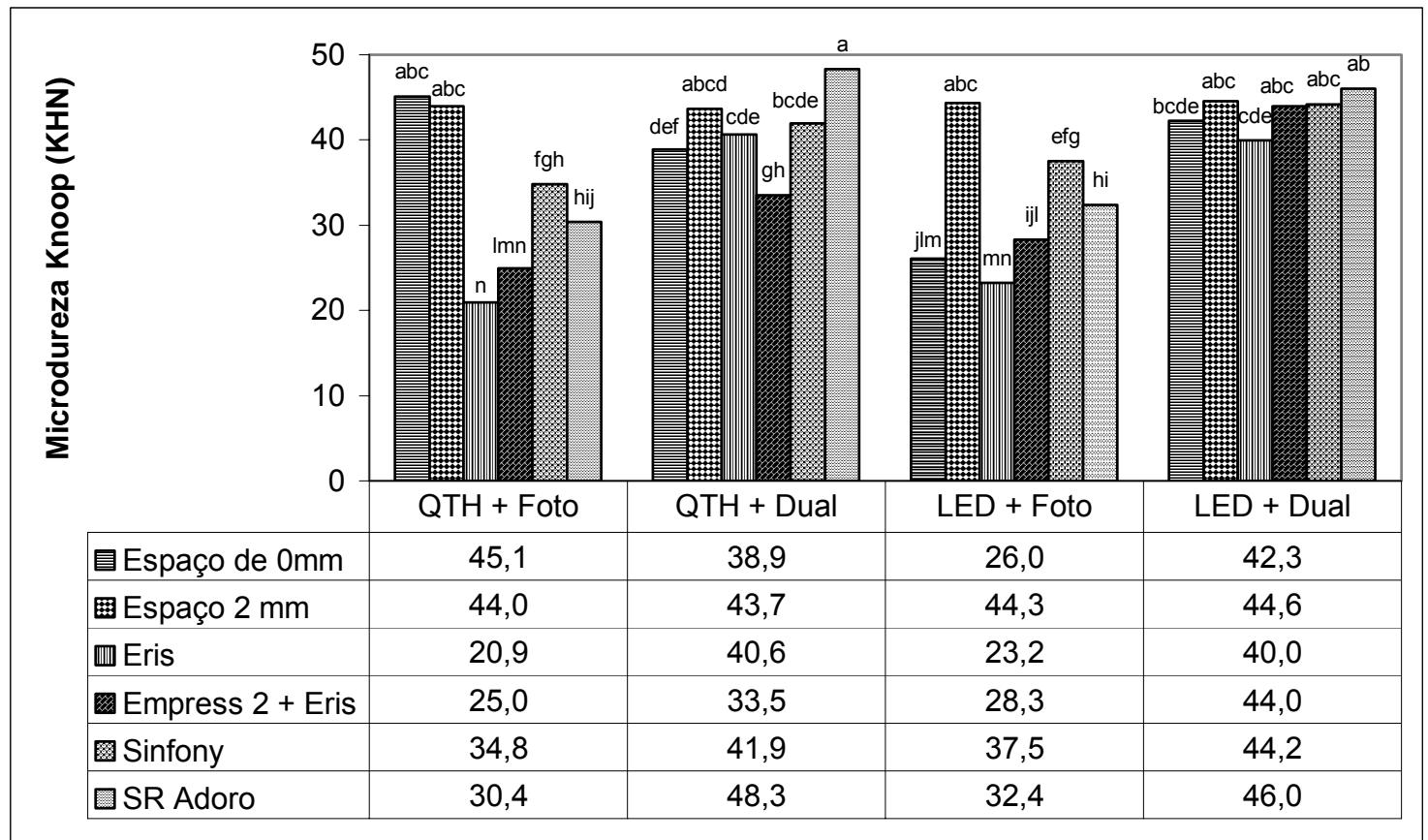

Gráfico 5.4.E - Médias de microdureza Knoop do cimento resinoso quando fotoativado ao aplicar a luz diretamente sobre o cimento, sem nenhum material interposto, deixando 0 e $2 \mathrm{~mm}$ de espaço e através de diferentes materiais restauradores indiretos estéticos, utilizando-se dois tipos de aparelhos de fotoativação (QTH e LED) e dois tipos de cimento (foto e dual)

A interação entre tipo de cimento, aparelho de fotoativação e zona de endentação (Gráfico 5.4.F), mostra também uma homogeneidade nos resultados obtidos com cimento dual fotopolimerizado pelo LED. Além disso, constata-se a nítida influência da distribuição não-uniforme da luz na ponta do aparelho de fotoativação no grupo do cimento de pasta única fotopolimerizado pelo LED. A influência da ativação química do cimento dual também é marcante ao comparar os resultados obtidos tanto pelo QTH como pelo LED. 


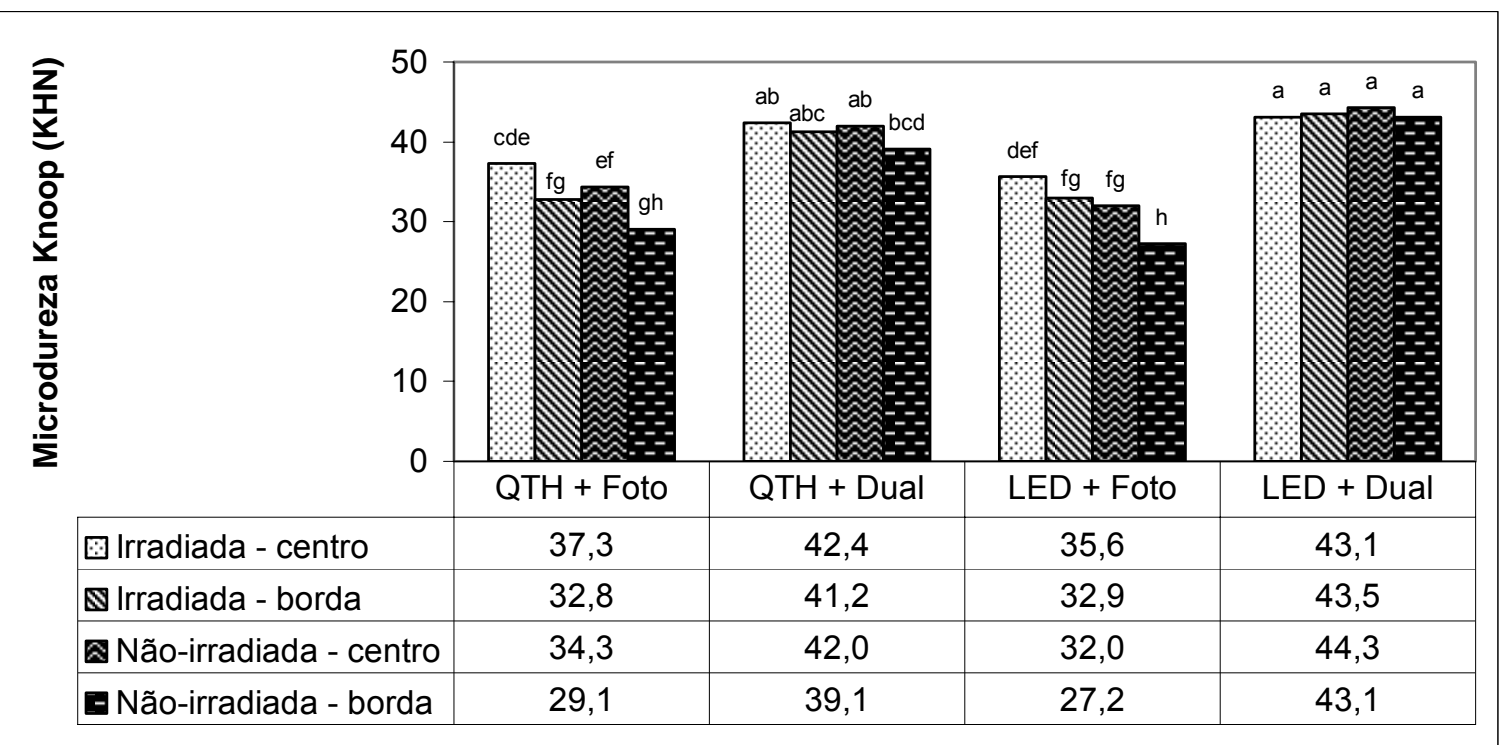

Gráfico 5.4.F - Médias de microdureza Knoop do cimento resinoso ao ser fotopolimerizado utilizando dois tipos de aparelhos de fotoativação (QTH e LED) e dois tipos de cimento (foto e dual), e analisando as quatro zonas de endentação

\subsection{GC pelo método FT-Raman}

A Tabela 5.5.A mostra a análise de variância dos valores de GC do cimento resinoso, onde somente detectou diferença estatística entre os dois tipos de cimento $(p<0,001)$, entre os espaçadores $(p<0,001)$, entre as regiões de análise no cp $(p<0,01)$ e entre a interação tipo de cimento e espaçadores $(p<0,05)$. 
Tabela 5.5.A - Análise de variância dos resultados de GC do cimento resinoso Nexus2

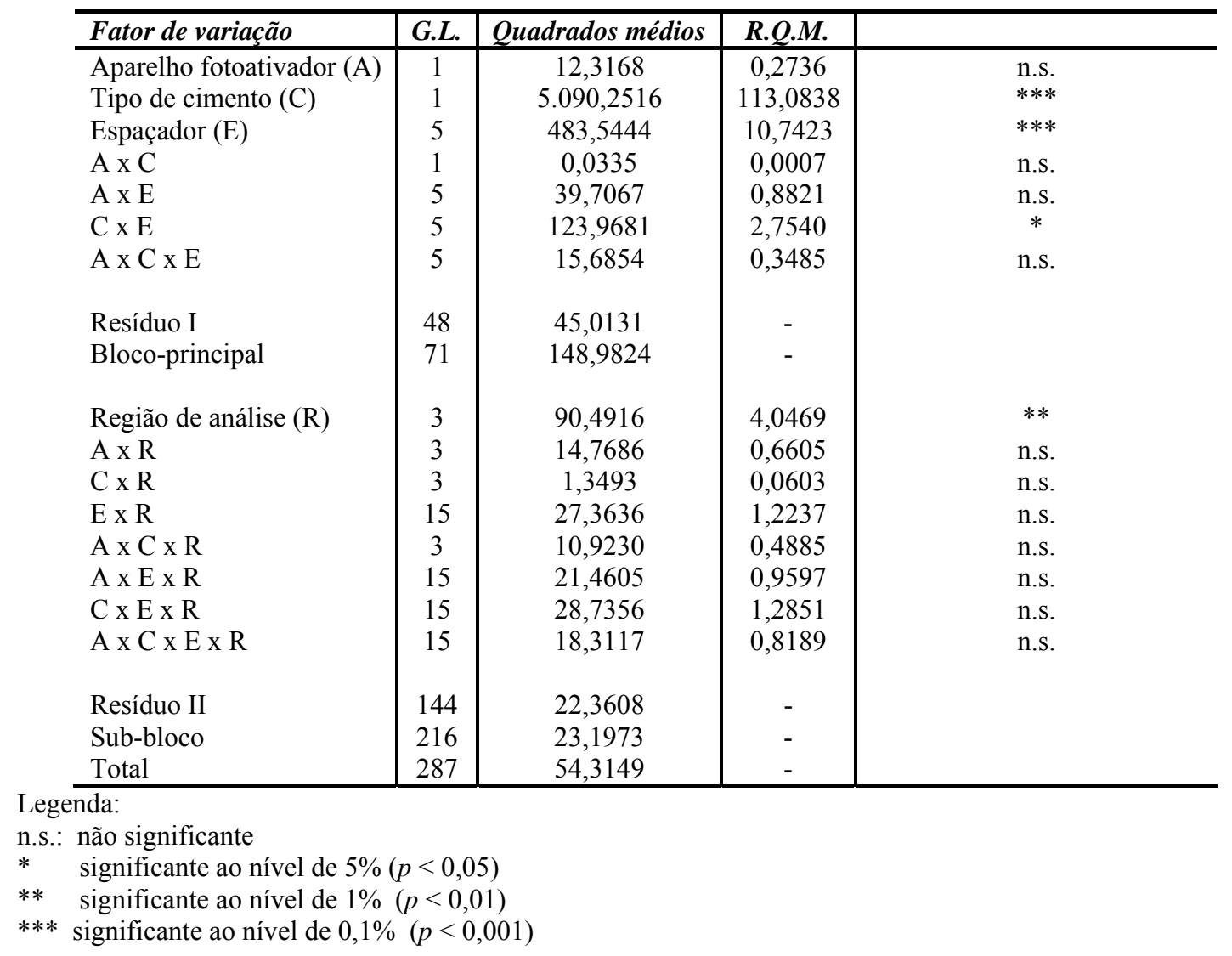

O cimento resinoso com ativação dual (66,3\%) apresentou uma média de 11,3\% maior em relação ao cimento de pasta única fotoativado $(74,8 \%)$. O contraste de Tukey $(p=$ $0,05 ; \Delta=4,07)$ revelou que não houve diferença estatística entre as médias do grupo em que o cimento foi fotopolimerizado a uma distância de $0 \mathrm{~mm}$ da ponta do aparelho $\left(75,8^{\mathrm{a}} \%\right)$ e daquele em que foi deixado um espaço de $2 \mathrm{~mm}$ sem espaçador $\left(72,7^{\mathrm{ab}} \%\right)$. As médias de GC do cimento obtidas com as resinas Sinfony $\left(70,2^{\text {bc }} \%\right)$ e SR Adoro $\left(68,9^{\text {bc }} \%\right.$ ) foram estatisticamente semelhantes entre si e entre o grupo em que foi deixado um espaço de $2 \mathrm{~mm}$ sem espaçador interposto. As médias de GC apresentadas com os grupos de Eris $\left(67,5^{\mathrm{c}} \%\right)$ e Empress $2+$ Eris $\left(68,2^{\mathrm{c}} \%\right)$ foram as menores e estatisticamente semelhantes entre si.

Nas regiões de análise no cp (Tukey ao nível de 5\%; $\Delta=2,05$ ), não houve diferença estatística entre os centros da face irradiada $\left(71,5^{\mathrm{a}} \%\right)$ e da face não-irradiada $\left(71,4^{\mathrm{a}} \%\right)$. Estas 
médias foram semelhantes à obtida pela região de borda do $\mathrm{cp}$ da face não-irradiada $\left(70,3^{\mathrm{ab}}\right.$ \%). E, esta última região apresentou média semelhante à obtida na borda do $\mathrm{cp}$ da face irradiada $\left(69,1^{\mathrm{b}} \%\right)$.

Com relação à interação tipo de cimento e espaçadores (Gráfico 5.5.A), o contraste de Tukey $(p=0,05 ; \Delta=6,66)$ mostrou que a maior média de GC obtida foi quando o cimento dual foi fotopolimerizado com a ponta do aparelho encostada sobre ele $(77,9 \%)$. No entanto, esta média foi estatisticamente semelhante às médias obtidas com todos os outros grupos de espaçadores utilizando o cimento dual e quando o cimento de pasta única foi fotoativado coma ponta do aparelho diretamente sobre ele. Além disso, observa-se, mais uma vez, a superioridade nos resultados ao utilizar a dupla ativação cimento. Todas as médias obtidas com o cimento de pasta única fotoativado através dos materiais restauradores estudados foram semelhantes entre si.

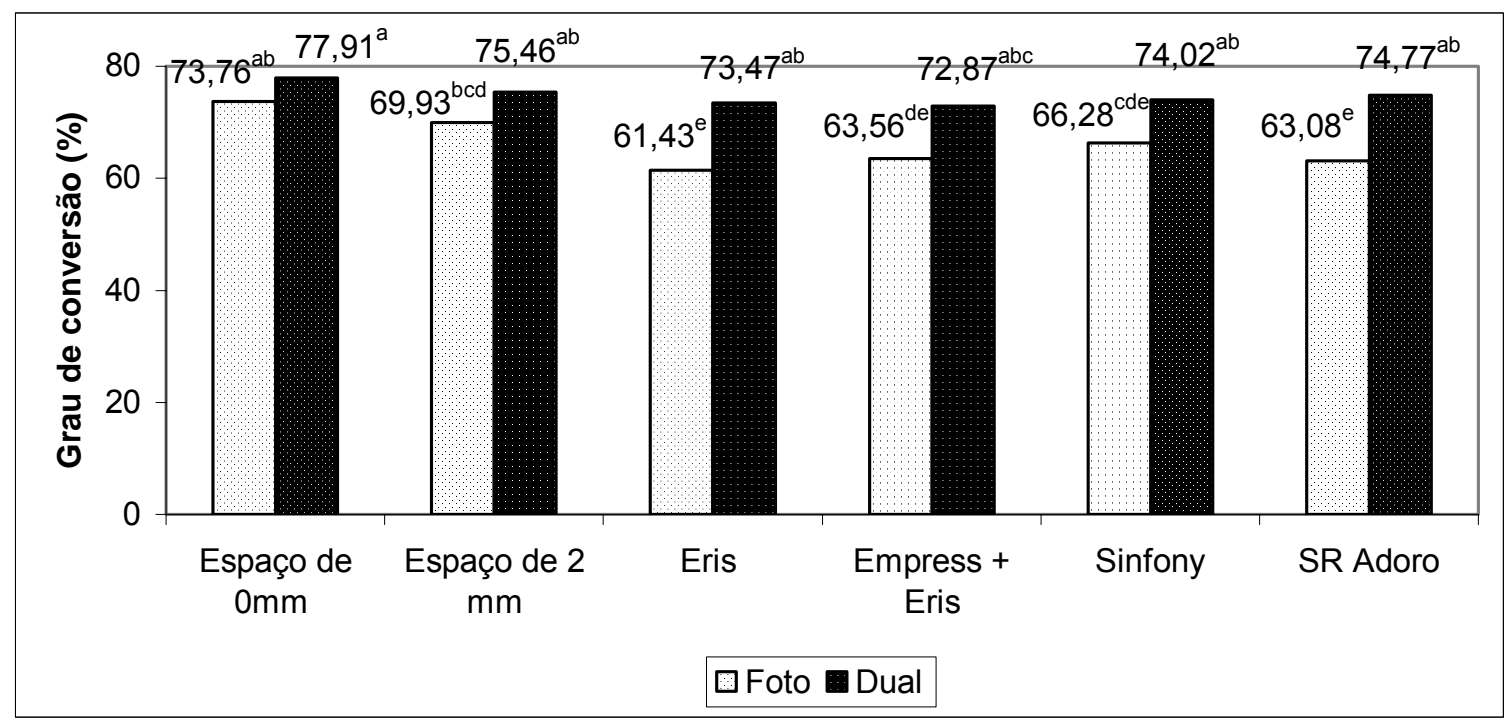

Gráfico 5.5.A - Médias de GC do cimento resinoso quando fotoativado ao aplicar a luz diretamente sobre o cimento, sem nenhum material interposto, deixando 0 e $2 \mathrm{~mm}$ de espaço e através de diferentes materiais restauradores indiretos estéticos, utilizando-se dois tipos de cimento resinoso (foto e dual). Letras diferentes indicam diferença estatística entre os grupos 


\subsection{Correlações e análises de regressão}

$\mathrm{Na}$ análise de correlação entre as médias de TR obtidas pela câmera CCD com os quatro diferentes materiais restauradores indiretos estéticos e as médias de resistência à flexão da interação tipo de cimento e materiais restauradores não indicou correlação tanto para o cimento dual $(r=0,805 ; p=0,48)$ como para o cimento fotoativado de pasta única $(r=0,799$; $p=0,49)$. O mesmo aconteceu para as médias de microdureza nas mesmas condições, tanto para o cimento dual $(r=0,108 ; p=0,44)$, como para o cimento fotoativado de pasta única $(r$ $=0,866 ; p=0,44)$.

Já a análise de correlação entre as mesmas médias de TR obtidas pela câmera CCD com os quatro diferentes materiais restauradores indiretos estéticos e as médias de GC obtidas pela mesma interação indicou uma correlação positiva somente o cimento fotoativado de pasta única $(r=0,997 ; p=0,01)$. A equação do tipo potência foi a que melhor se ajustou para as médias relacionadas ao cimento fotoativado (Gráfico 5.6.A). Não houve correlação com as médias obtidas com o cimento dual $(r=0,113 ; p=0,45)$. 


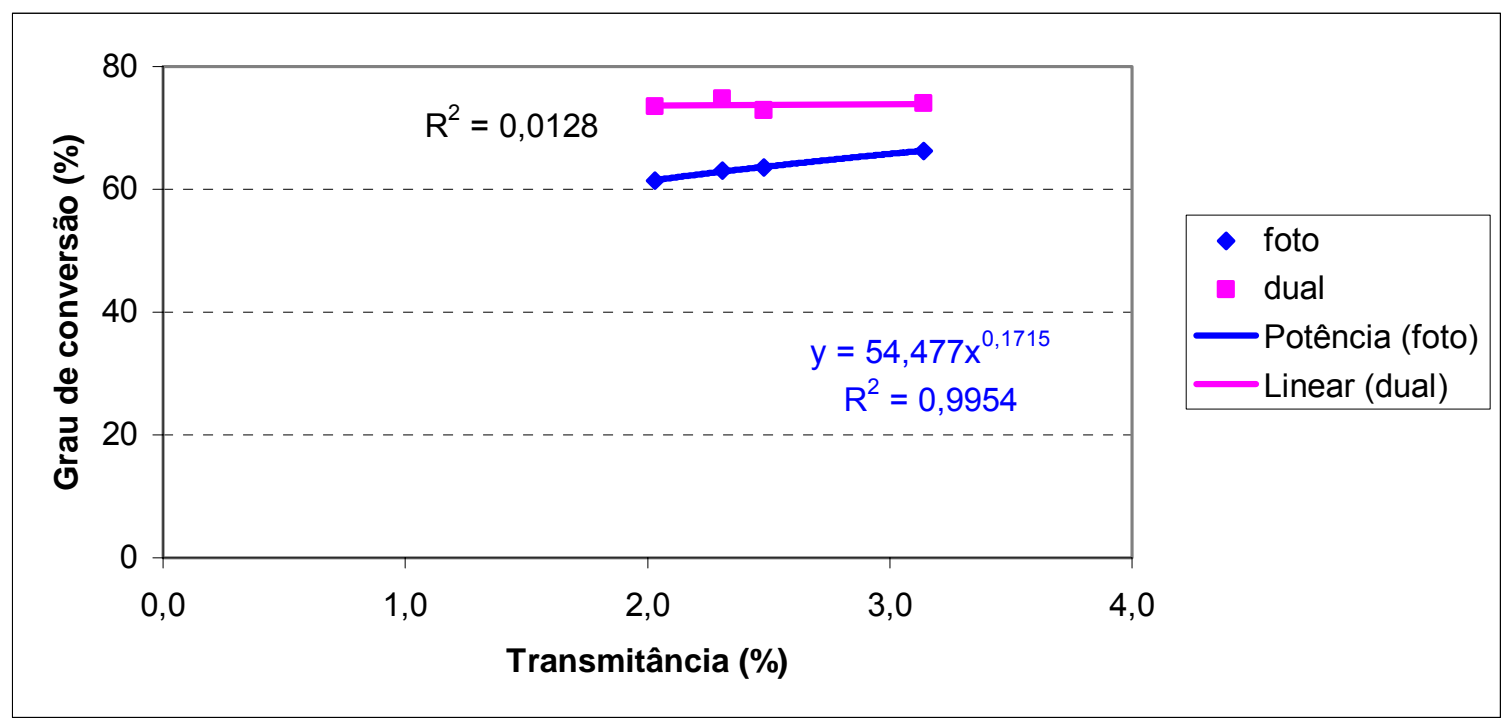

Gráfico 5.6.A - Correlação entre as médias de TR obtidas pela câmera CCD com os quatro diferentes materiais restauradores indiretos estéticos e as médias de GC da interação tipo de cimento e materiais restauradores, contendo a equação da análise de regressão do tipo potência e os valores de $\mathrm{R}^{2}$

A análise de correlação entre as médias de TR obtidas pelo espectrômetro com os quatro diferentes materiais restauradores indiretos estéticos e as médias de resistência à flexão, de microdureza Knoop e de GC obtidas pela interação tipo de cimento e materiais restauradores não indicou nenhuma correlação significativa tanto para o cimento dual como para o cimento fotoativado de pasta única.

Ao calcular o fator de correlação $(r)$ entre todas as médias obtidas com o ensaio de GC e microdureza Knoop, verificou-se que foi igual a 0,698 existindo, assim, uma correlação positiva e significante ao nível de $0,1 \%$ entre as variáveis. $\mathrm{O}$ tipo de equação que melhor se ajustou foi a do tipo potência (Gráfico 5.6.B). 


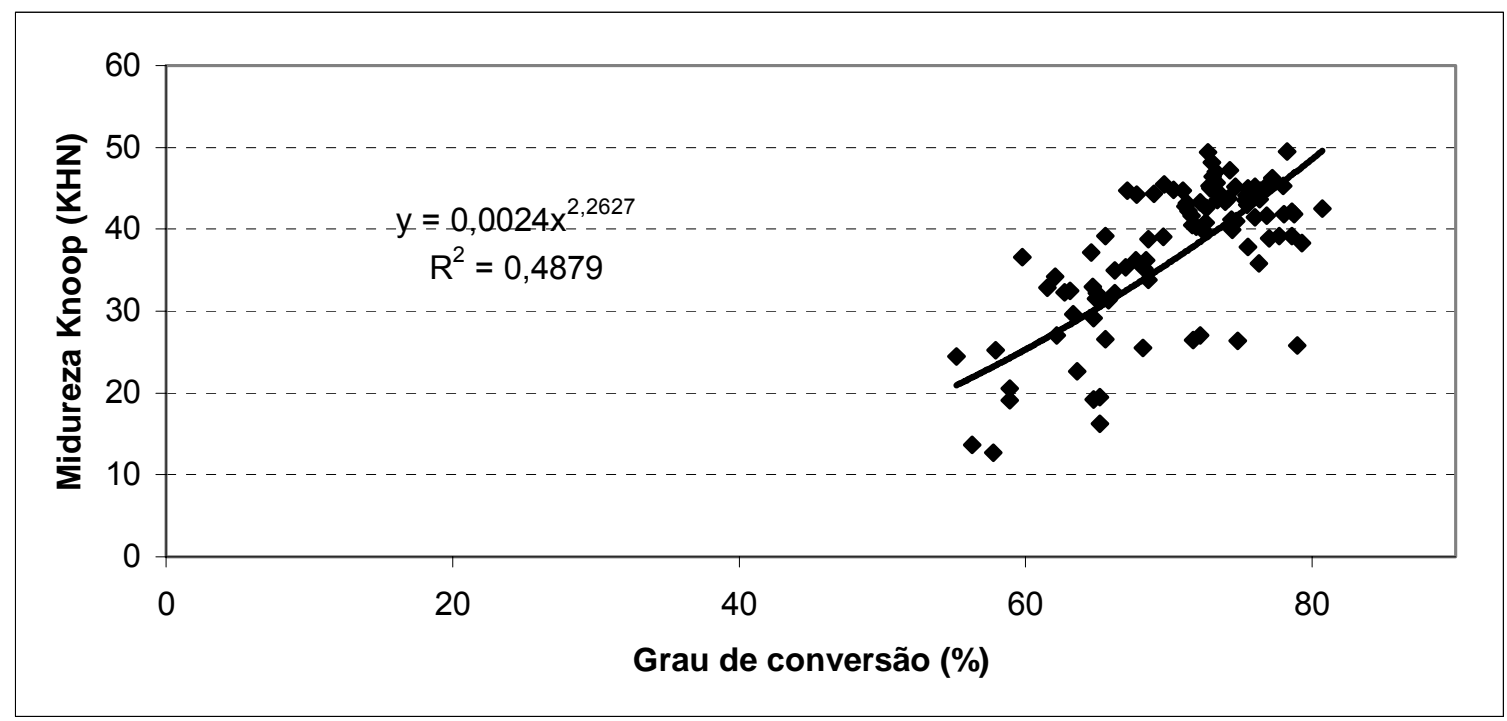

Gráfico 5.6.B - Correlação entre as médias obtidas no ensaio de GC e microdureza Knoop, contendo a equação da análise de regressão do tipo potência e o valor de $\mathrm{R}^{2}$

Houve correlação significativa entre as médias de GC e microdureza obtidas com o QTH $(r=0,760 ; p=0,001)$ e com o $\operatorname{LED}(r=0,636 ; p=0,001)$. A equação de regressão linear foi a que melhor se ajustou às curvas (Gráfico 5.6.C).

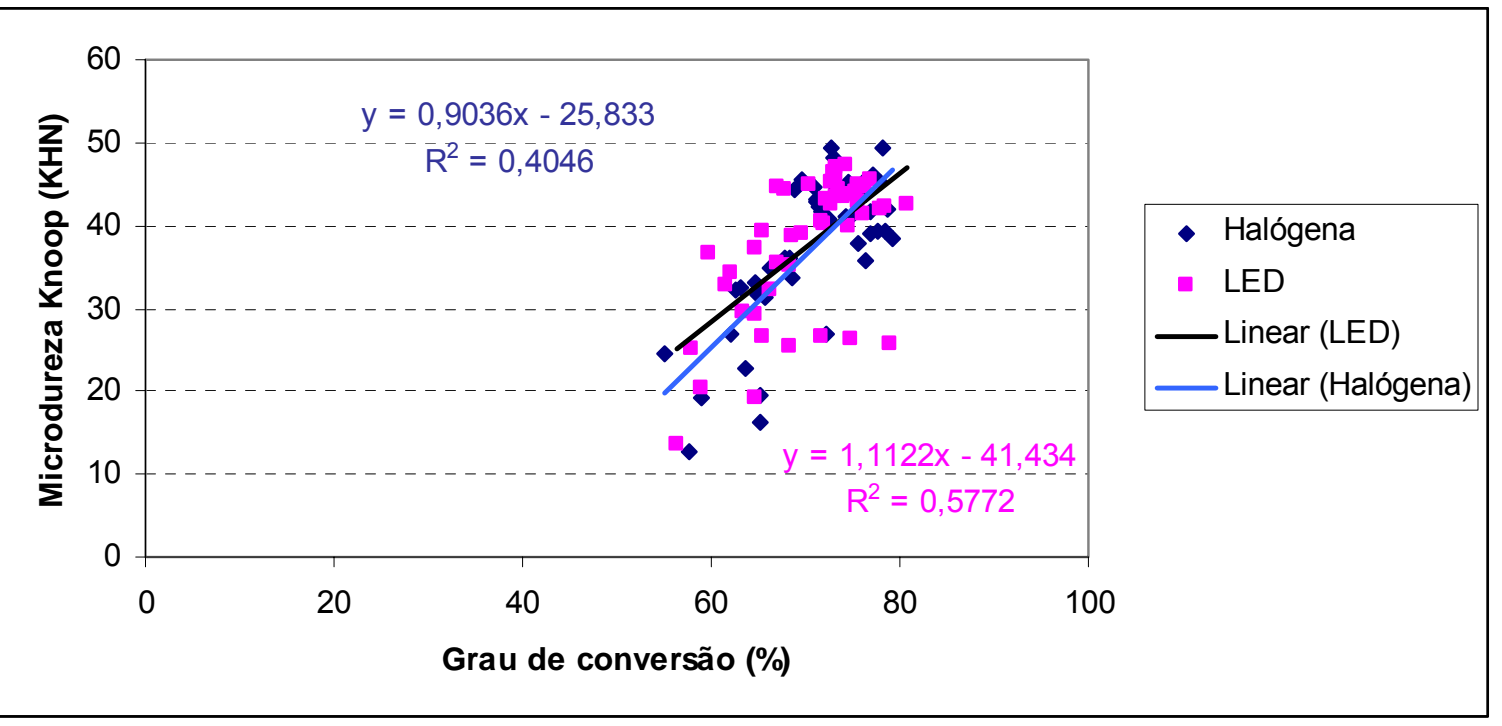

Gráfico 5.6.C - Correlação entre as médias obtidas no ensaio de GC e microdureza Knoop, separando as médias por tipo de aparelho de fotoativação (QTH e LED) contendo as equações de regressão lineares e os valores de $\mathrm{R}^{2}$ 
Com relação ao tipo de cimento, houve somente correlação positiva entre as médias de GC e microdureza obtidas com o cimento fotoativado $(r=0,584 ; p=0,001)$. No entanto, as mesmas médias alcançadas pelo cimento dual não se correlacionaram significativamente $(r=$ $0,584 ; p>0,05)$. A equação que melhor se ajustou à linha de tendência foi a do tipo potência (Gráfico 5.6.D).

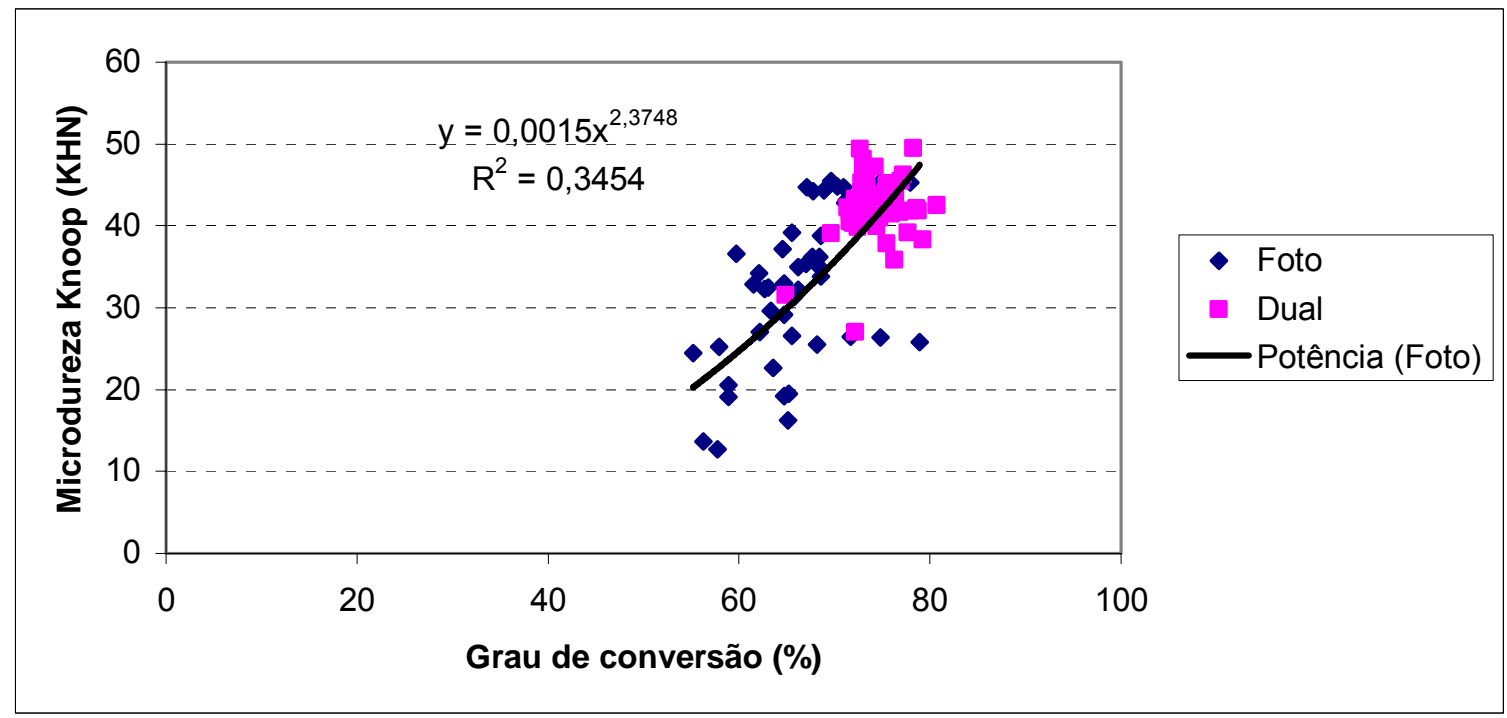

Gráfico 5.6.D - Correlação entre as médias obtidas no ensaio de GC e microdureza Knoop, separando as médias por tipo de cimento (fotoativado e dual) contendo a equação da análise de regressão do tipo potência e o valor de $\mathrm{R}^{2}$ 


\section{DISCUSSÃO}

Comprova-se com esta pesquisa que a polimerização de um cimento resinoso sob um polímero ou uma cerâmica depende de vários fatores, como: transmissão da luz através do material restaurador sobreposto; tipo de fonte de luz; composição e microestrutura do polímero e da cerâmica interposta; sistema de ativação do cimento resinoso a ser polimerizado.

Ao avaliar os resultados de TR fornecidos pela avaliação das imagens obtidas pela câmera CCD e pela espectrometria, a primeira observação é que a última foi a técnica mais sensível em detectar diferenças entre os materiais restauradores indiretos testados. O espectrômetro detectou que a cerâmica Eris apresentou uma TR menor que a resina SR Adoro, porém este valor foi estatisticamente semelhante ao conjunto cerâmico Empress $2+$ Eris. Esta sensibilidade da espectrometria faz com que seja a técnica mais utilizada em pesquisas ${ }^{(14,26,51)}$ que avaliam a transmissão de luz de um material e a correlacionam com comprimento de onda da luz incidente.

O método que utiliza a câmera CCD possui como principal vantagem a possibilidade de se usar o aparelho de fotoativação como a fonte de luz. E, desta maneira, é possível justificar, por exemplo, os resultados obtidos pelo cimento resinoso que foi fotoativado com a luz que atravessou um material interposto. A TR da resina Sinfony, obtida pelos dois ensaios, foi a maior dentre os quatros materiais analisados. Além disso, as médias de microdureza e de resistência à flexão do cimento fotoativado sob esta resina também foram maiores.

A diferença estatística entre as TR das duas resinas testadas, detectadas por ambos os métodos, pode estar correlacionada ao comprimento de onda da luz incidente e ao tamanho 
médio das partículas do material restaurador, pois o espalhamento máximo da luz ocorre quando o tamanho das partículas é a metade do comprimento de onda da luz incidente ${ }^{(26,32)}$. Assim, o maior espalhamento de luz e opacidade da resina SR Adoro em relação à Sinfony foram devidos à relação entre o tamanho das partículas da primeira resina e o comprimento de onda emitido pelos aparelhos de fotoativação. As partículas da SR Adoro possuem um tamanho médio de em torno de $0,05 \mu \mathrm{m}$, porém se aglomeram, e atingem um tamanho médio de $0,24 \mu \mathrm{m}{ }^{(53)}$, o que corresponde aproximadamente à metade do comprimento de onda dos picos de irradiância emitido pelos aparelhos de fotoativação QTH $(0,492 \mu \mathrm{m})$ e LED $(0,452$ $\mu \mathrm{m})$.

Com relação às cerâmicas, apesar da TR da Eris e do conjunto Empress 2 + Eris, obtida pelos dois métodos, não serem estatisticamente diferentes entre si, há uma tendência da cerâmica isoladamente transmitir menos luz do que o conjunto. Esta tendência ocorreu, pois o cimento resinoso que foi fotoativado sobre o disco de cerâmica Eris apresentou uma menor resistência à flexão, independentemente do sistema de ativação, e uma menor dureza quando analisado o cimento de pasta única.

Para entender este resultado é necessário conhecer a microestrutura e as propriedades óticas destes materiais. A vitrocerâmica Eris é um material de recobrimento que contém uma fase cristalina de apatita, representada pela fluorapatita $\left(\mathrm{Ca}_{5}\left(\mathrm{PO}_{4}\right)_{3} \mathrm{~F}\right)$, em uma matriz vítrea de silicato de zinco alcalino transparente. É a primeira vitrocerâmica translúcida a base de cristais de apatita com formato de agulha (Figura 6.A). Estes cristais medem de 0,03 a $3 \mu \mathrm{m}$ de comprimento ${ }^{(50)}$. A razão de contraste $(\mathrm{RC})$, que indica o grau de translucidez deste material é de $0,584^{(49)}$. 


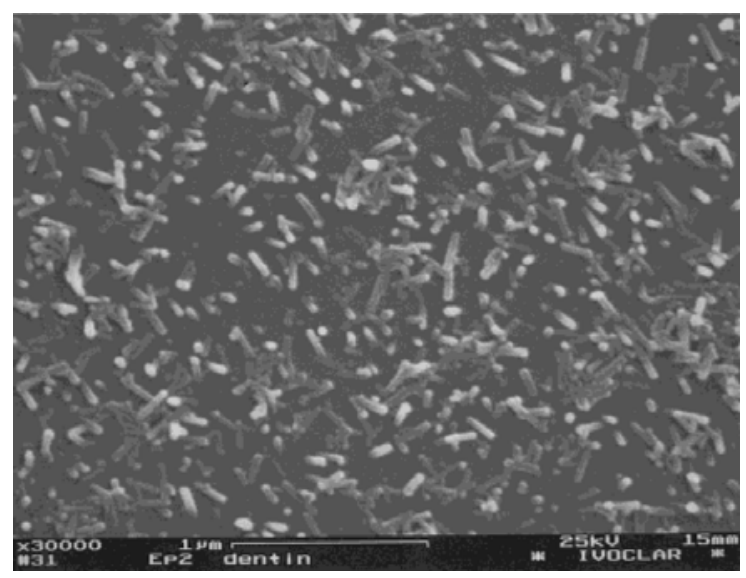

Figura 6.A - Microestrutura da vitrocerâmica Eris demonstrando os cristais de fluorapatita em forma de agulha $^{(50)}$

Já a cerâmica Empress 2 é uma vitrocerâmica reforçada por dissilicato de lítio $\left(\mathrm{Li}_{2} \mathrm{Si}_{2} \mathrm{O}_{5}\right)$ e pode ser utilizada como infra-estrutura de coroas e prótese fixas de até três elementos. Os cristais de dissilicato de lítio são alongados, apresentam de 0,5 a $4 \mu \mathrm{m}$ de comprimento e representam a sua fase cristalina principal (Figura 6.B). A fase cristalina secundária possui um conteúdo volumétrico menor e é representada pelo ortofosfato de lítio $\left(\mathrm{Li}_{2} \mathrm{PO}_{4}\right)$. Os cristais desta fase apresentam um diâmetro de 0,1 a $0,3 \mu \mathrm{m}$, estão localizados na matriz e na superfície dos cristais de dissilicato de lítio. Após a queima e a injeção sob pressão dos lingotes, a microestrutura do dissilicato de lítio é a mesma dos lingotes originais. O conteúdo de dissilicato de lítio nesta vitrocerâmica é de $70 \pm 5$ vol\%, sendo o RC do dissilicato de lítio é de $0,55^{(50)}$. 


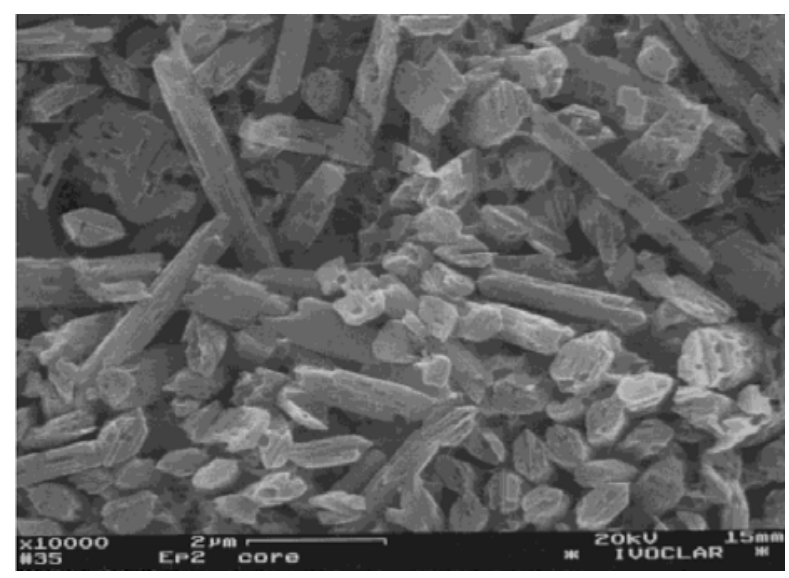

Figura 6.B - Microestrutura da cerâmica Empress 2, envidenciando os cristais alongados de dissilicato de lítio ${ }^{(50)}$

A cerâmica de recobrimento do Empress 2 é a vitrocerâmica Eris. Durante o processamento destes materiais, a superfície do Empress 2 é limpa e jateada. Após a queima da cerâmica de recobrimento, há um perfeito contato entre os materiais, que diminui a refletância de luz na interface (Figura 6.C). Após a aplicação da cerâmica Eris sobre a infraestrutura de Empress 2, a RC é alterada para $0,46^{(50)}$.

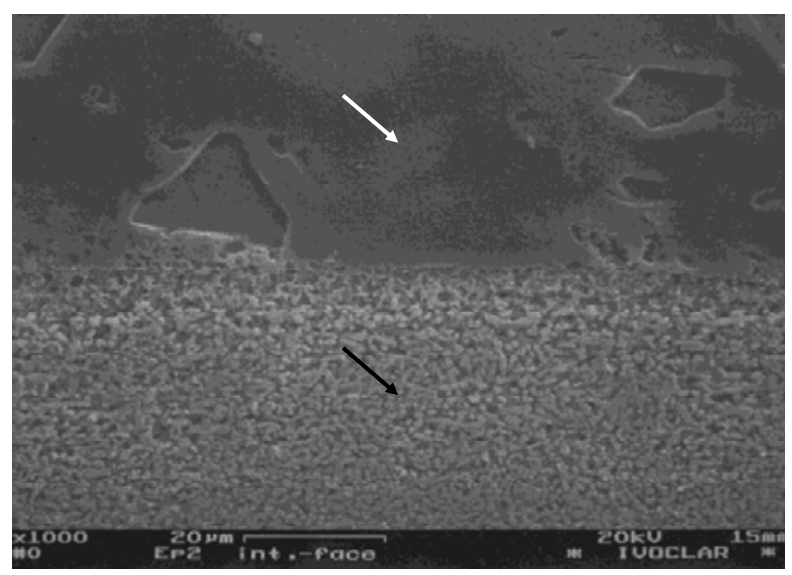

Figura 6.C - Interface entre as cerâmicas Eris (seta branca) e Empress 2 (seta preta) ${ }^{(50)}$

A partir destas informações e do que foi exposto no capítulo de Revisão de Literatura, quanto mais próximo o valor de RC for de uma unidade, mais opaco será o material. Logo, a 
cerâmica Eris $(\mathrm{RC}=0,58)$ possui uma tendência em ser mais opaca em relação ao conjunto Empress $2+$ Eris $(\mathrm{RC}=0,46)$. Isto explicaria o fato do cimento fotoativado sob a Eris ter apresentado propriedades mecânicas inferiores.

De forma geral, os resultados de TR obtidos pelos dois ensaios indicaram que as resinas transmitiram mais luz do que as cerâmicas. Isto está de acordo com os resultados de uma pesquisa prévia ${ }^{(38)}$ em que os autores analisaram a microdureza Knoop de três cimentos resinosos fotoativados através de espaçadores de resina composta e de porcelana. Dois dos cimentos analisados apresentaram valores de dureza inferiores ao serem fotoativados através de espaçadores de porcelana até $2 \mathrm{~mm}$ de espessura em comparação com espaçadores de resina com a mesma espessura. No entanto, quando a espessura dos espaçadores aumenta, os resultados se invertem: os valores de dureza são maiores para os espaçadores de porcelana ${ }^{(38)}$. Além dos diferentes tipos de materiais restauradores, um outro fator que influenciou a TR foi o tipo de aparelho de fotoativação. O aparelho que transmitiu mais luz foi o LED. Isto está relacionado ao fato do LED apresentar uma irradiância total maior $\left(1000,8 \mathrm{~mW} / \mathrm{cm}^{2}\right)$ que o QTH $\left(739,6 \mathrm{~mW} / \mathrm{cm}^{2}\right)$. Porém, a tendência de se transmitir mais luz e aumentar as propriedades mecânicas do cimento resinoso só foi constatada ao analisar a microdureza do cimento quando fotoativado através do conjunto cerâmico Empress $2+$ Eris. Este resultado era o esperado, pois a análise da emissão espectral dos aparelhos estudados mostrou que o LED emitiu uma irradiância maior $\left(277,1 \mathrm{~mW} / \mathrm{cm}^{2}\right)$ em relação ao QTH $\left(175,6 \mathrm{~mW} / \mathrm{cm}^{2}\right)$ na faixa de comprimentos de onda correspondente à absorção da CQ (460 a $470 \mathrm{~nm})$.

No entanto, esta tendência não foi verificada ao analisar a microdureza do cimento com os outros materiais restauradores interpostos, pois não houve diferença estatística entre os aparelhos de fotoativação. Já ao analisar a resistência à flexão do cimento, os maiores valores foram obtidos com o aparelho QTH. Provavelmente estes resultados foram 
influenciados pelo tipo de cadeia polimérica formada ou pela densidade de ligações duplas remanescentes.

Com relação aos valores de GC, a análise de variância não detectou diferenças significativas entre os aparelhos de fotoativação e nem entre a maioria das interações obtidas. Contudo, quando do tratamento estatístico dos dados de microdureza as diferenças foram significativas para os fatores principais e quase todas as interações. Esta diferença na sensibilidade dos ensaios laboratoriais também foi detectada em um trabalho prévio ${ }^{(71)}$, que revelou que o espectroscópio Raman é mais sensível para detectar pequenas diferenças nos estágios iniciais da reação de polimerização, enquanto, que a microdureza é mais sensível depois que a cadeia polimérica já está formada, isto é, nos estágios finais do processo de polimerização.

A média de microdureza do cimento resinoso Nexus 2 obtida da interação aparelho QTH, disco de Empress 2 + Eris e sistema de dupla ativação do cimento (33,5 KHN) foi semelhante à média obtida pelo mesmo cimento testado em condições similares $(31,7 \mathrm{KHN})$ em uma pesquisa recente ${ }^{(25)}$.

Já os valores de GC apresentados nesta pesquisa foram maiores do que os valores que se obtém normalmente para resinas compostas de uso direto, os quais variam entre 50 e $60 \%$ $(31,72)$. Isto pode estar relacionado à baixa viscosidade inicial do cimento resinoso quando comparado aos compósitos restauradores diretos. A diminuição da viscosidade pode permitir uma maior difusão dos radicais livres durante a reação de polimerização a assim proporcionar um alto potencial de conversão ${ }^{(57)}$.

Outro fato interessante ocorreu ao analisar os resultados de GC, resistência à flexão e microdureza dos grupos em que foi deixado um espaço de zero e dois mm entre a ponta do fotoativador e a superfície do cimento. Na distância zero, a irradiância foi maior que no grupo de $2 \mathrm{~mm}$, logo o seu GC também foi maior. E, esta relação está de acordo com estudos 
prévios $(46,72,73)$. No entanto, ocorreu uma diminuição da sua resistência à flexão e microdureza em relação ao grupo que foi deixado $2 \mathrm{~mm}$ de espaço.

Com relação às médias de resistência à flexão, os resultados estão de acordo com os resultados de outra pesquisa ${ }^{(74)}$, na qual os autores verificaram que conforme aumentava o GC dos espécimes de resina composta, os valores de resistência à flexão, em um primeiro estágio, também aumentavam (relação linear), mas em um determinado momento, a resistência dos espécimes atingia um platô e, logo em seguida, começava a diminuir com o aumento do GC. Este resultado indica que ao atingir um valor de GC específico, a resistência do material não consegue mais aumentar e até declina devido ao aumento da sua friabilidade (74). Em outro trabalho ${ }^{(46)}$, o GC também aumentou e a resistência à flexão diminuiu ao aplicar uma irradiância alta $\left(800 \mathrm{~mW} / \mathrm{cm}^{2}\right)$ em uma resina composta, quando comparados com uma irradiância baixa $\left(400 \mathrm{~mW} / \mathrm{cm}^{2}\right)$, ambos com o mesmo tempo de exposição (10 s).

Já os resultados de microdureza podem ser comparados com os valores de microdureza de resinas compostas que foram fotoativadas por QTH convencionais (irradiância moderada) e PAC (irradiância alta). Nestes estudos ${ }^{(75,76)}$, as resinas que foram fotoativadas com PAC obtiveram valores de dureza inferiores, da mesma forma que na presente pesquisa, onde os cps expostos a uma maior irradiância (espaço de $0 \mathrm{~mm}$ ) apresentaram valores inferiores de dureza em relação ao grupo que foi deixado um espaço 2 mm. Este fato está relacionado à alta velocidade de polimerização que leva a uma redução no tamanho das cadeias poliméricas, que diminui a dureza do material ${ }^{(76)}$.

Esta diminuição da dureza e da resistência à flexão acontece tanto para uma irradiância alta, conforme foi discutido acima, como para uma irradiância baixa, que ocorre quando um material restaurador com alto grau de opacidade é interposto entre o aparelho de fotoativação e o cimento resinoso. Para estas situações, a dupla ativação do cimento resinoso foi desenvolvida, pois combina as propriedades mais desejáveis dos materiais quimicamente 
ativados e dos fotoativados, e, desta forma, o cimento atinge uma polimerização satisfatória em áreas onde a luz não alcança, além de reduzir a zona de inibição pelo oxigênio e o tempo de polimerização. Assim, a parte de ativação química de um sistema dual deve ser efetiva para compensar o déficit de luz ${ }^{(61)}$.

A continuação da indução química na polimerização depois da fotoativação é difícil de se obter. A exposição inicial à luz causa um aumento rápido na conversão da resina que resulta em um gel muito viscoso. Este aumento rápido na viscosidade impede a migração dos radicais livres que seriam responsáveis pela indução química na polimerização. Portanto, a duração da inibição e o nível da conversão inicial causado pela fotoativação são fatores preponderantes na polimerização final de cimentos duais. Desta maneira, torna-se um desafio aos fabricantes elaborar a composição química destes materiais. Por um lado, um pequeno atraso na reação química é desejado para que se tenha um tempo de trabalho suficiente. Logo, maiores quantidades de inibidores seriam necessárias. Mas, por outro lado, estes inibidores podem interferir na fotoiniciação durante a polimerização. Além disso, grandes quantidades de iniciadores químicos não podem ser adicionadas, pois reduziriam o período de validade destas resinas ${ }^{(28)}$.

$\mathrm{Na}$ presente pesquisa, todos os ensaios laboratoriais aplicados e todas as interações envolvendo o tipo de cimento, indicaram a superioridade das propriedades mecânicas e do GC do cimento resinoso dual em relação ao cimento fotoativado (pasta base). Este resultado mostra que a proporção de iniciador químico e inibidores presentes no cimento Nexus 2 é apropriada e realmente induz a reação de polimerização em regiões onde há déficit de luz, quando comparado com os resultados dos grupos em que não foi colocado material restaurador interposto. Além disso, os resultados desta pesquisa estão de acordo com os resultados de vários estudos ${ }^{(10-12,27,57,77)}$. Portanto, quando somente a pasta base do cimento 
resinoso é fotoativada através de materiais restauradores indiretos estéticos, a atenuação da luz causa uma redução nas suas propriedades físicas.

Para reforçar este fato, estudos mostram que os cimentos resinosos duais que foram somente quimicamente ativados não atingiram as propriedades físicas máximas e isto está relacionado à quantidade de iniciador químico presente na composição do cimento ${ }^{(21,28,38,58,}$ 61).

Esta comparação entre cimentos fotoativados, duais e quimicamente ativados deve ser realizada entre espécimes de materiais com composições semelhantes (tipo de monômero, tipo de partículas inorgânicas e volume de carga) ${ }^{(12)}$. Cimentos duais são apresentados em duas pastas e os cimentos fotoativados em uma única pasta, isto faz com que o volume de carga inorgânica seja diferente e pode mascarar os resultados obtidos. Assim, os resultados de microdureza não podem ser usados para ilustrar o GC de espécimes de cimento fotoativado quando comparado com espécimes de cimento dual de um mesmo produto, pois diferenças no GC podem não ser necessariamente diferenças nas propriedades mecânicas ${ }^{(12)}$. Contudo, os valores de GC obtidos pelo método FT-Raman, que é um método direto e não depende da composição do material, confirmam que a superioridade das propriedades mecânicas dos espécimes de cimento confeccionados com o sistema de ativação dual.

Como o comprimento do cp permitiu que toda a extremidade da ponta do aparelho de fotoativação o recobrisse durante a fotoativação do cimento, pôde-se verificar a distribuição não-uniforme da luz, mesmo com o material restaurador interposto, resultando médias de dureza inferiores na face não-irradiada e nas bordas do cp. No entanto, estas evidências só são válidas para o cimento de pasta única (fotoativado). Os resultados com o cimento dual indicam que o componente de ativação química complementou a polimerização do cimento em locais onde havia um déficit de luz. 
A importância de se mapear as regiões do cp, apesar de possuir uma espessura quarenta vezes maior que a espessura desejada para a linha de cimentação $(25 \mu \mathrm{m}){ }^{(9)}$, é alertar o clínico a realizar múltiplas fotoativações com diferentes direções durante a cimentação de uma peça protética com um cimento de pasta única (fotoativado), visto a diferença na dureza obtida no centro e nas bordas do cp.

Um valor de dureza para a face não-irradiada entre 80 a 90\% do valor de dureza obtido na face irradiada do cp é um valor de profundidade de polimerização cientificamente aceitável (53). Ao calcular as médias da dureza obtidas nas faces irradiadas (34,7 KHN) e não-irradiadas (30,7 KHN) dos espécimes confeccionados com a somente a pasta base do cimento, verificase que, apesar das diferenças estatísticas apresentadas, o valor de dureza da face não-irradiada é $88,6 \%$ da face irradiada. Apresentando-se, portanto, uma boa profundidade de polimerização.

Ao delinear esta pesquisa, além do cuidado em se obter um cp que pudesse fornecer informações importantes quanto à distribuição e transmissão de luz, o armazenamento destes também foi discutido para que não interferisse. Desta forma, a água destilada foi selecionada, pois além do cimento resinoso ser clinicamente exposto à saliva após a cimentação de uma peça protética, os resultados de uma pesquisa prévia ${ }^{(78)}$ mostraram que não há diferenças entre a microdureza apresentada pelo cimento Nexus 2 (sistema de ativação dupla) quando armazenado a seco ou em água destilada por 24 h. Os mesmos autores apontam que a água destilada pode servir como barreira contra o ar, já que o oxigênio inibe a reação de polimerização dos cimentos resinosos ${ }^{(78)}$, e, desta forma, se elimina um fator que poderá modificar os resultados inerentes à polimerização do material.

Já, com relação ao tempo de armazenamento dos cps, foi verificada que a microdureza Knoop do cimento Nexus 2 dual fotoativado através de blocos de cerâmicas de $2 \mathrm{~mm}$ de espessura permaneceu inalterada a partir de 30 minutos até 120 horas após a irradiação ${ }^{(25)}$. 
Devido a este resultado, foi optado um tempo de armazenamento de 24 horas para os cps da presente pesquisa.

Até esta parte da discussão foram analisados os resultados das propriedades dos materiais restauradores, do cimento resinoso, dos aparelhos de fotoativação isoladamente e o delineamento experimental da pesquisa, no entanto, correlações entre estas propriedades permitiram um refinamento das conclusões.

A análise de correlação entre as médias de TR dos materiais restauradores, obtidas pela câmera CCD e pelo espectrômetro, e as propriedades mecânicas (resistência à flexão e microdureza) do cimento não foi estatisticamente significante, provavelmente, devido ao fato de se possuir uma amostragem com poucas médias correlacionadas (grau de liberdade igual a 2). Em contrapartida, a análise de correlação entre as médias de TR obtidas pela câmera CCD com os quatro materiais restauradores indiretos e as médias de GC obtidas pela interação entre materiais restauradores e cimento de pasta única foi significante e positiva. Portanto, se o grau de conversão do cimento aumenta com a maior quantidade de luz que o atinge, se as propriedades mecânicas do cimento, quando analisadas isoladamente, aumentam com a interposição dos materiais mais translúcidos e se estas relações só são constadas para o cimento de pasta única, está comprovada a necessidade de se utilizar um cimento de ativação dupla.

Com relação à correlação entre as médias de microdureza e de GC, um estudo clássico já havia comprovado uma correlação linear em resinas compostas sem carga inorgânica ${ }^{(64)}$, agora os resultados do presente estudo também confirmam esta relação para os cimentos resinosos. Porém, a linearidade só foi observada ao analisar as médias obtidas pelos aparelhos de fotoativação separadamente. A linha de tendência do tipo potência foi a que se melhor ajustou para os outros casos. 
A partir das informações que foram expostas, fica evidente a atenuação da luz causada pelos materiais restauradores, a necessidade de se utilizar um cimento resinoso com sistema de dupla ativação e as diferenças significantes entre os aparelhos QTH e LED na reação de polimerização. Além disso, a correlação de diferentes ensaios numa mesma pesquisa foi uma contribuição importante no presente estudo. 


\section{CONCLUSÕES}

Com base nos resultados deste estudo concluiu-se que:

I. O ensaio mais sensível para detectar diferenças entre TR dos materiais restauradores indiretos foi a espectrometria, diante disto:

- a maior TR foi obtida pela resina Sinfony;

- a cerâmica Eris e o conjunto Empress 2 + Eris foram os materiais que transmitiram menos luz;

- os valores de TR aumentaram com o comprimento de onda incidente;

- O LED foi o aparelho que mais transmitiu luz, provavelmente devido a sua maior irradiância.

II. A emissão espectral com os valores de irradiância relativa e absoluta dos aparelhos de fotoativação mostrou que o LED emite uma faixa de comprimento de onda mais estreita do que o aparelho QTH no espectro de luz visível e com isso concentra uma maior energia na faixa de comprimento de onda correspondente à absorção da CQ.

III. A interposição dos materiais restauradores interferiu nas propriedades físicas analisadas, no entanto, os ensaios de resistência à flexão e microdureza Knoop foram os mais sensíveis para detectar diferenças entre os materiais. Sendo assim:

- a atenuação da luz causada pela cerâmica Eris diminuiu significativamente a resistência à flexão do cimento resinoso de pasta única;

- a microdureza Knoop e o GC do cimento resinoso foram significativamente diminuídos pelo espalhamento da luz causado pela interposição da cerâmica Eris e do conjunto Empress $2+$ Eris; 
- os maiores valores de resistência à flexão foram obtidos pelo aparelho QTH;

- o LED promoveu valores de dureza superiores ao cimento resinoso quando fotoativado através do conjunto Empress 2 + Eris;

- não houve diferença estatística entre os valores de GC obtidos pelos aparelhos de fotoativação;

- os resultados de microdureza mostraram que houve uma distribuição não-uniforme da luz após atravessar o material restaurador, resultando em áreas de maior e menor dureza em um mesmo espécime;

- o sistema de ativação dual promoveu sempre melhores propriedades físicas ao cimento resinoso quando comparado ao sistema fotoativado.

IV. A(s) análise(s) de correlação:

- entre as médias de TR e das propriedades físicas do cimento foram nulas na maioria dos casos, provavelmente este fato está relacionado a uma amostragem com poucas médias;

- significante ocorreu somente entre as médias de TR obtidas pela análise das imagens fornecidas pela câmera $\mathrm{CCD}$ e GC dos espécimes de cimento de pasta única (fotoativado);

- entre as médias de microdureza Knoop e GC do cimento resinoso foi estatisticamente significante;

- mostraram uma tendência na qual os materiais restauradores que transmitirem mais luz ao cimento resinoso, principalmente o de pasta única (fotoativado), lhe proporcionará melhores condições para uma reação de polimerização mais eficiente e,consequentemente, propriedades físicas desejáveis. 


\section{REFERÊNCIAS ${ }^{1}$}

1. Akgungor G, Akkayan B, Gaucher H. Influence of ceramic thickness and polymerization mode of a resin luting agent on early bond strength and durability with a lithium disilicate-based ceramic system. J Prosthet Dent 2005;94(3):234-41.

2. da Silveira BL, Paglia A, Burnett LH, Shinkai RS, Eduardo Cde P, Spohr AM. Microtensile bond strength between a resin cement and an aluminous ceramic treated with Nd:YAG laser, Rocatec System, or aluminum oxide sandblasting. Photomed Laser Surg 2005;23(6):543-8.

3. Attia A, Kern M. Influence of cyclic loading and luting agents on the fracture load of two all-ceramic crown systems. J Prosthet Dent 2004;92(6):551-6.

4. da Silva SB, Hilgert LA, Busato AL. Fracture resistance of resin-based composite and ceramic inlays luted to sound human teeth. Am J Dent 2004;17(6):404-6.

5. Komine F, Tomic M, Gerds T, Strub JR. Influence of different adhesive resin cements on the fracture strength of aluminum oxide ceramic posterior crowns. J Prosthet Dent 2004;92(4):359-64.

6. Fleming GJ, Maguire FR, Bhamra G, Burke FM, Marquis PM. The strengthening mechanism of resin cements on porcelain surfaces. J Dent Res 2006;85(3):272-6.

7. Rosenstiel SF, Land MF, Crispin BJ. Dental luting agents: A review of the current literature. J Prosthet Dent 1998;80(3):280-301.

8. Li ZC, White SN. Mechanical properties of dental luting cements. J Prosthet Dent 1999;81(5):597-609.

9. Anusavice KJ. Phillips, materiais dentários. 11st ed. Rio de Janeiro: Elsevier; 2005.

\footnotetext{
${ }^{1}$ De acordo com estilo Vancouver. Abreviatura de periódicos segundo base de dados MEDLINE.
} 
10. Hofmann N, Papsthart G, Hugo B, Klaiber B. Comparison of photo-activation versus chemical or dual-curing of resin-based luting cements regarding flexural strength, modulus and surface hardness. J Oral Rehabil 2001;28(11):1022-8.

11. Jung H, Friedl KH, Hiller KA, Haller A, Schmalz G. Curing efficiency of different polymerization methods through ceramic restorations. Clin Oral Investig 2001;5(3):156-61.

12. Lu H, Mehmood A, Chow A, Powers JM. Influence of polymerization mode on flexural properties of esthetic resin luting agents. J Prosthet Dent 2005;94(6):549-54.

13. McCabe JF, Walls AWG. Applied Dental Materials. 8 ed. Cambridge: Blackwell Science; 1998.

14. O'Keefe KL, Pease PL, Herrin HK. Variables affecting the spectral transmittance of light through porcelain veneer samples. J Prosthet Dent 1991;66(4):434-8.

15. Barghi N, McAlister EH. LED and halogen lights: effect of ceramic thickness and shade on curing luting resin. Compend Contin Educ Dent 2003;24(7):497-500, 502, 504 passim; quiz 508.

16. Kumbuloglu O, Lassila LV, User A, Vallittu PK. A study of the physical and chemical properties of four resin composite luting cements. Int J Prosthodont 2004;17(3):35763.

17. Nalcaci A, Kucukesmen C, Uludag B. Effect of high-powered LED polymerization on the shear bond strength of a light-polymerized resin luting agent to ceramic and dentin. J Prosthet Dent 2005;94(2):140-5.

18. Rasetto FH, Driscoll CF, Prestipino V, Masri R, von Fraunhofer JA. Light transmission through all-ceramic dental materials: a pilot study. J Prosthet Dent 2004;91(5):441-6.

19. Cardash HS, Baharav H, Pilo R, Ben-Amar A. The effect of porcelain color on the hardness of luting composite resin cement. J Prosthet Dent 1993;69(6):620-3.

20. El-Mowafy OM, Rubo MH. Influence of composite inlay/onlay thickness on hardening of dual-cured resin cements. J Can Dent Assoc 2000;66(3):147. 
21. el-Mowafy OM, Rubo MH, el-Badrawy WA. Hardening of new resin cements cured through a ceramic inlay. Oper Dent 1999;24(1):38-44.

22. Blackman R, Barghi N, Duke E. Influence of ceramic thickness on the polymerization of light-cured resin cement. J Prosthet Dent 1990;63(3):295-300.

23. Ozyesil AG, Usumez A, Gunduz B. The efficiency of different light sources to polymerize composite beneath a simulated ceramic restoration. J Prosthet Dent 2004;91(2):151-7.

24. Uctasli S, Hasanreisoglu U, Wilson HJ. The attenuation of radiation by porcelain and its effect on polymerization of resin cements. J Oral Rehabil 1994;21(5):565-75.

25. Meng X, Yoshida K, Atsuta M. Hardness development of dual-cured resin cements through different thicknesses of ceramics. Dent Mater J 2006;25(1):132-7.

26. Arikawa H, Fujii K, Kanie T, Inoue K. Light transmittance characteristics of lightcured composite resins. Dent Mater 1998;14(6):405-11.

27. Linden JJ, Swift EJ, Jr., Boyer DB, Davis BK. Photo-activation of resin cements through porcelain veneers. J Dent Res 1991;70(2):154-7.

28. Rueggeberg FA, Caughman WF. The influence of light exposure on polymerization of dual-cure resin cements. Oper Dent 1993;18(2):48-55.

29. Rueggeberg FA, Craig RG. Correlation of parameters used to estimate monomer conversion in a light-cured composite. J Dent Res 1988;67(6):932-7.

30. Park SH, Kim SS, Cho YS, Lee CK, Noh BD. Curing units' ability to cure restorative composites and dual-cured composite cements under composite overlay. Oper Dent 2004;29(6):627-35.

31. Santos GB, Medeiros IS, Fellows CE, Muench A, Braga RR. Composite depth of cure obtained with QTH and LED units assessed by microhardness and micro-Raman spectroscopy. Operative Dentistry 2007;31(1):79-83.

32. Brodbelt RH, O'Brien WJ, Fan PL. Translucency of dental porcelains. J Dent Res 1980;59(1):70-5. 
33. Heffernan MJ, Aquilino SA, Diaz-Arnold AM, Haselton DR, Stanford CM, Vargas MA. Relative translucency of six all-ceramic systems. Part I: core materials. J Prosthet Dent 2002;88(1):4-9.

34. Callister WD. Ciência e Engenharia de Materiais: uma introdução. 5 ed. Rio de janeiro: LTC - Livros Técnicos e Científicos Editora S.A.; 2002.

35. Price RB, Felix CA, Andreou P. Evaluation of a dual peak third generation LED curing light. Compend Contin Educ Dent 2005;26(5):331-2, 334, 336-8 passim; quiz 348.

36. Goncalves F, Calheiros FC, Witzel MF, Kawano Y, Braga RR. Effect of photoactivation protocol and radiant exposure on monomer conversion and flexural strength of a resin composite after water and ethanol storage. J Biomed Mater Res B Appl Biomater 2006.

37. Attar N, Tam LE, McComb D. Mechanical and physical properties of contemporary dental luting agents. J Prosthet Dent 2003;89(2):127-34.

38. el-Badrawy WA, el-Mowafy OM. Chemical versus dual curing of resin inlay cements. J Prosthet Dent 1995;73(6):515-24.

39. Chan KC, Boyer DB. Curing light-activated composite cement through porcelain. J Dent Res 1989;68(3):476-80.

40. Hasegawa EA, Boyer DB, Chan DC. Hardening of dual-cured cements under composite resin inlays. J Prosthet Dent 1991;66(2):187-92.

41. Ferracane JL. Materials in dentistry: principles and applications. 1 ed. Philadelphia: J. B. Lippincott Company; 1995.

42. Noort RV. Introduction to dental Materials. 1 ed. Madrid: Mosby; 1994.

43. Poskus LT. Influência de diferentes métodos de fotoativação na contração de polimerização linear e no módulo de elasticidade de resinas compostas e do fator-C na microinfiltração marginal. [Doutorado]. São Paulo: Universidade de São Paulo; 2003. 
44. Yap AU, Soh MS, Han TT, Siow KS. Influence of curing lights and modes on crosslink density of dental composites. Oper Dent 2004;29(4):410-5.

45. Rueggeberg F. Contemporary issues in photocuring. Compend Contin Educ Dent Suppl 1999(25):S4-15; quiz S73.

46. Peutzfeldt A, Asmussen E. Resin composite properties and energy density of light cure. J Dent Res 2005;84(7):659-62.

47. Neumann MG, Schmitt CC, Ferreira GC, Correa IC. The initiating radical yields and the efficiency of polymerization for various dental photoinitiators excited by different light curing units. Dent Mater 2006;22(6):576-84.

48. Rueggeberg FA, Blalock JS, Callan RS. LED curing lights--what's new? Compend Contin Educ Dent 2005;26(8):586, 588, 590-1.

49. Zhang Y, Griggs JA, Benham AW. Influence of powder/liquid mixing ratio on porosity and translucency of dental porcelains. J Prosthet Dent 2004;91(2):128-35.

50. Holand W, Schweiger M, Frank M, Rheinberger V. A comparison of the microstructure and properties of the IPS Empress 2 and the IPS Empress glassceramics. J Biomed Mater Res 2000;53(4):297-303.

51. Watts DC, Cash AJ. Analysis of optical transmission by $400-500 \mathrm{~nm}$ visible light into aesthetic dental biomaterials. J Dent 1994;22(2):112-7.

52. Kawaguchi M, Fukushima T, Miyazaki K. The relationship between cure depth and transmission coefficient of visible-light-activated resin composites. J Dent Res 1994;73(2):516-21.

53. Pilo R, Cardash HS. Post-irradiation polymerization of different anterior and posterior visible light-activated resin composites. Dent Mater 1992;8(5):299-304.

54. Emami N, Sjodahl M, Soderholm KJ. How filler properties, filler fraction, sample thickness and light source affect light attenuation in particulate filled resin composites. Dent Mater 2005;21(8):721-30. 
55. Heffernan MJ, Aquilino SA, Diaz-Arnold AM, Haselton DR, Stanford CM, Vargas MA. Relative translucency of six all-ceramic systems. Part II: core and veneer materials. J Prosthet Dent 2002;88(1):10-5.

56. Braga RR. Influência do tempo e do sistema adesivo sobre a resistência da união entre porcelana feldspática e dentina bovina. São Paulo: Universidade de São Paulo; 1999.

57. Caughman WF, Chan DC, Rueggeberg FA. Curing potential of dual-polymerizable resin cements in simulated clinical situations. J Prosthet Dent 2001;85(5):479-84.

58. Soares CJ, da Silva NR, Fonseca RB. Influence of the feldspathic ceramic thickness and shade on the microhardness of dual resin cement. Oper Dent 2006;31(3):384-9.

59. Peters AD, Meiers JC. Effect of polymerization mode of a dual-cured resin cement on time-dependent shear bond strength to porcelain. Am J Dent 1996;9(6):264-8.

60. Miyazaki M, Onose H, Iida N, Kazama H. Determination of residual double bonds in resin-dentin interface by Raman spectroscopy. Dent Mater 2003;19(3):245-51.

61. Peutzfeldt A. Dual-cure resin cements: in vitro wear and effect of quantity of remaining double bonds, filler volume, and light curing. Acta Odontol Scand 1995;53(1):29-34.

62. Shin WS, Li XF, Schwartz B, Wunder SL, Baran GR. Determination of the degree of cure of dental resins using Raman and FT-Raman spectroscopy. Dent Mater 1993;9(5):317-24.

63. Poskus LT, Placido E, Cardoso PE. Influence of placement techniques on Vickers and Knoop hardness of class II composite resin restorations. Dent Mater 2004;20(8):72632.

64. Ferracane JL. Correlation between hardness and degree of conversion during the setting reaction of unfilled dental restorative resins. Dent Mater 1985;1(1):11-4.

65. Souza SA. Ensaios Mecânicos de Materiais Metálicos. Fundamentos teóricos e práticos. São Paulo: Edgard Blucher; 1995.

66. Zeng K, Oden A, Rowcliffe D. Flexure tests on dental ceramics. Int J Prosthodont 1996;9(5):434-9. 
67. Walker MP, Spencer P, Eick JD. Effect of simulated resin-bonded fixed partial denture clinical conditions on resin cement mechanical properties. J Oral Rehabil 2003;30(8):837-46.

68. ISO4049. International Organization for Standartization Dentistry -- Polymer-based filling, restorative and luting materials. 2000 [cited; Available from: www.iso.og

69. Muench A, Correa IC, Grande RHM, João M. The effect of specimen dimensions on the flexural strength of a composite resin. J Appl Oral Sci 2005;13(3):265-268.

70. Junior WS. Contribuição para o estudo da propagação da luz através do esmalte e dentina humanos. [Dissertação de mestrado]. São Paulo: Universidade de São Paulo; 2005 .

71. Soares LE, Martin AA, Pinheiro AL, Pacheco MT. Vicker's hardness and Raman spectroscopy evaluation of a dental composite cured by an argon laser and a halogen lamp. J Biomed Opt 2004;9(3):601-8.

72. Asmussen E, Peutzfeldt A. Two-step curing: influence on conversion and softening of a dental polymer. Dent Mater 2003;19(6):466-70.

73. Rueggeberg FA, Caughman WF, Curtis JW, Jr. Effect of light intensity and exposure duration on cure of resin composite. Oper Dent 1994;19(1):26-32.

74. Loza-Herrero MA, Rueggeberg FA, Caughman WF, Schuster GS, Lefebvre CA, Gardner FM. Effect of heating delay on conversion and strength of a post-cured resin composite. J Dent Res 1998;77(2):426-31.

75. Hofmann N, Hugo B, Schubert K, Klaiber B. Comparison between a plasma arc light source and conventional halogen curing units regarding flexural strength, modulus, and hardness of photoactivated resin composites. Clin Oral Investig 2000;4(3):140-7.

76. Deb S, Sehmi H. A comparative study of the properties of dental resin composites polymerized with plasma and halogen light. Dent Mater 2003;19(6):517-22.

77. Papazoglou E, Rahiotis C, Kakaboura A, Loukidis M. Curing efficiency of a photoand dual-cured resin cement polymerized through 2 ceramics and a resin composite. Int J Prosthodont 2006;19(1):34-6. 
78. Shimura R, Nikaido T, Yamauti M, Ikeda M, Tagami J. Influence of curing method and storage condition on microhardness of dual-cure resin cements. Dent Mater J 2005;24(1):70-5. 